Portland State University

PDXScholar

$1-1-1983$

\title{
The health policy gap: income, health insurance and source of care effects on utilization of and access to dental, physician and hospital services by Oregon households
}

Constance Hall Fitzgerald

Portland State University

Follow this and additional works at: https://pdxscholar.library.pdx.edu/open_access_etds Let us know how access to this document benefits you.

\section{Recommended Citation}

Fitzgerald, Constance Hall, "The health policy gap: income, health insurance and source of care effects on utilization of and access to dental, physician and hospital services by Oregon households" (1983).

Dissertations and Theses. Paper 830.

https://doi.org/10.15760/etd.830

This Dissertation is brought to you for free and open access. It has been accepted for inclusion in Dissertations and Theses by an authorized administrator of PDXScholar. Please contact us if we can make this document more accessible: pdxscholar@pdx.edu. 
THE HEALTH POIICY GAP:

INCOME, HEAITH INSURANCE AND SOURCE OF

CARE EFFECTS ON UTILIZATION OF AND ACCESS TO

DENTAL, PHYSICIAN AND HOSPITAL SERVICES

BY OREGON HOUSEHOLDS

by

CONSTANCE HALL FITZGERALD

A dissertation submitted in partial fulfillment of the requirements for the degree of

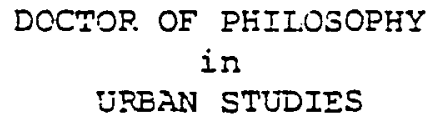

Portland State University

(C)1983 Constance Hall Fitzgerald 
TO THE OFFICE OF GRADUATE STUDIES AND RESEARCH:

The members of the committee approve the dissertation

of Constance Hall Fitzgerald presented November 2, 1982.

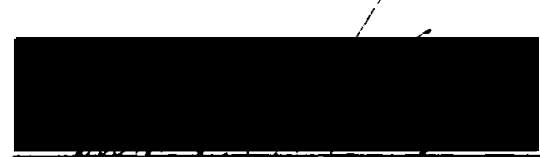

Dr Nohad Toulan, Chaitman

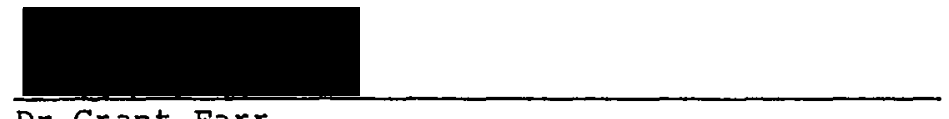

Dr Grant Farr

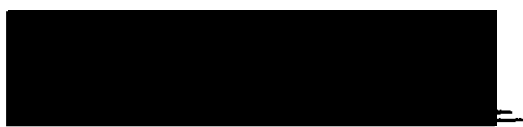

Dr Donald Freeborn

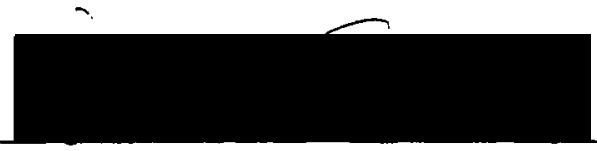

Dr Arthur Emlen

\section{APPROVED :}

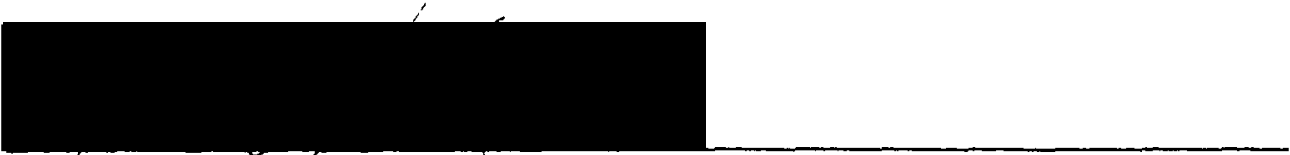

Dr Kohad A Toulan, Dean, School of Urban Affairs

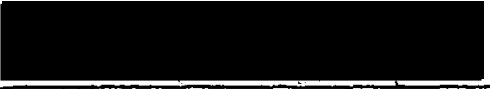

Dr Stanley E Rauch, Dean, Graduate Studies and Research 
AN ABSTRACT OF THE DISSERTATION OF Constance Hall Fitzgerald for the Doctor of Philosophy in Urban Studies presented on November 2, 1982.

Title: The Health Policy Gap: Income, Health Insurance, and Source of Care Effects on Utilization of and Access to Dental, Physician, and Hospital Services by Oregon Households.

APPROVED BY MEMBERS OF THE DISSERTATION COMMITTEE:

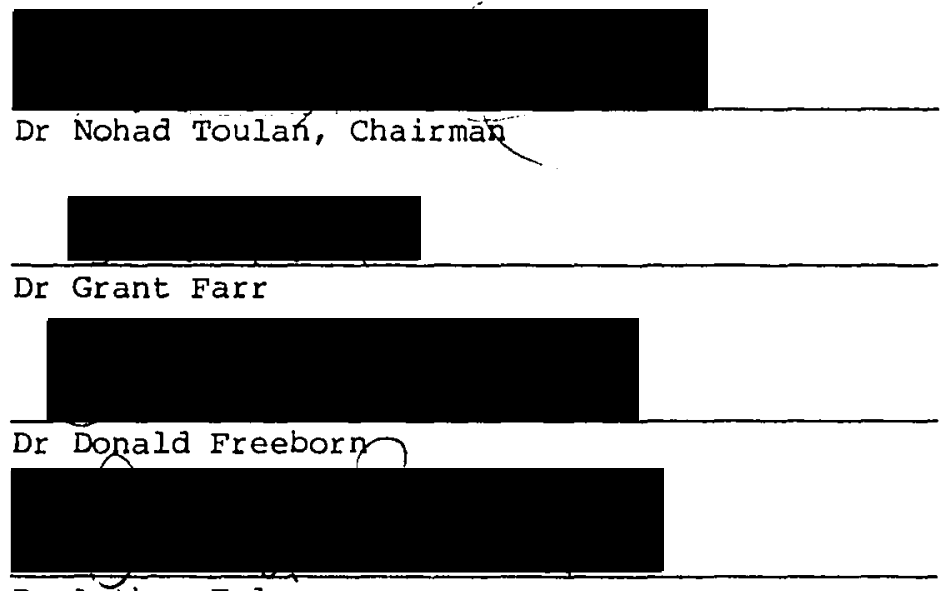

Dr Arthur Emlen

This study explores the effects of income, insurance, and source of medical care on access to and utilization of health services. Profiles of dental, physician, and hospital services use are developed for more than 3,500 oregonians. Low income, lack of health insurance, and/or an inappropriate source of medical care are hypothesized to be barriers to access and utilization. Households which face one or more of these barriers are identified as falling into a "Health Policy Gap."

The data for this study were drawn from a 1978 random telephone survey of 1249 oregon households. The survey was commissioned by the State Health Planning and Development Agency in conjunction with the 
Northwest Oregon Health Systems Agency, the Western Oregon Health Systems Agency, and the Eastern Oregon Health Systems Agency. The questionnaire was developed by the Oregon State University Research Center. Information was collected on use of health services, insurance coverage, income, household structure, health needs, health behaviors, and health satisfaction.

A behavioral model of health services utilization was constructed, dividing the independent variables according to their relative mutability or amenity to policy intervention. Income, insurance, and source of care were selected as policy variables, while other variables less under policymakers' control were labelled household characteristics. The latter were assumed to reflect a household's propensity to consume services. They included household structure, health need, residential mobility, and health behaviors. Dependent variables included measures of dental and physician visits, use of the telephone for physician advice, preventive exams, and hospitalization during the past year. Multiple techniques of analysis were employed. Cross-tabular procedures were applied to investigate the interrelationship of income, insurance, and source of care. Multiple linear regression and partial correlation methods were used to select as control variables household characteristics highly correlated to each measure of health services use. Analysis of variance and multiple classification analysis were used to develop profiles of health services use. These last techniques allowed an examination of the relationship of each policy variable and health measure while applying increasing levels of statistical control. The initial bivariate relationship was studied in isolation; it was then 
studied while controlling for the other policy variables, and finally while controlling for both the other policy variables as well as selected household characteristic variables.

Findings support the hypotheses. Income is found to be related to insurance coverage, and insurance coverage to source of medical care, although income is not found to be directly related to source of care. Low income, lack of insurance, and an inappropriate source of medical care depress use across almost all services. However, their relative barrier effects differ by the measure of service examined. After controlling for the effects of household structure, health need, residential mobility, and health behaviors, the greatest disparity in use of dental services remains due to income, in physician services to insurance and income, and in hospital services to insurance.

Clear implications arise for policymakers, whether in the public or private sectors. The low income, the uninsured, and those with an inappropriate source of care face real barriers to access. Since the relative magnitude of these barrier effects vary by the health measure examined, neither income, insurance, nor health system delivery strategies can be assumed to evenly enhance use patterns. Their effects must be separately estimated for differing measures of health services. Furthermore, the relationship between these policy variables needs detailed study before large-scale policy interventions are undertaken. Understanding the complexity of these findings for different measures of health services as well as the interrelationship of income, health insurance, and source of care is crucial in designing and implementing more effective and equitable health policies in the future. 


\section{ACKNOWLEDGEMENTS}

This work, as are all such efforts, is in large part aue to the extensive and continued psychological and financial support of family, friends, my committee, the Multnomah County Fellowship, the Project for Women and Minorities in Research and Development, Northwest Regional Educational Laboratory, the Health Services Research Center, Raiser Foundation Hospitals and Northwest Oregon Health Systems Agency.

I would like to express my appreciation to Drs. Nohad Toulan, Grant Farr and Donald Freeborn for their unfailing patience.

I am extremely grateful to Carolyn Lane and Jose Romero of the Project for women and Minorities for their support and investments of time and resources for this work. The editing of Sally Iopez, and the hard work put in by Joyce Hollis, Dorinne Ross, and especially Debbie Kline were invaluable. My release from ongoing duties during the final phases of this :rok is : se to the kinciness of Barbara Jean Williams. Finally, I would like to express my deepest love and appreciation to my family. I attribute my goal of achieving a doctorate to my mother who has never set limits on her children's futures, to James for over a decade of unstinting support, and to my hope for a better world for my daughters, Jamaica and Maya. 
TABLE OF CONTENTS

PAGE

ACKNOWLEDGEMENTS ................... . . . . .

IIST OF TABLES . . . . . . . . . . . . . . . . . viii

LIST OF FIGURES .................... . . . . . ix

CHAPTER

I THE HEALTH POLICY GAP: AN OVERVIEW . . . . . . . 1

Access to Health Care: A Right or

a Privilege?.............. . . . 1

Historical Trends: Growth of Private

and Public Insurance........... . . 2

Expansion of Private Health Insurance . . . 2

Public Health Insurance Prograns . . . . . 3

Incremental Growth .......... 4 4

Categorical Eligibility ....... 5

The Health Policy Gap . . . . . . . 6

The Present: New Federalism, Recession, and

Local Responsibility . . . . . . . . . 6

New Federalism............. . . 6

Block Grants . . . . . . . . . 7

Funding Cuts . . . . . . . . . . 7

State and Local Impacts ........ . 9

State Funding . . . . . . . . . 9

Local Responsibility ........ 10

Provider Cost Shifts ........ 12

Endnotes . . . . . . . . . . . . 15 
II A MODEL FOR HEALTH SERVICES UTILIZATION . . . . . .

Introduction $\ldots \ldots \ldots$

Individual Characteristics Models . . . . .

Structural/Ecological Models. . . . . .

Holistic, or Joint Interaction Models . . .

The Poor: A Special Case of Health

Services utilization . . . . . . . . . . . . 24

The Culture of Poverty Explanation . . . . 24

Financial/Systems Barriers Explanations . . . 26

A Behavioral Model of Health Services

Utilization . . . . . . . . . . . . . . 26

The Model .. . . . . . . . . . . 27

Health Services Use... . . . . . . . 28

The Independent Variables . . . . . . . 29

Household Characteristics . . . . . . . 30

Household structure ......... 30

Health Need............. 30

Residential Mobility. . . . . . . 31

Health Behaviors . . . . . . . . 31

The Policy Variables . . . . . . . . . 31

Income ............. . . 32

Insurance . . . . . . . . . . 37

Source of Medical Care . . . . . 39

Hypotheses .. . . . . . . . . . . 40

The Sample .................. 44

Methods of Analysis... . . . . . . . 43

Summary . . . . . . . . . . . . . . . . 44

Endnotes ................... 45 
III PATTERNS OF UTILIZATION OF HEALTH SERVICES

BY HEALTH POLICY GAP HOUSEHOLDS . . . . . . . . .

Introduction ...............

51

Causal Relationship of Income, Insurance

Coverage and Source of care . . . . . . . .

Relative contributions of Income, Insurance and Source of Care to Explained Variance in

Health Services Utilization . . . . . . . .

Dental services . . . . . . . . . .

Physican services..............

Hospital services . . . . . . . . .

Patterns of Health Services Use . . . . .

Dental services . . . . . . . . . .

Physician services .............

71

Hospital services . . . . . . . . . .

77

Summary of Findings . . . . . . . . . .

81

Endnotes . . . . . . . . . . . . .

IV ACCESS WIDENING STRATEGIES AND HEALTH POLICY

GAP HOUSEHOLD . . . . . . . . . . . . . .

Introduction ................

National Health Insurance (NHI) . . . . . .

Administrative and Fiscal Criteria . . . 
Types of Alternative Delivery System

Options . . . . . . . . . . . . . .

Health Maintenance Organizations (HMOs) ...

Primary Provider Organizations . . . . .

Primary Care Networks . . . . . . . . .

Project Health's Brokerage Concept

and Multicare . . . . . . . . . .

Proposed State Health Plan (SHP)

NHI, ADS and Health Policy Gap Households . . .

Conclusion .................

Oregonians in the Health Policy Gap.......

Relative Importance of the Policy

variables ............. 120

Initial Considerations for Policymakers . . . . 124

Single Intervention Strategies . . . . . 124

Income ............... 124

Health Insurance . . . . . . . . 127

Delivery Systems Strategies..... . 129

Conclusion and Implications for Policy

Directions .............. . . 130

Endnotes . . . . . . . . . . . . 134

A Selected Bibliography . . . . . . . . . 135 
I Block Grant Proposals - Health . . . . . . . . .

I Preliminary Estimate of Oregon's Block Grant Allocation of FFY 1982 at the Authorization Level. . . . . . . . . . . .

III Percentage of Individuals by Medical Insurance Coverage and Household Income . . . . .

IV Percentage of Individuals by Source of Medical Care and Household Income . . . . . . .

$V$ Medical Insurance Coverage by Usual Source of Medical Care . . . . . . . . . . . .

VI Percentage of Individuals with an Inappropriate Source of Medical Care by Medical Insurance Coverage Controlling for Household Income . . . . . . . . . . . . .

VII Zero-order Correlations . . . . . . . . . . .

VIII Regression Betas and Cumulative $\mathrm{R}^{2}$. . . . . .

IX Partial Coefficients: zero-order, First-order and Second-order . . . . . . . . . . . . .

$x$ Partial Coefficients: zero-order and Controlling for Household Structure, Health Need, Residential Mobility and Health Behaviors . . . . . . . . .

XI Comparison of organizational Characteristics . . . . 
LIST OF FIGURES

FIGURE

PAGE

1. A behavioral model of families' use of health services...............

2. A framework for viewing health services utilization . . . . . . . . . . . . . . .

3. The causal sequence of household health services utilization . . . . . . . . . . . .

4. Barriers to health services utilization by Health Policy Gap households . . . . . . . .

5. Consumer/provider control over utilization by type of health service . . . . . . . . . .

6. Physician visits by family income - 1969 . . . .

7. Physician visits by family income adjusted for health status - 1969 . . . . . . . . . .

8. Physician visits for families with less than $\$ 5,000$ income - health and aid status - 1969 . . .

9. Percentage of high, medium and low income groups seeing a dentist in a twelve month period... . .

10. Percentage of high, medium and low income groups seeing a physician in a twelve-month period... .

11. Physician visits by family income, presence or absence of public assistance, before and after adjusting for health status . . . . . . . . . .

12. Causal model relationships of the policy variables of income, medical insurance and source of medical care . . . . . . . . . . .

13. Causal model of health services utilization . . . 
14. Mean number of times household members saw the dentist in the past year by income, medical insurance coverage, and appropriateness of source of medical care controlling for the other policy variables and household characteristics (structure, residential mobility and health behaviors) . . .

15. Mean number of times household members saw a physician during the past year by income, medical insurance coverage, and appropriateness of source of medical care controlling for other policy variables and household characteristics (structure and health need) ..........

16. Mean use of the telephone by the household by income, medical insurance, and source of medical care controlling for the other policy variables and household characteristics (structure, health need and health behaviors) . .

17. Mean number of preventive exams received by household members in the past year by income, medical insurance coverage, and appropriateness of source of medical care controlling for the other policy variables and household characteristics (structure, health need and health behaviors) . . . . . . . . . . .

18. Mean number of household members in the hospital during the past year by income, medical insurance coverage, and appropriateness of source of medical care controlling for the other policy variables and household characteristics (structure and health need) . . . 
CHAPTER I

THE HEALTH POLICY GAP: AN OVERVIEW

ACCESS TO HEALTH CARE: A RIGHT OR A PRIVILEGE?

\begin{abstract}
A privilege is a right which is granted as a special favor. Privileges are inherently private matters. A right is a privilege which has been extended to all people, and the preservation and protection of that right becomes a public matter . - . If we, as a people, declare that access to health care is a right, then private medicine becomes a public matter and the right of access must be protected just as is our right to a basic education or freedom of speech. We have not yet made access to needed medical care a right in this country. Not in law, and not in practice. We have said it, and declared it, and even tried to promise it, but until we make it a legally enforceable right. . . it will remain, in practice, a privilege.I
\end{abstract}

In this country, there is a growing consensus that all Americans have a right to at least a minimum level of health care. ${ }^{2}$ This is a consemence of several developments within the past two decades which include the public's increased expectations of modern medicine's miracles, their demand for relief from the spiraling costs of health care, and the widespread view that government is responsible for ensuring health care to the needy. ${ }^{3}$ opinion polls demonstrate the pervasiveness of this belief; they show that the majority of Americans accept the concept of national health insurance and insist on the federal government's accepting primary responsibility for ending poverty. Paradoxically, these sentiments coexist with the convictions that any able-bodied person who wants to can provide for himself and 
that Americans should rely more heavily on individual initiative and less on government programs. ${ }^{4}$ Ambivalence, in terms of individual versus collective responsibilities towards the needy, is an underlying theme in the American value system.

Within the context of a diffuse success ideology, the adult population discriminates among welfare state policies. If the beneficiaries seem to work for it (earnings-based pensions, prepaid medical insurance) it is good, and big majorities of the respondents in national cross section samples generally support an actual or proposed program. If the benefit is unearned or perceived as unearned (AFDC, unemployment compensation), it is bad and majorities typically reject the program. 5

HISTORICAL TRENDS: GROWTH OF PRIVATE AND PUBLIC INSURANCE

\section{Expansion of Private Health Insurance}

Two trends have influenced Americans' access to her: $\because$ :are: the expansion of private insurance and the advent of public: nce for certain groups of the low income and elderly. The former, in particular, has played a major role in changing the American household's use of health services. Since the 1940's, health insurance coverage is estimated to have expanded by nearly six times -- from $15 \%$ to 888.6 Employer-provided health insurance programs provide mainstream access to health care for the majority of Americans. Accompanying the growth in private insurance coverage is the establishment of public insurance programs designed to protect the disadvantaged. 


\section{Public Health Insurance Programs}

The advent of Medicaid and Medicare in the $1960^{\prime}$ 's has reduced existing financial barriers to the 49 million poor and elderly estimated eligible for coverage under these programs. ${ }^{7}$ Eligible households are generally either those headed by poor females with dependent chiiaren, those including persons 65 years of age or older, or those containing disabled persons. Entrance of the millions of publicly insured to the health marketplace has contributed to the escalating costs and rising levels of demand for health services. ${ }^{8}$ Unfortunately, the growth of private insurance and the start of public insurance programs may well only worsen existing barriers to access for households which are unable to obtain private coverage and ineligible for Medicaid and Medicare.

Present patterns of public insurance eligibility are best understood by considering the history of social welfare program growth in the United States. Increasingly, government has intervened to provide food, shelter, and medical care to the needy through disbursement of cash and also through in-kind social programs (e.g., Aid to Families with Dependent Children, Social Security, Foodstamps, Medicare, and Medicaid). These programs indicate society's commitment to provide a social safety net to protect its members against the unpredictability and devastation of such catastrophes as death, disability, and divorce. However, society encourages its members to attempt to be self-sufficient before seeking aid; therefore, a system of health care has evolved in which the majority of households are 
assured access to health care by employer-provided insurance. Those needy eligible for public insurance are enabled access through Medicare or Medicaid, and the remaining needy get by as best they can.

Two facts are important in understanding why public insurance programs protect some types of needy households while purposely excluding others. These are the categorical eligibility requirements of the early social welfare programs to which Medicare and Medicaid eligibility are linked. The incremental and unrestrained growth of these social programs over time has culminated in today's fragmented and exlusionary system of public health insurance.

Incremental Growth. In December of 1974, the subcommittee on Fiscal Policy of the Joint Economic Committee made the following assessment:

The current crisis in social welfare policy is due to the mushrooming growth of an array of programs that were inaugurated at different times to meet specific problems by means of different strategies. A series of piecemeal efforts have created a system built on conflicting principles. 9

The first of these programs was the Social Security Act of 1935 . It began a movement away from a laissez-faire philosophy and towards what has been termed the welfare state. Social security depended on the theory of social insurance to protect workers and their familites against the financial ravages of retirement, disability, and death. The program was originally based on the principle of assigning benefits according to the amount the worker had earned. Almost immediately this principle was compromised by the concept of need-equity, which adjusted the worker's earnings-based benefit level by the number of dependents. 
Certain other groups judged unable to support themselves $(a . g .$, the blind, the disabled, and the children of disabled or deceased workers), were later included. ${ }^{10}$ Today's Social Security program illustrates the historical ambivalence of society towards benefit level adequacy versus work incentives, as well as the conflict between equal help for equal need versus differential rewards for past work and saving. 11

Categorical Eligibility. Aid to Families with Dependent Children (AFDC) was the first purely need-based social welfare program. It provided a model for other categorical programs. Generally speaking, only women with young children qualified for benefits. Eligibility was affected by race, family structure, and judgments by program staff of applicants' morality. Not until 1948, for example, did Black households appear on the welfare rolls in any number, whatever their family structure or financial need. ${ }^{12}$ Unmarried mothers, or those with nonmarital relationships, and male-headed households were often summarily excluded. Even today, only one half of the states offer benefits to male-headed families, regardless of financial need. ${ }^{13}$ The exclusion of households who do not Eit narrow categories of eligibility for Social security and AFDC has been carried over to Medicare and Medicaid requirements. The original programs excluded some of the needy so as to enhance work effort for noneligible households, cut program costs, and enhance the political viability of the programs involved. ${ }^{14}$ Medicaid was intended to serve those households eligible for AFDC, while Medicare focused on individuals eligible for social security. 
The Health Policy Gap. The unhappy result of fragmented social welfare program growth and exclusionary eligibility requirements for such programs is that a sizeable number of financially needy American households are now left in a health policy gap. Households headed by a working adult, by two parents, or by those barely above the official poverty line are penalized for their efforts to be self-sufficient, to provide a stable family structure, and to avoid stigmatizing social programs such as velfare. ${ }^{15}$ Twelve percent of all Americans, or twenty-four million people, are estimated to be without health insurance. ${ }^{16}$ In Oregon, this 128 represents approximately 250,000 people of all ages. ${ }^{17}$ The history of social welfare program growth has helped create this Health policy Gap, and the pressures of New Federalism and the economic recession have widened it.

THE PRESENT: NEW FEDERALISM, RECESSION, AND LOCAL RESPONSIBILITY

\section{New Federalism}

President Reagan's inaugural speech clearly articulates the concept of New Federalism:

It is my intention to curb the size and influence of the Federal establishment and to demand recognition of the distinction between the powers granted to the federal government and those reserved to the states or people. All of us need to be reminded that the Federal government did not create the states; the states created the Federal government. 18

A national economic recession and the Administration's emphasis on a balanced federal budget, in conjunction with New Federalism, means that at least the immediate future holds little promise for increased 
spending on health care for the needy. The explosive growth of social programs in the past two decades and the concurrent inadequate utilization and cost controls on Medicaid and Medicare programs have led to disenchantment with the goals of social opportunity and increased equity. As a result, the trend of policymaking has recently shifted in the direction of fiscal conservatism and an "If-I-can-makeit,-you-can-make-itn attitude towards the poor. Cost containment has become the potent rallying cry usea by conservative forces in Congress to fight social welfare spending.

Block Grants. President Reagan stated in 1981 that block grants consolidation would be used to cut subsidies to regional and local government as a means of reducing wasteful administrative overhead and to give state and local government more autonomy. ${ }^{19}$ A key objective of the block grant proposals was to lessen federal involvement in and control over program design and delivery. This, it was reasoned, would give state and local governments more flexibility, authority, and responsibility within broad federal guidelines. ${ }^{20}$ As signed by the President, the Act combines over twenty health care programs into seven block grants with an overall twenty-five percent reduction in funding. 21

Funding Cuts. Administration officials contended that some of the losses in funding to the states would be offset by administrative savings due to decreased federal red tape. Table I compares the Administration's original two block grant proposals with those eventualiy adopted by the Congress. 
TAELE I

HLOCK GRART PHOHOSALS - HEALTH 22

HEAITH SERVICES

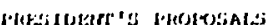

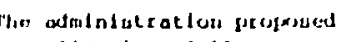

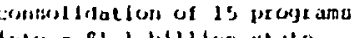
Imtse a \$l. billlon atalo

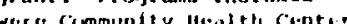

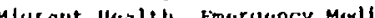
cal servilcess, Meneal llesitho

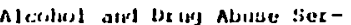

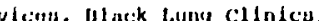

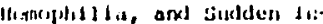
taith. Dhath symdrome (sidus)

The arlininlulerat lan proposed inti1 a $\$ 260$ million atato

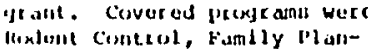

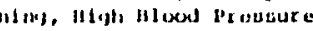
comtrol, Heastll Incomt tve it nillu, lituk hesluct lon and

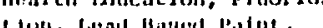

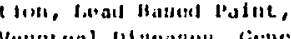

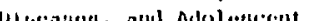
lleallut siervicus.
SEMATP.

Sume as administration propodal except that the Haternal and Child Health, Homophilla. and erifferent bus were placed sitates rould receive a share of the block grant proport tona to the amoult that they and entitles in tie state recelved in FY 1981 .

\section{PHEVENTIVE. UIEALTH SERUICES} All prexgrams proposed by the
predident except for Lead Based puint and Genetic Diseases were included. These two projr ams were consol ldated in the Maternal and Child Health Block Grant.

The llouse did not recommend a realth block grant comparable to the one proposed by Ge achinistration or the en Alcolo did provide for an Alcohol and Drug Abuse five alcohol and drug abuse cateyorical prograns.

Health Incentive Grants ris reduction, Rodent Control and Fluoridation wer consol idated.
CONFERENCE COMMITTEE

The conference comnittee agreed to an Alcohol, Drug Abuse and Mental Health block grant, a praternal and child health block grant. Ten health programs, in cluded in the President's grant proposals were author 12 ed cate gorical programs.

The Conference committee consolIdated Home Health, Rodent Control, Fluoridation, Health Education, and Risk Reduction, Health Incentive Grants, Emergency Medical Services Rape Crisis, and Hypertension.

Imununization, Tuberculosis, Venereal Disease and Family planning were reauthorized as categorical 
Attempts to cut existing levels of funding for Medicare and Medicaid have alarmed many congressmen. Proposed administration cuts brought this response, for example, from Oregon Representative, Ron Wyden:

Flying in the face or reason, the Administration has proposed slashing some $\$ 2.2$ billion from Medicaid and some $\$ 2.5$ billion from Medicare in 1983 . . . the Administration has once again ignored the prescription for long-term recovery, preferring the meat-axe approach that will only shift the burden of health care onto the shoulders of senior citizens, the needy and health care providers.

The Medicare system is . . . In the red because the federal government has perpetuated a perverse reimbursement system that actually rewards waste and inefficiency ... . We hand health care providers a blank check to fill in after the care is provided, rather than negotiating reasonable health care packages in advance. 23

In 1982 , almost $\$ 325$ million was slashed from reimbursemients to hospitals for Medicare and Medicaid patients, reducing payments to only 858 of the cost of medical care given the poor and elderly under these programs. ${ }^{24}$ Such losses are shifted, at least in part, to the costs of privately insured patients and to those households without insurance coverage. Because the primary responsibility for serving the health care needs of the poor has historically been left to state and local governments, the effects of block grants and reduced funding have put these policymakers into a moral and economic quandry.

State and Local Impacts

State Funding. Under the rubric of new federalism and consumer sovereignty, the importance of social services has been de-emphasized by the federal government; absolute decreases in resource transfers have accompanied the de-emphasis. In Oregon, these reductions in the 
availability of federal monies have occurred as revenue sources have become outstripped by an upswing in demand for services and surging health care costs. These factors in combination significantly decrease state and local governments' ability to meet even existing levels of need.

During the 1981 Oregon Legislative Session, the Department of Human Resources attempted to address federal funding reductions for social service programs in the amount of $\$ 118.7$ million dollars. 25 (A preliminary estimate of Oregon's 1982 block grant authorization is found in Table II). The state's initial strategy was to attempt to replace reduced federal monies with General State Funds. Even as replaced by general funds health, block monies for primary health care, alcohol/drugs and mental health, preventive health, and child health were diminished by approximately 258. Absolute decreases in revenue transfers for health care by the federal government have drastically lessened existing health care access for Oregon's needy.

Local Responsibility. Inflationary forces may now be the strongest the health care system has faced since the early 1930's. 26 The danger exists that with the growth of a medically indigent population, the current system will eventually collapse. Don Schictman, Director of the State Medicaid program, states:

The questions now being raised are not simply what level of care the poor can expect, or who should shoulder the costs of providing it. The question is, how do we keep the health care system from collapsing. 27

State and local governments are restricted in their ability to cover federal revenue shortfalls by a combination of constitutional 
TABLE II

PRELIMINARY ESTIMATE OF OREGON'S BLOCK GRANT ALLOCATION FFY 1982 AT THE AUTHORIZATION LEVEL 28

\begin{tabular}{|c|c|c|c|c|c|}
\hline \multirow{2}{*}{\multicolumn{2}{|c|}{ Blocks }} & \multirow[b]{2}{*}{$\begin{array}{c}\text { Oregon's Share } \\
\text { of Current } \\
\text { Programs } \\
\end{array}$} & \multicolumn{3}{|c|}{ Estimated Allocations Under } \\
\hline & & & $\begin{array}{l}\text { Current } \\
\text { Programs } \\
\text { FFY } 1981 \\
\end{array}$ & $\begin{array}{r}\text { Block } \\
\text { Grant } \\
\text { FFY 1982 } \\
\end{array}$ & $\begin{array}{c}8 \\
\text { Changes }\end{array}$ \\
\hline & Social Services & 1.162 & $33.186 \mathrm{~m}$ & $27.736 m$ & -16.4 \\
\hline & A/D \& Mental Health & 0.905 & $5.775 \mathrm{~m}$ & $4.444 \mathrm{~m}$ & -23.0 \\
\hline 3. & Energy & 1.245 & $22.723 \mathrm{~m}$ & $23.346 \mathrm{~m}$ & +2.7 \\
\hline & Primary Health Care & 1.670 & $5.428 \mathrm{~m}$ & $5.052 \mathrm{~m}^{*}$ & -6.9 \\
\hline & Community Services & 0.846 & $3.182 \pi$ & $2.999 \mathrm{~m}$ & -5.8 \\
\hline & Preventive Health & 1.045 & $1.359 \mathrm{~m}$ & $.993 \mathrm{~m}$ & -26.9 \\
\hline \multirow{2}{*}{\multicolumn{2}{|c|}{ 7. Maternal \& Child Health }} & 1.185 & $5.049 \mathrm{~m}$ & $3.758 \mathrm{~m}$ & -25.6 \\
\hline & & & $76.702 \mathrm{~m}$ & $68.328 \mathrm{~m}$ & -10.9 \\
\hline
\end{tabular}

* States cannot administer the Primary Health Care program during FFY 1982, the figure shown is the FFY 1983 authorization level. 
limitations on raising the property tax, practical enforcement restraints on the income tax, and constituent unwillingness to impose a regressive sales tax. These revenue inelasticities are exacerbated by increased rates of unemployment, failures of businesses, and escalating costs of health care. The results are that many oregon households now face even greater financial barriers to obtaining necesary health care than they faced in the recent past.

Locally, Multnomah County's problems illustrate the situation of local government in meeting the responsibility of health care for the medically indigent. Currently, this demand seems insurmountable. with a 68 annual increase cap on property taxes, the county's main revenue source, it is virtually impossible for revenues to keep pace with current rates of inflation and increased demand. Unemployment rates (9.82 in Rugust of 1982) are some of the highest since such records have been collected. ${ }^{29}$ Reductions in federal funding are passed on to local government. Local government, unable to meet these costs, ultimately places the burden on the shoulders of providers with negative implications for the disadvantaged's access to health care. Provider Cost Shifts. In recent years, hospital write-offs for charity, bad debts, and inadequate reimbursement by Medicaid and Medicare have been growing steadily. ${ }^{30}$ Northwest area hospitals have seen losses rise from 6.18 in 1974 to 168 in $1981 .^{31}$ In 1981, losses from these factors totalled $\$ 94$ million, a $\$ 19$ million increase over previous years. The Northwest Oregon Council of Hospitals estimates that cost shifts (efforts by providers to pass along such costs to private patients) have added $\$ 150-\$ 170$ per day to the bill of 
privately-insured patients. ${ }^{32}$

The elderly, the poor, and the unemployed tend to be concentrated in urban areas, and therefore inner city hospitals bear the brunt of such losses; suburban hospitals remain relatively unaffected. Hospitals' alternatives are to shift adaitional costs to private patients, cut personnel, institute prepayment practices, eliminate high cost, technologically intensive programs (e.g. neonatal care), and eventually turn those who cannot pay away from their doors. ${ }^{33}$ In many areas of the United States, the urban-poor/suburban-rich dichotomy has already created two hospital systems. ${ }^{34}$

The plight of Emanuel Hospital illustrates the seriousness of the crisis. An inner-city hospital attempting to meet the needs of its area's poor and elderly, Emanuel is hard hit. Cost shifts per day are over $\$ 226$, increasing the bill for one day of hospitalization to $\$ 587$ dollars. With 628 of its patient population insured by Medicaid and Medicare, this hospital is currently forced to shift almost $22 \%$ of its revenues or $\$ 14$ million dollars annually. By January 1981, Emanuel's losses on care given the poor were $\$ 9.7$ million dollars. Hospital administrators implemented the following strategies to colnnter anticipated fiscal year deficits: laying off 158 employees, cancelling the building program, forbidding elective surgery without prepayment, and seriously considering the elimination of several programs. Fising unemployment had already caused the number of patients obtaining elective surgery to drop almost 408 from the same period the year before, as households lost employer-provided health insurance and suffered reductions in the ability to pay for care out-of-pocket. 35 
Implications for the future of health services delivery are ominous. The question raised by administrators of hospitals such as Emanuel is, "At what point can these costs no longer by shifted onto the private sector? ${ }^{36}$ Blue Cross and OPS Blue Shield, the state's two largest insurance carriers (now in the process of consolidation), pay the bulk of these cost shifts to private patients. Blue Cross of Oregon lost $\$ 4.9$ million in 1981 and has subsequently announced rate increases of 20-508. A spokesperson states that Blue Cross is pricing itself out of the market. This observation seems borne out as employers seek lower-cost employee benefit packages; and the unemployed, unable to self-insure, join the swelling ranks of other households in the health policy gap.

In summary, need in the American system of social welfare, is not now and never has been the sole determinant of eligibility for assistance. Access to health care is ensured for those with employer-provided private insurance coverage, assured for those needy who are eligible for Medicaid or Medicare, and ignored for those needy who are not eligible for public insurance. This historical background provides a perspective from which to examine access and equity issues in health care for Oregion households in the Health Policy Gap. 
ENDNOTES

IGeorge E. Pickett, "The Basics of Health Policy: Rights and Privileges: The 1977 Presidental Address," American Journal of Public Health 68, 3 (March 1978): 236.

2Ronald Andersen and John F. Newman, "Societal and Individual Determinants of Medical Care Utilization in the United States," Milbank Memorial Fund Quarterly 54 (Winter, 1973): 95; Morris, The American Hertitage Dictionary of the English Language $(1970)$, p. 1118 .

${ }^{3}$ Douglass Cater, "An Overview," Politics of Health (New York: Medcom, Inc., 1972), pp. 3-4.

${ }^{4}$ Harold L. Wilensky, The Welfare State and Equality: Structural and Ideological Roots of public Expenditures (Berkeley, Ca.: University of California Press, 1975), p. 37.

5 Ibid.

6Andersen, Ronald, and Newman, John F. "Societal and Individual Determinants of Medical Care Utilization in the United States." Milbank Memorial Fund Quarterly 51 (Winter, 1973): 105; Robert Wood Johnson Foundation. "Special Report, No. 1, 1978." Princeton: Robert Wood Johnson Foundation, 1978: 8.

${ }^{7}$ Davis, Karen, and Reynolds, Roger. "The Impact of Medicare and Medicaid on Access to Medical Care." The Role of Health Insurance in the Health Service Sector, pp. 391-417. Edited by R. N. Rosett. New York: National Bureau of Economic Research, 1975: 397; Dutton, Diana B. "Explaining the Low Use of Health Services by the Poor: Costs, Attitudes, or Delivery Systems?" American Sociological Review 43 (June 1978): 348-368.

${ }^{8}$ Andreano, Ralph L., and Weisbrod, Burton A. American Health Policy: Perspectives and Choices. Chicago: Rand McNally Publishing Co., 1974: $35-36$.

9Joint Economic Committee Subcommittee, Dec. 5, 1974.

10United States Congress, Joint Economic Committee, Subcommittee on Fiscal Policy, Income Security for Americans: Recommendations of the Public Welfare Study. Washington D.C.: United States Government Printing Office, 1974: p. 33.

llibid., p. 47.

12Frances Fox Piven and Richard A. Cloward, Regulating the Poor: The Functions of Public Welfare, New York: Vintage Books, 1971, Pp. 4, 127-128. 
${ }^{13}$ United States Congress, Joint Economic Committee, Subcomittee on Fiscal Policy, Income Security for Americans: Recommendations of the Public Welfare Study. Washington D.C.: United States Government Printing Office, 1974: pp. 30-37.

${ }^{14}$ Ibid., pp. 4, 38-43.

${ }^{15}$ Ibid., p. 33.

16 Robert Wood Johnson Foundation. "Special Report, No. 1, 1978." Princeton: Robert Wood Johnson Foundation, 1978: pp. 6-8.

${ }^{17}$ Multnomah County, Oregon, Department of Human Services, "Background Paper: Blue Ribbon Committee on Health Care Financing for the Medically indigent," April 28, 1982, p. 1.

18 "President Reagan's Inaugural Address," Congressional Quarterly Weekly Report 39 (Jan. 24, 1981): 187 as quoted by Alan Tresidder, "Legislative History of Block Grants for Health Services," Legislative Research, Salem, Oregon, Nov. 3, 1981, p. 4.

19 "President Reagan's Economic Proposals Text," Congressional Quarterly Weekly Report, 39 (Feb. 21, 1981): P. 362 as quoted by Tressider 1981, p. 4 .

20 Office of Program Review, Director's Office, Department of Human Resources, State of Oregon, "Overview: Block grant and Welfare Reform Issues in the Omnibus Budget Reconciliation Act of 1981, Estimated FFY 1982 Authorization Levels," (Salem, Oregon: Sept. 1981) p. 1.

$21_{\text {Ibid., p. } 1 .}$

22 Allen Tressider. "Legislative History of Block Grants for Health Services," Research Monographs. Legislative Research, Salem, Oregon, Nov. 3,1981, p. 8.

23 Ron Wyden. "Special on Health Issues," Congress of the United States, House of Representatives, Washington, D.C. 20515 (Newsletter) March 10, 1982, p. 1.

24 Peter Dammann, "Non Sufficient Funds," Willamette week. 8, 16 Feb 16-22, 1982, p. 11 .

25 Office of Program Review, Sept. 1981, p. 1.

26 Multnomah County Oregon, Background Paper, April 28, 1982, p. 9.

27 Ibid. 
${ }^{28}$ Office of Program Review, Director's Office, "Overview: Block Grant and Welfare Reform Issues in the Omnibus Reconciliation Act of 1981 Establishing FFY 1982 Authorization Levels," Department of Human Resources, State of Oregon, Sept. 1981, p. 16.

${ }^{29}$ Oregon Journal, Sept. 3,1982, p. 1 .

30

Dammann, Feb. $16-22,1982$, p. 11 .

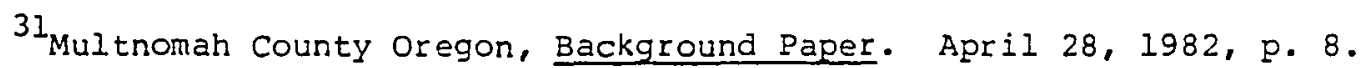

32 Ibid., pp. 11,14 .

33

Wyden, March 10, 1982, p. 2.

${ }^{34}$ Dammann, Feb. 16-22, 1982, p. 11 .

${ }^{35}$ Ibid., p. 11.

${ }^{36}$ Ibid. 
CHAPTER II

\title{
7. MODEL FOR HEAITH SERVICES UTILIZATION
}

\author{
INTRODUCTION
}

The purpose of this chapter is to construct a behavioral model of health services utilization. For policymakers, the potential of a behavioral model lies in its delineation of causal patterns and the subsequent increased understanding and prediction of patterns of human behavior. Empirical testing of such a model allows inferences to be drawn from the data which may ultimately lead to increased control over the occurrence of ratural events. No model, however, exists outside a larger and more complex system of synergistic cause and effect, a system composed of decisionmakers frequently at crosspurposes about values, goals, and the means to those goals.

Models attempting to explain the relationship between various correlates and utilization of health services can be placed in one of three general categories, depending upon where the locus of responsibility for utilization is put: on the individual, on system factors, or on the joint interaction of the individual and system factors. 1 
Individual Characteristics Models

The perspective which emphasizes the importance of the individual's characteristics on use of health services is typified by the Health Belief Model. ${ }^{2}$ This model assumes a sequential behavioral decision process wherein the individual perceives, evaluates, and responds to symptoms. Threats of illness are weighed against the benefits of obtaining treatment in order to make decisions about use of services. Given an individual's particular set of symptoms and social-structural characteristics, four key elements affect the . decision to act:

1) health motivations which represent differences in concern for health matters;

2) the threat posed by the symptoms, including physical harm and possible interference with daily functioning;

3) benefits, efficacy, or value of actions to reduce the threat; and

4) costs of or barriers to the action. 3

In related work, stoeckle, zola, and Davidson (1963) conclude that a patient's decision to seek medical care in response to symptoms depends on the objective clinical disorder; the patient's perceptions, knowledge, beliefs, and attitudes about the symptoms; attitudes and expectations of the physician and medical system; definitions of health and sickness; and the point at which medical care becomes necessary. 4

A global model of medical services utilization is proposed by Suchman (1965). He suggests that the degree of social group organization and the medical orientation of an individual are directly related to differences in patterns of medical services use. ${ }^{5}$ He 
describes social group organization as varying from parochial to cosmopolitan, while he sees medical orientation as depending on the individual's cognitive knowledge about disease, affective skepticism about medical care, and behavioral dependency during illness. 6 Suchman links parochial social group organization and nonscientific medical care orientation, concluding that both are major causes of inappropriate utilization. ${ }^{7}$ kosa and Robertson (1969) also emphasize the influence of the individual's family, friends, and other lay advisors in the analysis of and response to illness symptoms. Their model includes cultural, situational, and interactional patterns. ${ }^{8}$ Fabrega (1973) uses a sequential model to outline behavioral process stages associated with illness. This model assumes that symptoms are interpreted through the person's individual taxonomy and that the person is rational and prefers an illness-free condition. Decisionmaking behavioral stages include illness recognition, assessment of the costs and benefits of treatment, selection of treatment, and the recycling of information for the next episode of illness behavior. 10

Structural/Ecological Models

A second category of models places the locus of decisionmaking and responsibility for utilization primarily on structural factors--the "ecological and functional relationships between economic or community resources and the recipients of services." 11 Access, or the individual's ability to obtain health services when and where needed, is often an implicit or explicit concern. These models emphasize the 
demand-inducing or demand-suppressing effects of structural variables on health services use. ${ }^{12}$ The structural/ecological approach stresses, among others, the following factors:

- methods of financing (insurance coverage, prepayment, deductibles, co-insurance, fee-for-service, etc.),

- geographic variables (distance and availability), and

- organizational resources (facilities and range, quality, scope, and coordination of services).13

Methods of financing are the major thrust of models emphasizing demand theory in health services utilization. The effects of insurance types, elasticities of demand, and national health insurance on use of services are common emphases of these models. ${ }^{14}$ other research examines the effects of public insurance on access to health services for the poor. ${ }^{15}$

Other structural/ecological research examines geographic factors and organizational resources as influences on health services use. 16 Source of medical care loutpatient or emergency room treatment versus services of a private physician) has been found to vary by social class. Geographical distance and services availability are also related to patterns of utilization.

Holistic, or Joint Interaction Models

The third category of behavior models assumes utilization to be a joint function of factors both internal and external to the individual. ${ }^{17}$ This holistic approach is typified by Andersen's (1968) model of health services utilization and Andersen and Newnan's 
(1973) framework for viewing health services utilization. ${ }^{18}$ This

type of model incorporates the following concepts:

- an economic emphasis upon the family as the unit of analysis;

- separation of economic and social factors;

- analysis of separate types of health services;

- inclusions of perceptions of health and illness; and

- specification of causal paths leading to health service use. 19

This model posits that a family's use of health services depends on its predisposition to use them, its ability to secure them, and its need for them (see Figure 1 ).

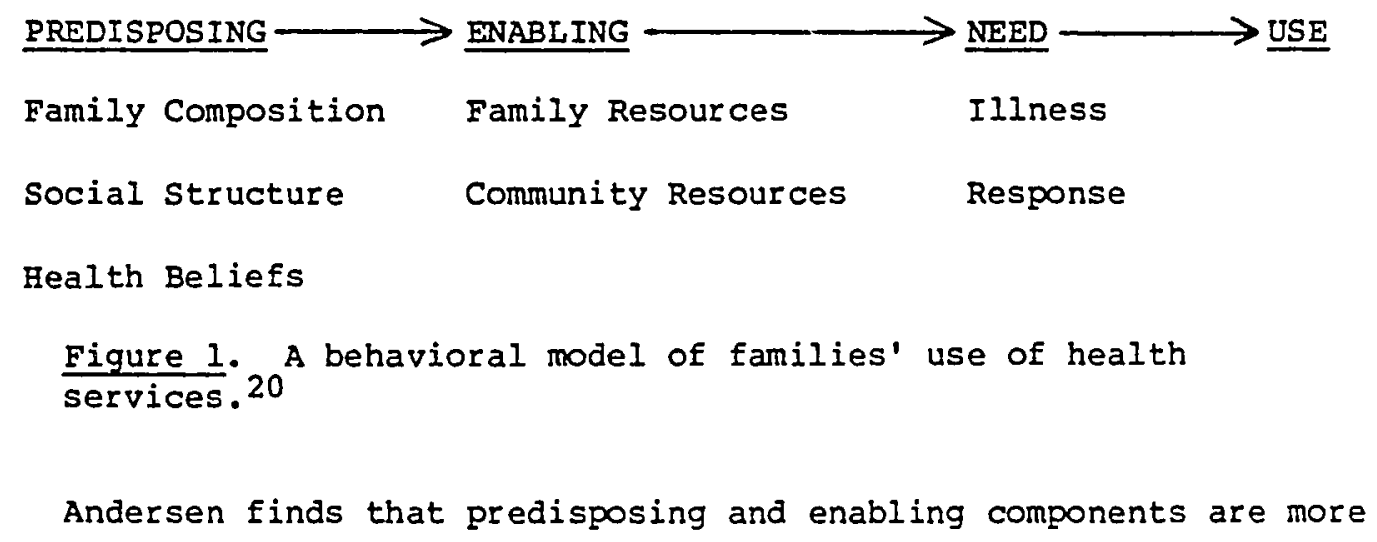
useful in explaining the utilization of discretionary services (such as dental), while the need component figures largest for nondiscretionary uses (for example, hospital and physician services). 21

The behavioral model of health services utilization focuses on the interplay of factors--both external and internal--which affect families' use of health services. The model is placed within a larger context by Andersen and Newman's framework for viewing health services utilization (see Figure 2.) 


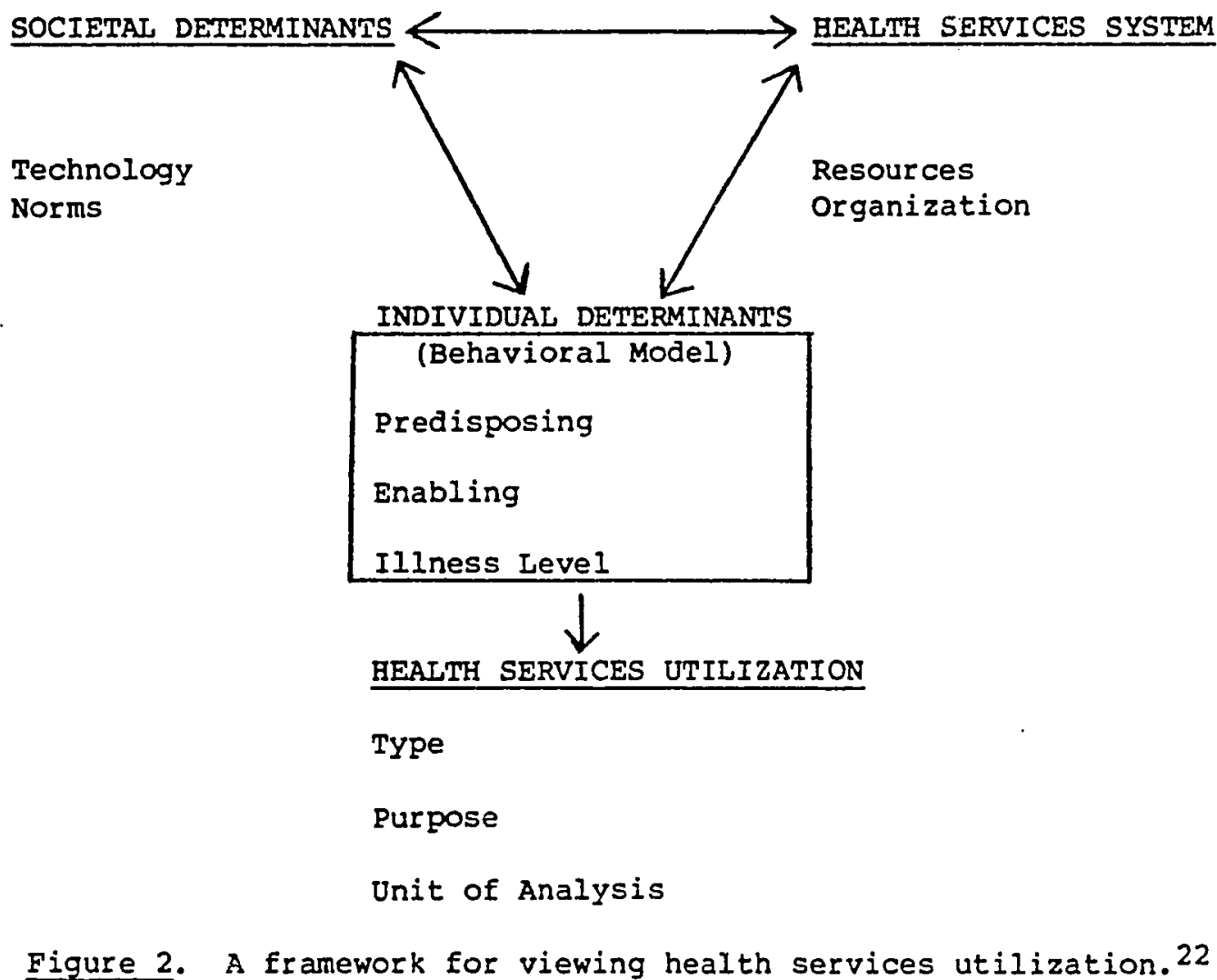

This framework postulates reciprocal causal links between societal determinants, the health services system and individual determinants, i.e., each affects, and in turn is affected by, the others. Societal determinants are subdivided in the model into technology and norms. Norms are reflected, not only through legislation, but also through society's converging beliefs and opinions, as, for exampie, the emerging belief that all Americans have a right to health care. The health services system is perceived as being divided into resources (including the volume and distribution of labor and capital) and organization, which involves both access (system entry) and structure (system characteristics which determine what happens to the patient following entry). 23 
THE POOR: A SPECIAL CASE OF HEALTH SERVICES UTILIZATION

Andersen's (1969) and Andersen and Newman's (1973) research work together constitute a systems model of health services utilization. Ecological, organizational, and individual factors are integrated within the model. Some factors are relatively constant and unchangeable from a policy perspective, while others are more policy mutable and therefore more likely to be under the control of policymakers. For the disadvantaged, variables emerge as important determinants of access which are of little import for other types of households. For example, Davis and Reynolds (1975) develop a model of utilization for the publicly insured that includes not only patient characteristics, but also physician preferences for certain kinds of patients, and features of public insurance programs which vary by state. 24

Seeking an explanation for the lower use of health services by the poor, Dutton (1978) looks at the impact of financial coverage, the culture of poverty, and systems barriers to health services use. 25 Each of these explanations has been presented as a reason why the poor use fewer health services than do others. Noting disputes over the relative importance of financial versus health system barriers, Lefcowitz (1973) notes, "Whichever side of the argument is taken, two 'facts' are accepted as true: 1) poverty leads to less medical care; and 2) poverty results in diminished health. " 26

\section{The Culture of Poverty Explanation}


Lewis' (1966) theory of the culture of poverty. Lewis suggests that poverty is an intergenerational phenomenon, handed down as a collection of adaptive and reactive responses by the poor to their social and economic situations. Socioeconomic characteristics of the individual are seen as causing inappropriate use of health services, which in turn leads to poor health. Policy implications of the acceptance of this theory verge on what Ryan (1971) labels as "blaming the victim." 27 zola (1973) places responsibility for inappropriate delays in obtaining medical care on

- . a list of faults--the patient has no time, no money - . is of lower education, socioeconomic status, or an ethnic or racial minority. As the researchers might put it, there is something about these people or in their backgrounds which has disturbed their rationality, for otherwise they would "naturally" seek aid. 28

This approach assumes that the individual is irrational and at fault for not using medical services appropriately. No consideration is given to barriers to appropriate use due to environmental factors outside the individual's control. Fixed individual characteristics (religion, ethnicity, race) are lumped together with factors which are more mutable. The inference that culture alone accounts for low use of health services by the poor places the blame directly on those least able to help themselves. It may also lead to the erroneous conclusion that individual characteristics should be the major focus of policy interventions, while important environmental and structural factors are perceived as immutable. Hyman (1970), for example, concludes that by

\footnotetext{
- . reducing Eatalism and discontent, or establishing lay referral networks where none yet exist, an increase in utilization can be effected without dealing directly with the economic poverty variable which is antecedent to these variables. 29
} 


\section{Financial/Systems Barriers Explanations}

Both financial and system barrier explanations place the major responsibility for inappropriate use of health services of the poor primarily on the environmental/ecological/structural context within which this group functions. The financial barrier explanation posits that poor people, given financial access, can ultimately "express their demand in the medical marketplace, and that this demand will then attract a sufficient supply of health producers. ${ }^{30}$ source of care, distance from a health care facility, and quality of care are perceived as creating barriers to system use by the poor. In examining cultural, financial, and systems access explanations, Dutton (1978) finds that income-related factors, especially the type of health system used, play a greater role (at least for discretionary care) than do inadequate financial coverage and negative attitudes towards health care. ${ }^{31}$

Separately considered, the cultural, financial, and system barriers explanations are inadequate. The weakness of each of these explanations lies in the attempt 'o ignore the interaction of internal and external forces on indiyidual consumption patterns.

\section{A BEHAVIORAL MODEL OF HEALTH SERVICES UTILIZATION}

This study developes a model based on an extensive litelature review of variables correlated to health services use. Income, health insurance coverage, and appropriateness of usual source of medical care are selected as policy mutable variables. Their effects on Health Policy Gap households are examined, both singly and in combination. 
Utilization profiles are compared for dental, physician, and hospital services.

Variables are classified into three types: measures of utilization, household characteristics, and policy variabies. The relative individual and combined effects of lower income, lack of health insurance, and an inappropriate source of medical care are hypothesized to act as barriers to utilization of health services by Health Policy Gap households.

\section{The Model}

The model postulates a causal process wherein the effects of household characteristics (household structure, occupation, residential mobility, health behaviors, and health need) on use of health services are mediated by the above-mentioned policy variables. In an equitable health care system, the influences of the policy variables on health service use should be negligible. Differences proceeding from household characteristics unrelated to system or structural barrier effects remain a matter of consumer preference or taste. Differences in health services use attributable to system or structural barriers, however, are determined to be the basis 'for policy interventions (see Figure 3). 


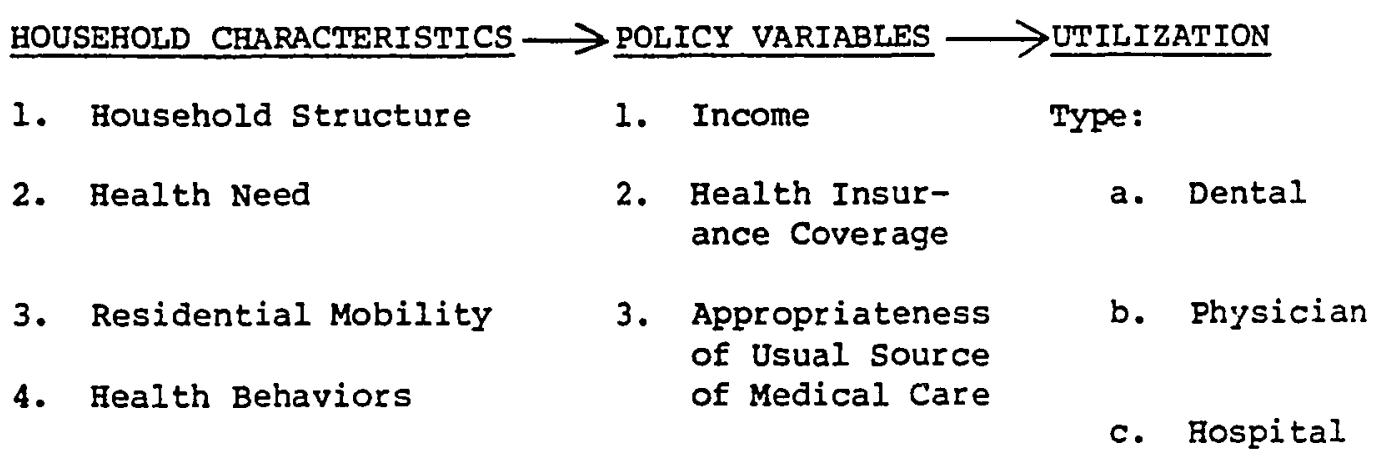

Figure 3. The causal sequence of household health services utilization.

Lower Income $\longrightarrow$ Lack of Health Insurance

Inappropriate Source on Medical Care

Figure 4. Barriers to health service utilization by "Health Policy Gap" households.

\section{Health Services Use}

Use of health services is the dependent or outcome variable. Access to health care is defined as use of health services after controlling for the effects of differing levels of need for

services. ${ }^{32}$ Dental, physician, and hospital services use are considered separately. To arrive at an empirical estimate of access, health need is treated as an independent variable whose effects on the dependent variable are controlled for, thereby insuring that higher levels of need associated with low income will not obscure the overall patterns of use.

Dental, physician, and hospital services are assumed to vary in terms of the discretionary control afforded the consumer. The 
household is perceived to retain most control or choice over the use of dental services, less for physician services, and least for hospital services, if every other factor remains constant. The policy variables combined with household characteristics should have more explanatory power for those services where the consumer retains the most choice. This may result from the consumer's perception of some services as less immediately health- or life-threatening than others (such as dental or preventive services) and from differences in the degree of provider control over the extent, duration, and quality of services used (see Figure 5).

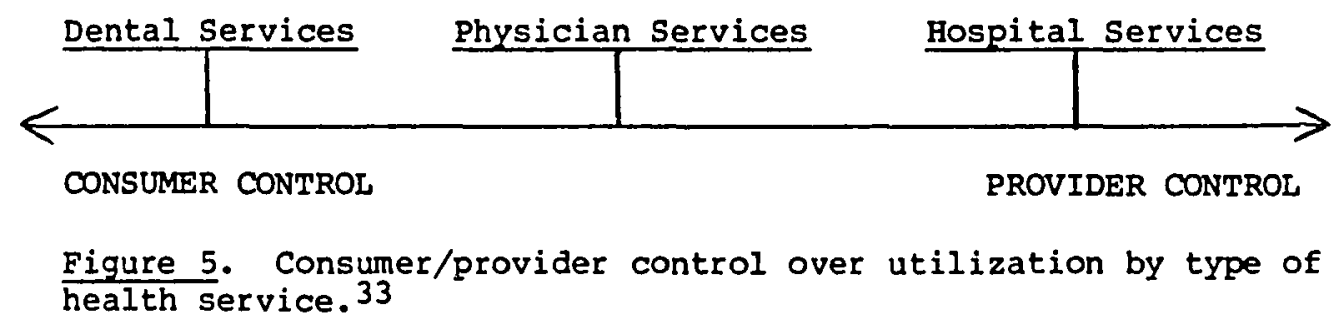

Rates of use for various health services are analyzed both for individuals and, when appropriate, for households. Dental services use is defined as the number of times each household member has seen a dentist during the preceding twelve months. Use of physician services is measured by the number of times such services are reported as being used, either by in-person visits, telephone calls, or use of preventive exams (blood pressure, blood sugar, Pap Smear, breast, or prostate).

The Independent Variables

Eight independent variables are chosen for their relevance to utilization. They are divided into household characteristics and 
policy variables. Household characteristics are hypothesized to reflect the propensity of the household to need or use services and are used as control measures. They include household structure, residential mobility, health behaviors, and reported health need. policy variables, chosen for their relative mutability or amenability to wide-scale policy intervention, include income, insurance coverage, and appropriateness of source of medical care. Low income, lack of health insurance, and an inappropriate source of medical care are the hypothesized predicted inhibitors of appropriate health services use.

\section{Household Characteristics}

Eousehold Structure. Household structure includes measures of members' ages, gender, and household size. ${ }^{34}$ This variable is included to specify stages in the life cycle of households and to determine associated needs for health care. Both the very young and very old, for example, are high users of health services. 35 Household size and use of health services are also related: as size increases, average rates of service use tend to level off. ${ }^{36}$ Family size and number of restricted due to illness disability days together have been found to contribute almost 308 of the total variation in physician services use. ${ }^{37}$ Gender is also found to influence health services use. For example, females in the child-bearing years consume more health services than do males. 38

Health Need. Measures of health need include reported health conditions of household members, number of disability days reported in the past twelve months due to ill health, and the respondent's rating 
of and general satisfaction with the household's health. Need is the strongest predictor of differences in families' use of health services. Number of disability days is the best predictor of families' total use of health services. ${ }^{39}$ This also holds true for individual use of services: the more disability days an individual reports, the more likely that individual is to seek a physician's services. 40

Residential Mobility. Residential mobility is measured by the number of years the household has lived both in the community and in its current dwelling unit. Mobility is included as an indicator of lifestyle, and higher rates of residential mobility are positively associated with higher rates of social and cultural mobility. Social and cultural mobility have been correlated with higher rates of disease and conditions such as coronary heart disease, complications of pregnancy and depression. ${ }^{41}$

Health Behaviors. Measures of health behavior include the frequency and quantity of alcohol consumption, quantity of cigarettes smoked, and amount of regular exercise by at least one household member. Generally speaking, health behaviors are those behaviors which reflect the individual's attitudes towards health maintenance and which are assumed to affect health. They may have a negative impact (such as smoking or excessive alcohol consumption) or a positive impact (such as regular exercise). 42

\section{The Policy Variables}

This study examines the effects of three possible barriers--low income, lack of health insurance, and an inappropriate source of 
care--on services use. Households facing one or more of these barriers are hypothesized to use fewer health services than households not facing such barriers. Exceptions occur as a function of unique characteristics of the health care system or of the household in question. A low income household eligible for public insurance, for example, may face no financial barrier in obtaining health services. A household with certain antihealth care beliefs, sufficient resources, and/or extremely high levels of health may prefer to handle its health care expenses on an out-of-pocket basis or to utilize alternative lay sources of health care. Household numbers may lack an appropriate source of care because they have recently moved to a new area, because they are dissatisfied with known health care sources, or simply because they do not feel a need for health care. In general, however, the factors of low income, lack of insurance, and an inappropriate source of care, both singly and in combination, are hypothesized to comprise substantial barriers to the use of health services.

Income. Four income groups are used for purposes of comparison: low income (households grossing less than $\$ 10,000$ in 1977), lower middle income (households with a gross income in 1977 or $\$ 10,000$ to $\$ 14,999)$, upper midale income (households in the $\$ 15,000$ to $\$ 24,999$ range for 1977), and high income (households grossing more than $\$ 25,000$ in 1977). 43 The low income are found to experience higher levels of sickness and mortality than higher income groups. Findings suggest that income plays an important role in the severity of health conditions of the poor and in their lower levels of health services 
use. Those in the lower classes have historically had lower life expectancies and higher death rates than other socio-economic groups. 44 Even today, mortality rates for the poor run four times higher than the national average for persons under twenty-five years of age. 45 Illness conditions reported by those below the poverty line are found to be serious more often than those by other segments of the population. ${ }^{46}$ The poor are found to have far higher rates of heart disease, diabetes, hypertension, arthritis, rheumatism, visual impairments, liver and stomach problems, and other chronic health problems (especially long-term activity-restricting problems). ${ }^{47}$

Low income persons are initially found to use health services more frequently than middle income persons (see Figure 6). However, once rates of use are adjusted for need for health care, the pattern is transformed into one in which use of health services rises uniformly with income; i.e., the low income use least health services, the lower middle income use more, the upper middle income use even more, and the high income use most (see Figures 7 and 8 ). 


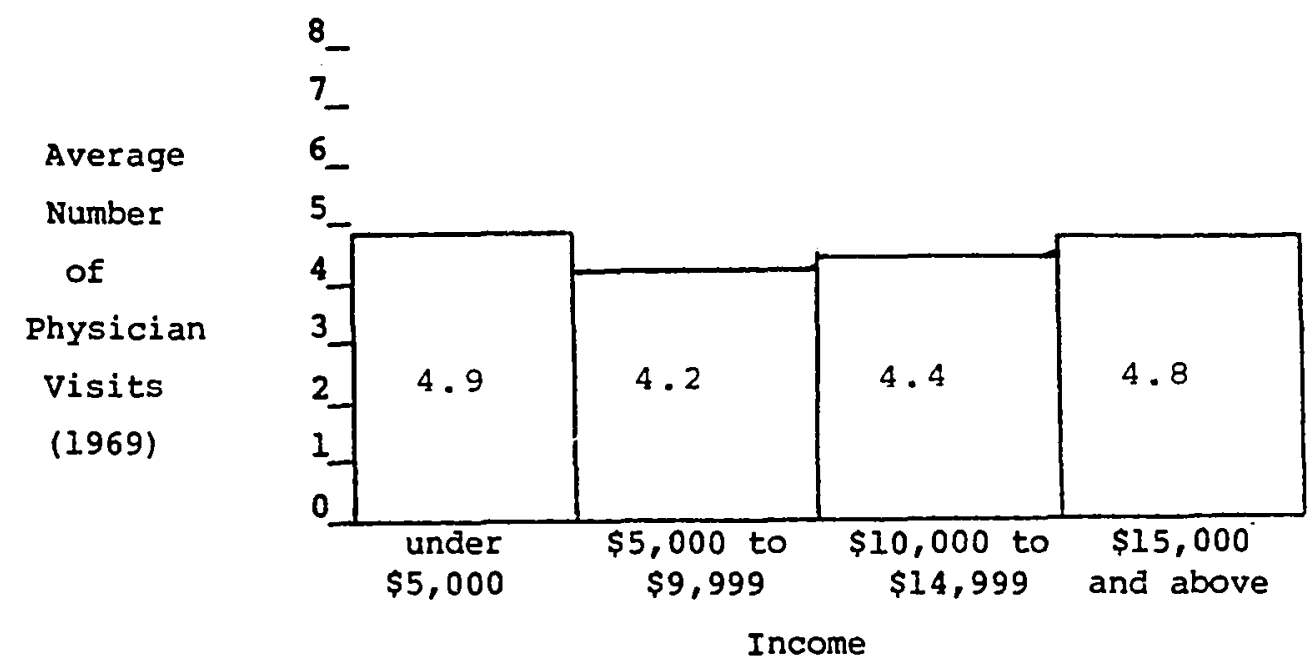

Figure 6. Physician visits by family income - 1969.48

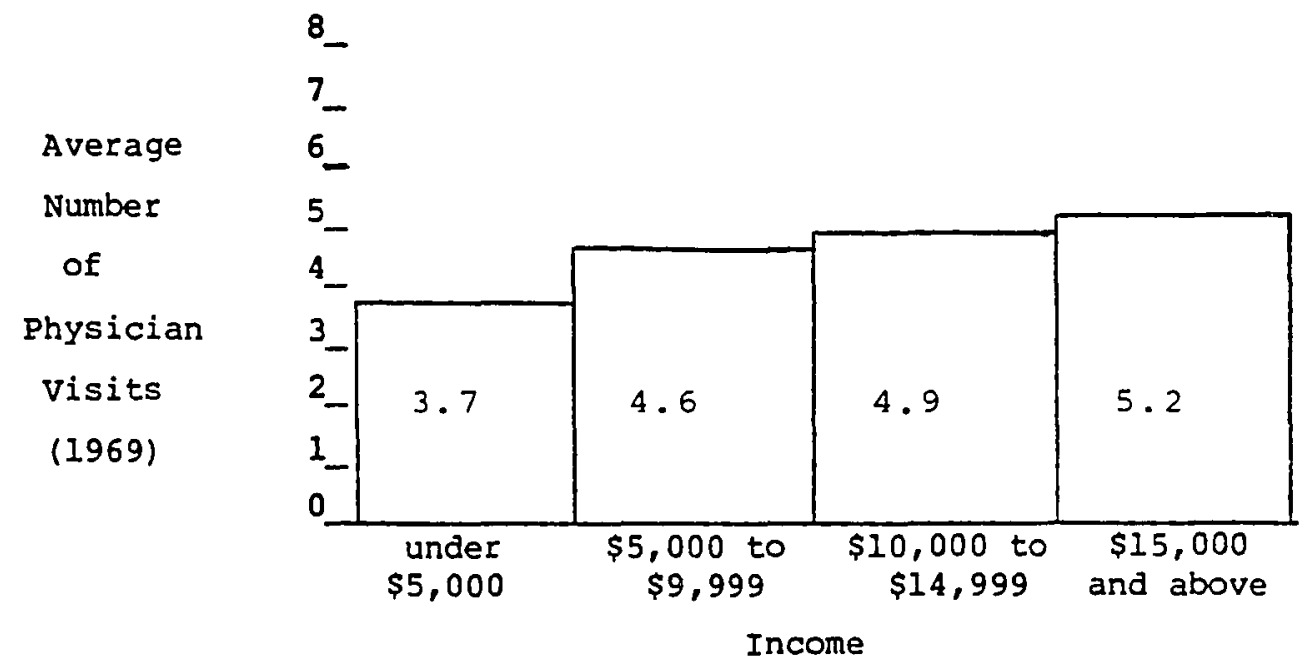

Figure 7. Physician visits by family income adusted for health status - 1969.49 


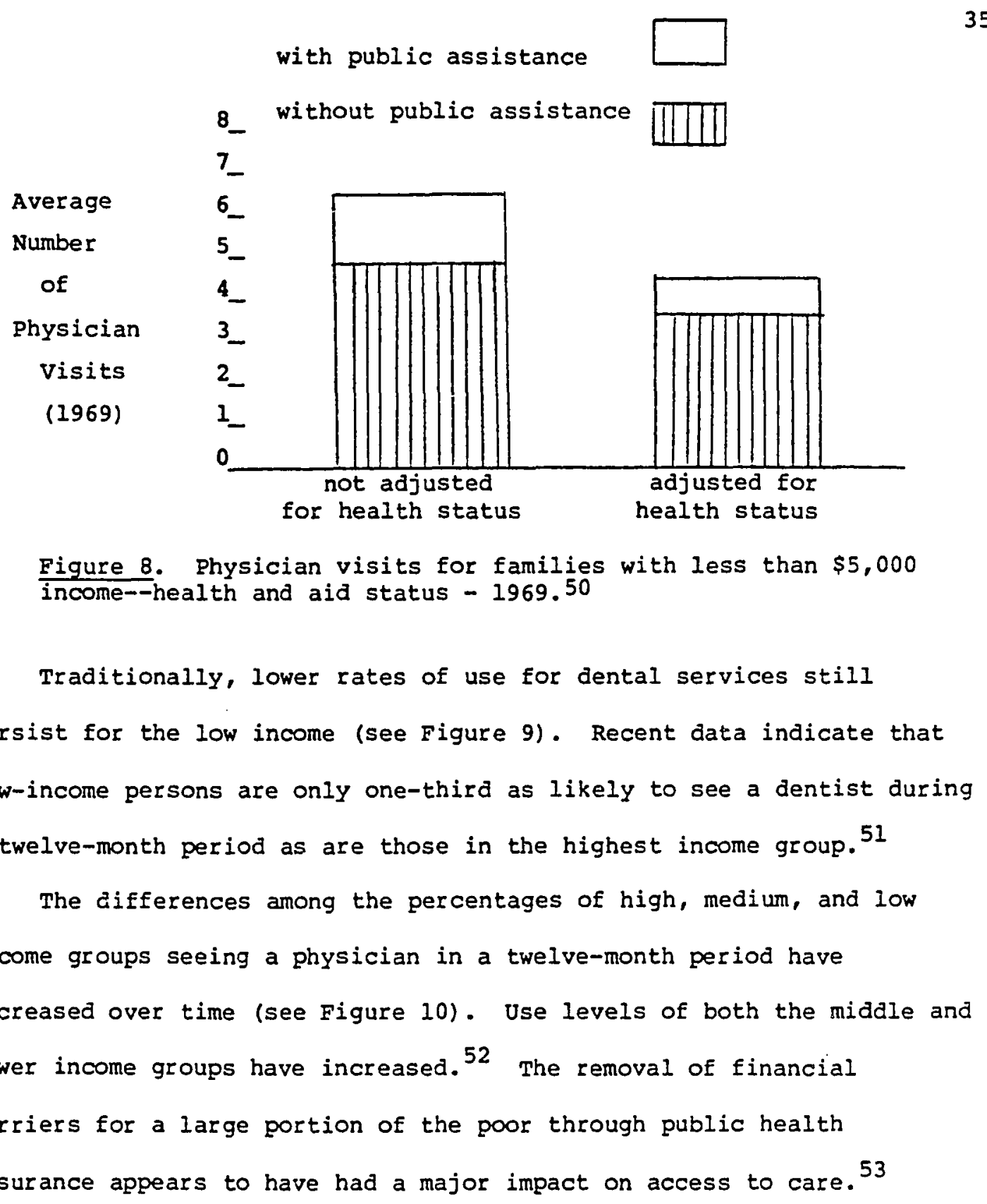




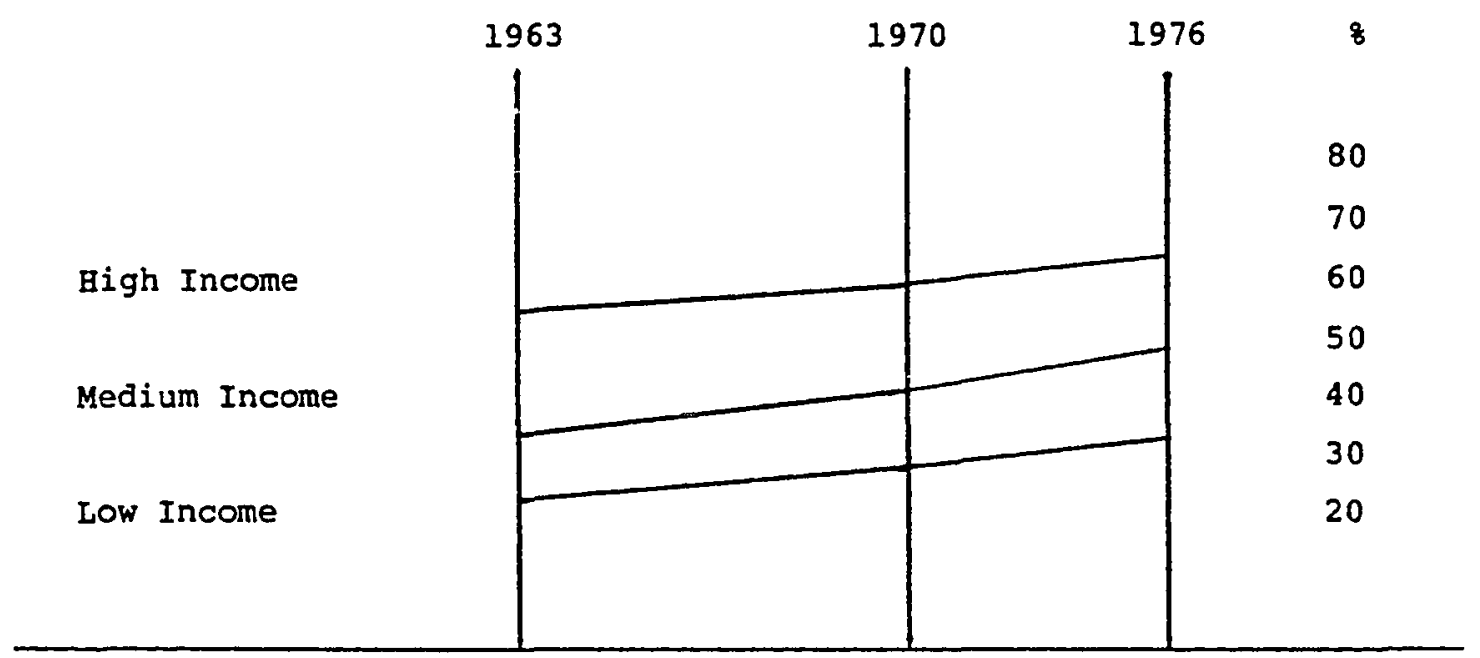

Figure 9. Percentage of high, medium and low income groups seeing a dentist in a twelve-month period. 54

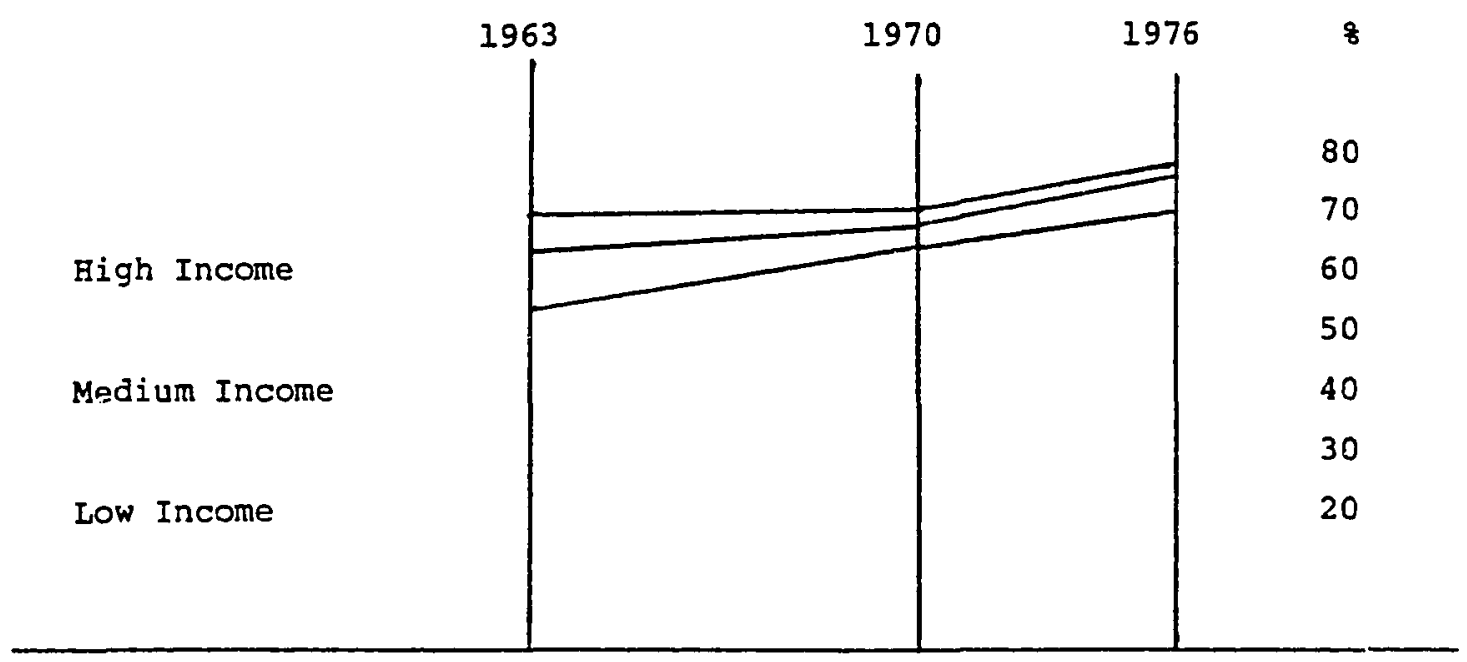

Figure 10. Percentage of high, medium and low income groups seeing a physician in a twelve-month period. 55 
Eistorically, lower income groups have had lower hospital admission rates than higher income groups. 56 However, this relationship has shown a reversal in the past few decades, largely due to the growth of health insurance and income transfer programs such as Aid to Families of Dependent Children (AFDC). 57 For the decade ending in 1973, data describing frequency of hospital use displayed a bimodal distribution, with both the high and low income groups being more substantial users than the midale income. 58

Insurance. Health insurance categories are defined as uninsured households (in which no member is insured) and insured households (in which at least one member is covered by health insurance).

Two insurance trends have influenced health service use patterns for American households: the expansion of private health insurance and the advent of public insurance for certain segments of the low income and the elderly. The expansion of private health insurance has played a major role in changing health service utilization patterns of the American household. Nationwide, health insurance coverage has expanded nearly six times, from 158 for hospital and surgical-medical in the 1940 's to 888 for all forms of health insurance in 1978.59

Estimates vary widely regarding the extent of coverage through private health insurance. For persons under the age of sixty-five, estimates range from 788 to 868 in 1976 (151 to 164 million insured persons). 60 Evidence shows that approximately 328 of Medicaid eligibles in that year also had private insurance. Almost 408 of these were elderly persons who had both private and Medicare coverage. 61 
The advent of public health insurance (Medicare and Medicaid) in 1965 reduced differences in use of medical services among income groups. Public insurance has significantly increased rates of health services use for the eligible poor compared with those poor either ineligible for public insurance or unwilling to apply for it (see Figure 11). Program data from 1976, however, show that only 408 of those eligible for Medicaid actually received benefits during the period of the study. The participation rate was judged to be even lower for the medically needy, with only 308 of the 6 million eligibles using benefits in states offering them. 62

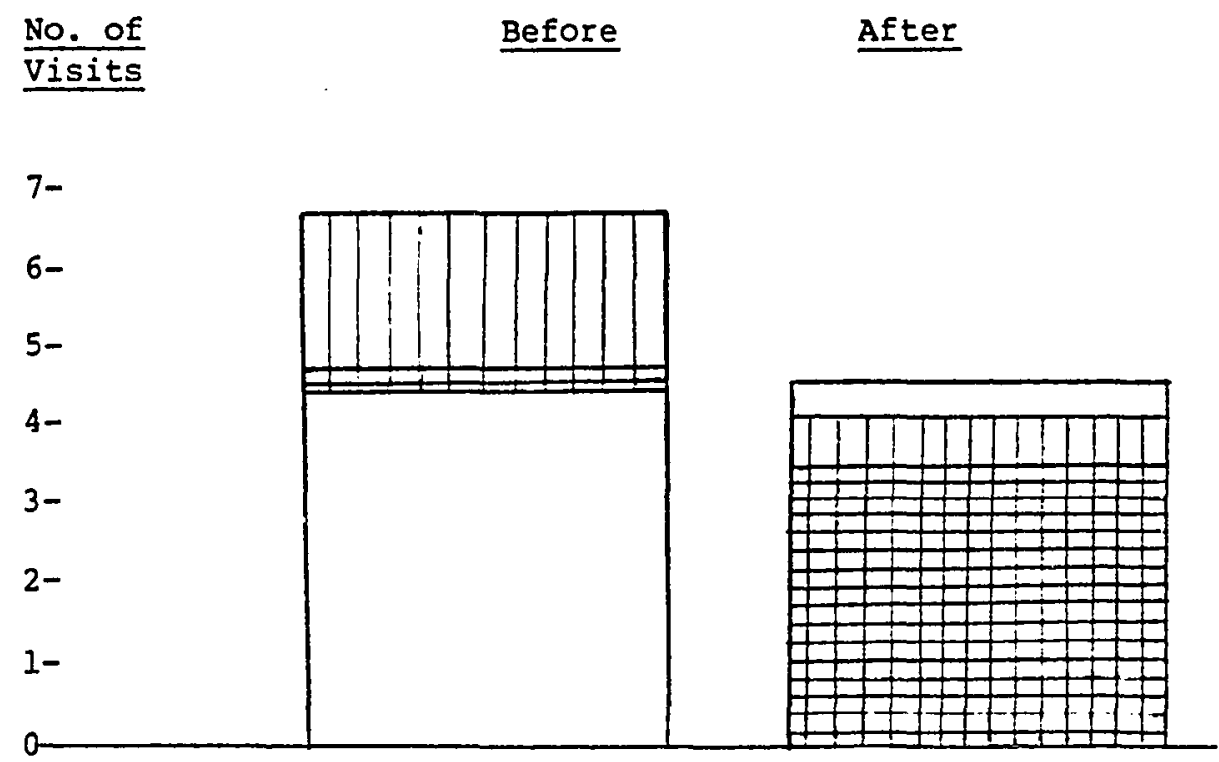

All families

प11 Low income families with public assistance

EOW income families without public assistance

Figure 11. Physician visits by family income, presence or absence of public assistance, before and after adjusting for health status. 63 
Levels of health services use have been significantly increased by public insurance for those households eligible for coverage under Medicare or Medicaid (see Figure 11). Those low income households not insured by either Medicaid or Medicare still lag substantially behind, particularly for physician services use. Many of the differences in use of dental, physician, and hospital services by income groups are due to the lack of insurance. As late as 1976, for example, 888 of the population had medical insurance, while only 188 had dental insurance. ${ }^{64}$ One researcher comments:

\footnotetext{
- . dental services are least apt to be covered by existing financing mechanisms and it is this service for which the greatest inequities in use by family income.. . continue (s) to persist. 65
}

Although dental care is still generally not covered by insurance, research shows that persons with any type of health insurance are more likely to see a dentist than those who are uninsured. ${ }^{6}$ Third party coverage notably attenuates income differences and may even reverse the effects of poverty on use, especially for services use initiated by the patient. 67

\section{Source of Medical Care}

A distinction is made between an appropriate and an inappropriate source of usual medical care. The only appropriate source of medical care is a physician's office. An inappropriate source of care is defined as either no reported source of usual care, or use of a hospital emergency room, hospital outpatient clinic, public health clinic or company clinic for routine treatment. 
Different patterns of health care access emerge for the poor than for other income groups. ${ }^{68}$ Findings suggest that the lower use rates found for the poor may be due to inadequacies in the health system they use. $^{69}$ The system that serves the poor is characterized by uneven quality and a lack of coordination of services, in conjunction with as imperfect integration of the entire care system. 70

Patterns of health care use by the poor differ from the norm in terms of types of facilities and services, as well as in the stability of the patient-provider relationship. ${ }^{71}$ Low income households are more likely to either lack an appropriate provider of care or to report an inappropriate source of care. ${ }^{72}$ The poor are found to be twice as likely as the general population to go to a hospital clinic or an emergency room, and 148 of the low income report no regular source of medical care. ${ }^{73}$ Davis and Reynolds (1975) find that even the insured poor do not obtain care in the same type of setting, from the same kind of physicians, and with the same ease and convenience as do higher income persons, although they are more likely than the uninsured poor to procure medical care, especially hospitalization. ${ }^{74}$

\section{Hypotheses}

The hypotheses are:

- Lower income is related to lack of health insurance, which, in turn, is related to an inappropriate source of usual medical care.

- Income explains more variation in the utilization of health services than either health insurance coverage or appropriateness of usual source of medical care do. 
- Income, insurance coverage, and appropriateness of usual source of medical care account for the variation in services utilization: greater for dental, less for physician and least for hospital.

- Households with low incomes are less apt to utilize health services than are households with high incomes.

- Households lacking health insurance are less apt to utilize health services than are households with health insur ance.

- Households without an appropriate source of usual medical care are less apt to utilize health services than are households with an appropriate source of usual medical care.

\section{The Sample}

The data source for the study is a 1978 telephone survey of 1249 Oregon households comprised of 3521 individuals. The survey instrument was commissioned by the State Health Planning and Development Agency in conjunction with the Northwest Oregon Health Systems Agency and Eastern Oregon Health Systems Agency. The questionnaire was developed by the Oregon State University Research Center. Information was collected on use of health services, insurance coverage, income, household structure, health needs, health behaviors, and health satisfaction. The sample was randomly drawn from noninstitutionalized adults residing in the state of oregon. The sampling frame is estimated to have drawn from 858 of Oregon households (approximately 958 of Oregon households have telephone service, but approximately 118 of these have unlisted numbers). ${ }^{75}$ Names were randomly selected from telephone directories for each Health Services Agency area (HSA's 1, 2 and 3). A total of 2,000 households were selected. However, dus to budget and time constraints, counties in which 12 or fewer interviews had been 
scheduled were reallocated proportionately to larger, similar, nearby counties (constricting selection of households to 26 of the state's 36 counties). 76

Household interviews were conducted by telephone during June 1978. Any available responsible adult was selected as the respondent; the respondent was asked to provide information about each individual household nember and about the household as a whole. Each interview averaged an hour in length. As many as twenty callbacks were made, if necessary. The completed sample of 1710 households resulted in a $73 \%$ response rate. ${ }^{77}$ of the nonresponses, $598(\mathrm{~N}=272)$ were refusals, with the remaining $41 \%(\mathrm{~N}=189)$ being households that could not be reached after repeated attempts. ${ }^{78}$ Comparisons of age and sex distributions for the sample are relatively similar to those for the general population. Differences for age groups between HSA 2 and the 1970 census are, while considerable, likely to have negligible effects on data-based statistical estimates. 79

AlI surveys have Iimitations. Telephone interviews, while enabling more interviews with more kinds of households than possible with face-to-face interviews, are less controllable. This raises the potential danger of nonresponse and lessens the interviewer's ability to check the information's veracity. The interviewer must accept reported information without checking receipts or other written information. As with all survey types, when one respondent is selected to report data for other household members, the additional danger of selective perception or lack of accurate knowledge as to other members' behaviors and health needs, etc., must be considered. 
In particular, the use of telephone listings as the basis for a sampling frame may result in certain household types being undersampled or not sampled at all. Among these are the poor, the highly mobile, and those without listed numbers. The poor and extremely mobile are estimated to constitute the majority of the 58 of households missing from the sampling design. ${ }^{80}$ Because households lacking telephone service include the poorest of the poor who presumably face the greatest obstacles to use of health services, findings of this study may understimate the gravity of the hypothesized barriers. Expected differences between use patterns of Health Policy Gap households and other households would then likely be also underestimated.

Methods of Analysis

Multiple methods of analysis were employed to examine the data from several perspectives and to elicit descriptive information in an intuitive extension of Webb, Campbell, Schwarz, and Sechrest's (1966) method of triangulation. ${ }^{81}$ Cross-tabular procedures were applied to investigate the interrelationship of income, insurance, and source of care. Multiple linear regression and partial correlation methods were used to select as control variables household characteristics highly correlated with each measure of health services use. Analysis of variance and multiple classification analysis were used to develop profiles of health services use. These last techniques allowed an examination of the relationship of each policy variable and health measure, while applying increasing levels of statistical control. The initial bivariate relationship was studied in isolation; it was then 
studied while controlling for the other policy variables, and finally while controlling for both the other policy variables as well as selected household characteristics variables.

\section{SUMMARY}

The focus of this chapter was to develop a model to measure the relative separate and combined barrier effects of low income, lack of health insurance, and an inappropriate source of medical care on Health Policy Gap households' use of health services. A behavioral model of health services utilization was proposed, and independent variables were classified as either policy or control. Finally, the hypotheses were set forth and a description was given of the data source, sampling limitations, and methods of anelysis.

The next chapter discusses study findings on the relative barrier effects of the policy variables, as well as the specific effects of low income, lack of insurance, and an inappropriate source of care on utilization profiles for householäs in the Health Policy Gap. 
ENDNOTES

$1_{\text {Thomas }}$ T. H. Wan and Scott J. Soifer, "Determinants of Physician Utilization: A Causal Analysis", Journal of Health and Social Behavior 15 (1974): 100 .

2Marshall H. Becker, ed., The Health Belief Model and Farsunal Health Behaviors: Health Education Monographs 2 (Winter, 1974).

3John P. Kirscht, "The Health Belief Model and Illness Behavior," The Health Belief Model and Personal Health Behavior: Health Education Monographs, M. Becker, ed. 3 (Winter, 1974):61-62.

4J. Stoeckle, I. Zola and G. Davidson, "On Going to see the Doctor, The Contribution of the Patient to the Decision to Seek Medical Aid," Journal of Chronic Diseases 16 (Sept. 1963) 975-978.

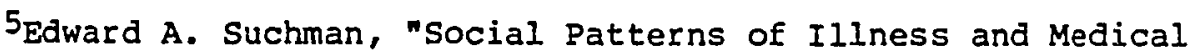
Care," Journal of Health and Human Behavior 6 (1965):3.

6Ibid.

7 Edward A. Suchman, "Health Orientation and Medical Care," American Journal of Public Health 56, I (Jan. 1966):100; Suchman, 1965, p. 15.

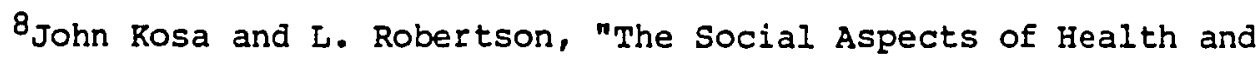
IIlness," Poverty and Health: A Sociological Analysis, J. Rosa, et al., eds. (Cambridge: Harvard University Press, 1969), pp. 319-342.

9Horacio Fabrega, "Toward a Model of Illness Behavior," Medical Care 11 (Nov.-Dec. 1973): 476 .

I0Ibid., p. 473

$11_{\text {Wan }}$ and Soifer, 1974, pp. 100.

12Donald K. Freeborn and Merwyn R. Greenlick, "Evaluation of the Performance of Ambulatory Care Systems: Research Requirements and Opportunities," Medical Care 11 (March-April Supplement, 1973):69. p. 100 .

13Freeborn and Greenlick, 1973, p. 69; Wan and Soifer, 1974, 
${ }^{14}$ Some examples are: Joseph $P$. Newhouse, The Health Insurance Study: A Sumnary (Santa Monica: Rand Corporation, March, 1974); Joseph P. Newhouse and Charles E. Phelps, Price and Income Elasticities for Medical Care Services (Santa Monica: Rand Corporation, 1974); Charles E. Phelps, The Demand for Health Insurance: A Theoretical and Empirical Investigation (Santa Monica: Rand Corporation, July, 1973); Paul J. Fieldstein, Health Care Economics (New York: John Wiley \& Sons, 1979); Ronald Andersen and Lee Benham, "Factors Affecting the Relationship Between Family Income and Medical Care Consumption, " H. E. Klarman, ed., Empirical studies in Health Economics: Proceedings of the Second Conference on the Economics of Health, (Baltimore: John Hopkins Press, 1970), pp. 73-95).

15Davis and Reynolds, 1975, pp. 391-417

16 James E. Weiss and Mervyn R. Greenlick, "Determinants of Medical Care Utilization: The Effect of Social Class and Distance on Contacts with the Medical Care System" Medical Care 8, 6 (Nov.-Dec. 1970) : 456-462; Stephen M. Shortell, William C. Richardson, James P. LoGerfo, Paula Diehr, Barbara Weaver, and Rathy E. Green, "The Relationships Among Dimensions of Health Services in Two Provider Systems: A Causal Model Approach," Journal of Health and Social Behavior 18 (June 1977):139-159; Richardson, 1970, Pp. 131-142.

17Thomas W. Bice and Kerr L. Whit,, "Factors Related to the Use of Health Services: An International Comparative Study," Medical Care 7 (March-April 1969):124.

18 Ronald Andersen, A Behavioral Model of Families' Use of Health Services (Chicago: University of Chicago, Center for Health Administration Studies, Graduate School of Business, Research Series 25 (1968); Andersen and Newman, 1973, pp. 95-124.

19 Andersen, 1968, p. 55

20 Ibid., p. 14

21 Ibia., p. 55 .

22Andersen and Newman, 1973, pp. 98-102.

23 Ibid., p. 102

${ }^{24}$ Davis and Reynolds, 1975, p. 401.

25Dutton, 1978, pp. 349-351, 360-361.

26 Myron J. Lefcowitz, "Poverty and Health: A Re-examination," Inguiry 10 (March, 1973):3.

27William Ryan, Blaming the Victim (New York: Vintage Books, 1971). 
${ }^{28}$ Irving R. Z0la, "Pathways to the Doctor--From Person to Patient," Social Science and Medicine 7 (Sept. 1973):678.

29Martin D. Hyman, "Research Report: Some Links Between Economic Status and Untreated Illness," Social Science and Medicine 4 (1970): 397.

30 Dutton, 1978, p. 350 .

31 Ibid., pp. 361-362.

32 Ronald Andersen and Lu Ann Aday, "Access to Medical Care in the U.S.: Realized and potential," Medical Care 16 (July 1978):534.

33 Mervyn R. Greenlick, David R. Lairson, John P. Mullooly, and Joan E. O'Bannon, "Determinants of Utilization of Health Care Systems," pp. 5-6 Proceedings of an International Conference on Health Technology Systems, M. Collen, ed. (San Francisco, Ca., Nov. 14-16, 1973).

34 Fink, 1969, p. 15. The use of the household as the unit of analysis is based on the premise that individuals' consumption of health services is affected by the consumption patterns of the households within which they reside. The household as a unit of analysis subsumes the family unit. The latter has been emphasized as important in determining utilization patterns of its members.

35 Andersen, 1968 , p. 6.

36 Raymond Fink, "The Measurement of Medical Care Utilization," Proceedings of a Conference on Conceptual Issues in the Analys is of Medical Care Utilization Behavior, M. Greenlick, ed. (Portland, Or.: DHEW, Public Health Service, Health Services and Mental Health Administration, 1969), p. 15.

37 Andersen, 1968 , p. 49.

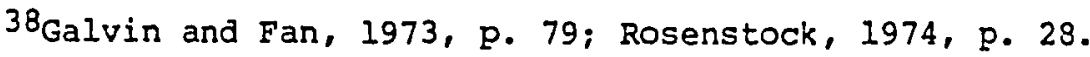

39Fink, 1969, p. 45.

40 The Utilization of Health Services: Indices and Correlates (Rockville, Maryland: The National Center for Health Services Research and Development. Department of Health, Education and Welfare, 1972), pp. 27-28.

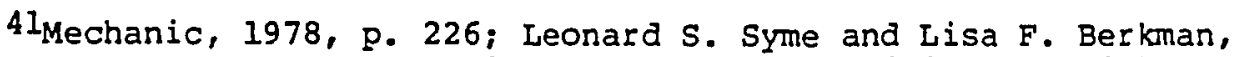
"Reviews and Commentary: Social Class, Susceptibility and sickness," American Journal of Epidemiology (July, 1976): 5 .

42Rosenstock, 1974, pp. 39-54. 
43United States Congressional Budget office, Background Paper No. 17: Poverty Status of Families Under Alternative Definitions of Income, Congress of the United States (Washington D.C.: U.S. Government Printing office, 1977), pp. 5-8. The definition of lower income includes, but is not limited to, households officially defined as "poverty" households. The criticisms of the existing standard definition of poverty makes its use as the only acceptable poverty measure questionable. Other means of defining poverty have included adjustments of gross income by in-kind transfers or taxes. By including all households with gross annual income of less than $\$ 10,000$ for 1977, it is possible to include low-income households with members in the labor force.

44 Aaron Antonovsky, "Social Class, Life Expectancy, and Overall Mortality," Milbank Memorial fund Quarterly 45 (1967):37.

45 Kane, Rasteler and Gray, 1976, p. 6

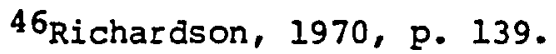

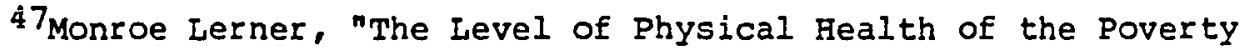
Population: A Conceptual Reappraisal of Structural Factors," Medical Care 6, 5 (Sept.-Oct. 1968):363; Kane, Rasteler and Gray, 1976, p. 6 .

48 Derived from $R$. Davis and R. Reynolds, "The Impact of Medicare and Medicaid on Access to Medical Care," The Role of Health Insurance in the Health Services Sector, New York: National Bureau of Economic Research, 1975, p. 396.

49 Ibid.

50 Ibid.

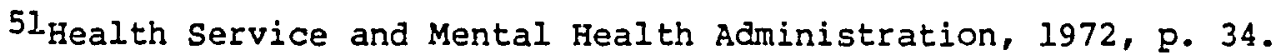

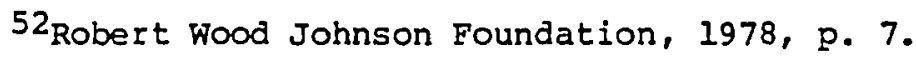

53Ibid., p. 6

54 Robert wood Johnson Foundation, "Special Report, No. 1, 1978," Princeton: Robert wood Johnson Foundation, 1978, p. 8. Income was classified as follows: Low (below $\$ 7,999)$, Medium $(\$ 8,000$ to $\$ 14,999)$ and High ( $\$ 15,000$ and over) based on 1976 income data.

55 Ibid.

56 Aday and Eichorn, 1972, p. 23.

57 Ibid. 
58 Ronald Andersen and Odin $W$. Anderson, A Decade of Eealth Services (Chicago: University of Chicago Press, 1967), p. 38.

$59_{\text {Andersen }}$ and Newman, 1978, p. 8.

${ }^{60}$ Ibid. , p. 8.

61 United States Congress, Congressional Budget office, 1979, p. 12 .

62United States Congress, Congressional Budget office, 1979, pp. $9-10$.

63Derived from 1969 Health Interview Survey data discussed by Raren Davis and Roger Reynolds, "The Impact of Medicare and Medicaid on Access to Medical Care," The Role of Health Insurance in the Health Services Sector, R. N. Rosett, Ed. New York: National Bureau of Economic Research, 1975, p. 396.

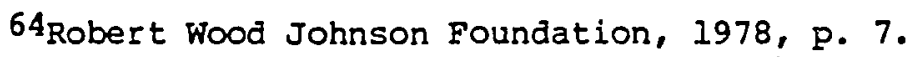

65 Ibid., p. 6 .

66 Andersen and Anderson, 1967, p. 135.

67 Richardson, 1970, pp. 141-142.

68 Aday and Andersen, 1975, pp. 72-79.

${ }^{69}$ Dutton, 1978 , p. 360 .

${ }^{70}$ Irving Leveson, "The Economics of Health Services for the Poor," The Nation's Health: Some Issues, S. Berki and w. Heston, eds., The Annals of the American Academy of Political and Social Sciences 399 $(1972): 23$.

7lJulius A. Roth, "The Treatment of the Sick," Poverty and Health: A Sociological Analysis, A. Antonovsky and $\overline{I . ~ Z o l a, ~ e d s . ~}$ (Cambridge: Rarvard University Press, 1969), p. 229.

72Davis and Reynolds, 1975, p. 398; Dutton, 1978, p. 362.

${ }^{73}$ Robert Wood Johnson Foundation, 1978, p. 8.

74Davis and Reynolds, 1975, pp. 397-398; Dutton, 1978, p. 362 .

${ }^{75}$ Survey Research Center, Data Users' Guide for 1978 Oregon Health Interview Survey (Corvallis: Oregon State University) 1979, p. 3 . 
76Vicky Burnham and Donald R. Freeborn, "Oregon Health Survey: Initial Findings for HSA 1, "Health Services Research Center, Raiser Permanente Medical Program, Oregon Region, July 1979, p. 2.

77Survey Research Center, 1979, p. 4; Burnham and Freeborn, 1979 , p. 3.

78Ibid. , pp. 2-3.

${ }^{79}$ Ibid., p. 4.

${ }^{80}$ Robert Mason, Director, Survey Research Center, Oregon State University, Telephone Conmunication, Corvallis, January 1979.

${ }^{81}$ E. J. Webb, D. T. Campbell, R. D. Schwarz and I. Sechrest, Unobtrusive Measures: Nonreactive Research in the Social Sciences (Chicago: Rand McNally, 1966), p.3. 
CHAPTER III

\section{PATTERNS OF UTILIZATION OF HEALTH SERVICES \\ BY HEALTH POLICY GAP HOUSEHOLDS}

\section{INTRODUCTION}

The purpose of this chapter is threefold: to explore the causal linkage between the policy variables (income, medical insurance coverage, and source of medical care); to test the relative magnitude of the policy variables' on use of health services; and to examine the barrier effects of low income, lack of health insurance, and an inappropriate source of medical care.

A temporal/causal order is assumed among the policy variables in which income acts as an independent variable on insurance coverage, which in turn acts on source of care (see Figure 12). Within the subset of policy variables, source of care is treated as a dependent variable. When the policy variables are entered into the larger model developed in this chapter, source of care is treated as an independent variable on the premise that at least part of its impact on use of services is separate from that which is due to income and insurance. The same reasoning applies to insurance coverage, which is considered to be antecedent to income, yet precedent to source of care. 


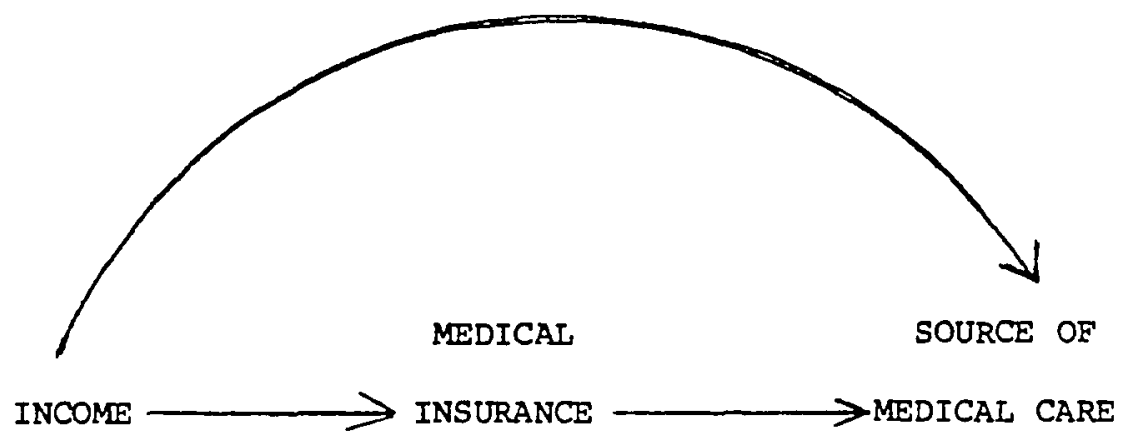

Figure 12. Causal model relationships of the policy variables of income, medical insurance and source of medical care.

A behavioral model of health services utilizatici: is constructed to integrate the policy variables, measures of health services, and selected household characteristics. The latter includes factors such as personal health behaviors, age, sex, and lifestyle stability, which are associated with levels of health services use. They are incorporated into the model as statistical controls on the relationship of the policy to the dependent use of measures. This avoids the problem of attributing observed levels of use entirely to income, for example, when they may, in fact, be due to other factors (such as excessive smoking). The control variables include measures of household structure, need for health services, residential mobility, and health behaviors (see Figure 13 ). 


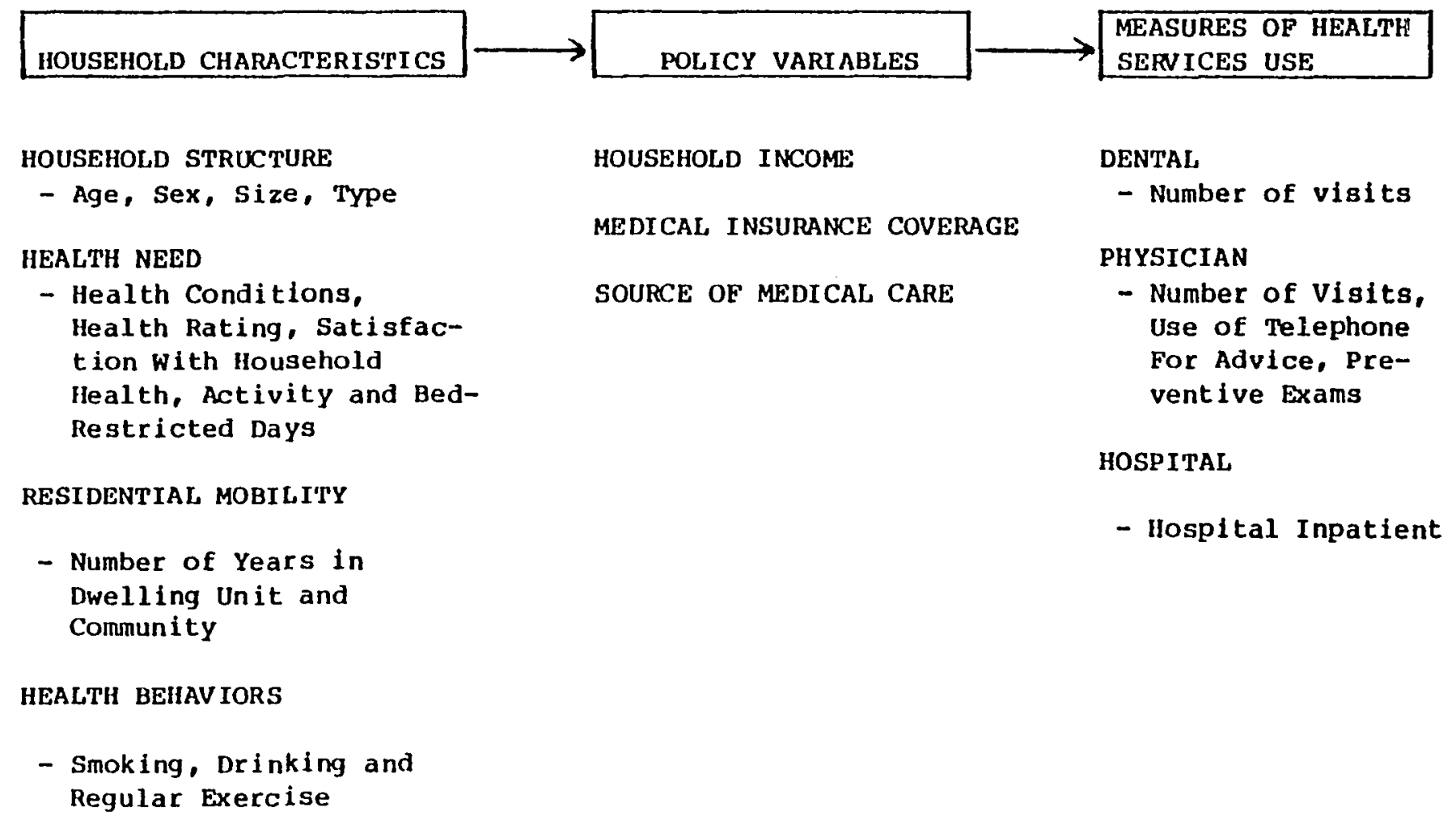

Figure 13. Causal model of health services utilization. 
The study investigates six hypotheses. The first explores the causal relationship of income, insurance coverage, and source of care. The next two examine the relative effects of the policy variables on use of health services. The last three test the barrier effects of low income, lack of insurance, and an inappropriate source of care upon patterns of use.

\section{CAUSAL RELATIONSHIP OF INCOME, INSURANCE COVERAGE AND SOURCE OF CARE}

The introductory hypothesis is:

Low income is related to lack of medical insurance, which, in turn, is related to an inappropriate source of medical care.

This hypothesis is explored by inspecting the association between income and insurance coverage, and income and source of care. The relationship between insurance and source of care is then investigated, with income held constant to ascertain whether or not insurance has an independent effect on source of care. The analysis begins by looking at income, insurance, and source of care data.

Low income persons comprise 18.18 of the total sample ( $N=3341$ )

(see Table III); lower midale income persons $(\$ 10,000$ to $\$ 14,999)$ constitute 19.28 of the sample, and upper midale income persons $(\$ 15,000$ to 24,999$)$ make up $39.0 \%$. High income persons $(\$ 24,000$ or more) total almost a quarter $(23.78)$ of the sample. 
TABLE III

PERCENTAGE OF INDIVIDUALS BY MEDICAL INSURANCE COVERAGE AND HOUSEHOLD INCOME

\begin{tabular}{|c|c|c|c|c|c|}
\hline $\begin{array}{l}\text { Insurance } \\
\text { Coverage }\end{array}$ & $\begin{array}{l}\text { Less than } \\
\$ 10,000\end{array}$ & $\begin{array}{l}\$ 10,000 \text { to } \\
\$ 14,999\end{array}$ & $\begin{array}{l}\$ 15,000 \text { to } \\
\$ 24,999 \\
\end{array}$ & $\begin{array}{l}\$ 25,000 \\
\text { or more }\end{array}$ & Total \\
\hline Non-Insured & 18.78 & 7.58 & 5.78 & 4.88 & 8.28 \\
\hline Insured & 81.38 & 92.58 & 94.38 & 95.28 & 91.88 \\
\hline \multirow[t]{2}{*}{ Total } & 100.08 & 100.08 & 100.08 & 100.08 & 100.08 \\
\hline & $(605)$ & (64I) & $(1302)$ & (793) & (3341) \\
\hline
\end{tabular}

Since all household members are considered to be insured even if only one member reports coverage, the findings are likely to overestimate the extent of actual insured among the sample. ${ }^{1}$ Despite this conservative bias, 10.18 of all Oregonians sampled report no private insurance coverage $(\mathrm{N}=338)$. When estimates of public health insurance (Medicaid and Medicare) are included, the estimate of persons totally without insurance drops to 8.28 .2

Within income classes, nearly one in five (18.7\%) of the low income live in households without insurance coverage, which is two to four times the incidence of lack of insurance reported for other income classes. Only 7.58 of lower middle income persons, 5.78 of upper middle income persons, and 4.88 of high income persons are not insured. The data reveals a positive relationship between income and insurance coverage. As income rises, the probability of a household's having at least one member insured increases dramatically. 
Twelve percent of household members, or approximately one in eight, reports an inappropriate source of medical care.

Within income classes, almost thirteen percent (12.58) of the low income, nearly fifteen percent (14.5\%) of the lower middle income, approximately twelve percent (11.88) of the upper middle income and slightly more than ten percent (10.18) of the high income report an inappropriate source of medical care (see Table IV). No association emerges between income and source of care.

TABLE IV

PERCENTAGE OF INDIVIDUALS BY SOURCE OF MEDICAL CARE AND HOUSEHOLD INCOME

\begin{tabular}{|c|c|c|c|c|}
\hline $\begin{array}{l}\text { Source of } \\
\text { Usual Care } \\
\end{array}$ & $\begin{array}{l}\text { Less than } \\
\$ 10,000 \\
\end{array}$ & $\begin{array}{l}\$ 10,000 \text { to } \\
\$ 14,999\end{array}$ & $\begin{array}{l}\$ 15,000 \text { to } \\
\$ 24,999\end{array}$ & $\begin{array}{l}\$ 25,000 \\
\text { or more }\end{array}$ \\
\hline Not & & & & \\
\hline Appropriate & 12.58 & 14.58 & 11.88 & 10.18 \\
\hline Appropriate & 87.58 & 85.58 & 88.28 & 89.98 \\
\hline Total & $\begin{array}{l}100.08 \\
(559)\end{array}$ & $\begin{array}{l}100.08 \\
(622)\end{array}$ & $\begin{array}{l}100.08 \\
(1239)\end{array}$ & $\begin{array}{l}100.08 \\
(751)\end{array}$ \\
\hline
\end{tabular}

Insurance coverage and appropriateness of source of care are connected (see Table v). Twelve percent (12.18) of the uninsured also lack an appropriate source of care. At this point a caution must be issued: inappropriate source of care may be due to the household's inability to obtain insurance which enables it to secure an appropriate source of care, or it may be due to the household's not attaching importance to either insurance coverage or to source of care. That insurance coverage and source of care are related is 
evident: almost one in four individuals (24.38) in uninsured households report an inappropriate source of care as contrasted with only one in nine individuals (11.08) in insured households.

TABLE V

MEDICAL INSURANCE COVERAGE BY USUAL SOURCE OF MEDICAL CARE

Usual Source
of Medical Care

Not

Appropriate

Appropriate

Total
Medical Insurance Coverage

None Insured Total

24.38

11.08

12.18

75.58

89.08

87.98

100.08

(267)

100.08

100.08

(3046)

$$
\left(x^{2}=42.84, p=.00\right)
$$

The explanation that difficulty in obtaining insurance may cause difficulty in securing an appropriate source of care is supported by the data. The relationship between insurance and source of care is not affected by economic class. Sixteen percent (16.38) of low income uninsured persons mention an inappropriate source of care as compared with only 11.78 of insured low income persons (see Table VI). Similarly, 34.38 and 28.98 of the upper middle and high income, respectively, are found to have an inappropriate source of care as compared with an appropriate source of care (10.48 and 8.98$)$. Income, as hypothesized, is found to have a significant relationship to insurance coverage. Table III shows that persons in 
low income households are twice as likely to be uninsured as those in lower middle income households, and almost three times as likely as those in upper middle and high income households. A possible explanation is that higher income households contain employed adults who obtain employment-related coverage for themselves and their dependents, while adults in low income households tend either to be unemployed or to work in jobs not offering employee health insurance coverage (i.e., seasonal, domestic and/or minimum wage occupations).

TABLE VI

PERCENTAGE OF INDIVIDUALS WITH AN INAPPROPRIATE SOURCE OF MEDICAL CARE BY MEDICAL INSURANCE COVERAGE CONTROLLING FOR HOUSEHOLD INCOME

Inappropriate source of Care by Household Income

Under $\$ 10,000$

$\$ 10,000$ to 14,999

$\$ 15,000$ to 24,999

$\$ 25,000$ or more
Medical Insurance Coverage None Insured Total

$\begin{array}{lll}16.38 & 11.78 & 12.58\end{array}$

18.28

14.28

14.58

34.38

10.48

11.88

28.98

$8.9 \%$

9.98

Although income has no direct effect on source of care, it is clearly related to insurance coverage, as are the effects of insurance coverage on source of care. More than two times as many of the uninsured have an inappropriate source of medical care than do the insured. This finding persists even after possible income effects are ruled out by inspecting insurance coverage and source of care within income classes. Almost one and a half times as many uninsured low 
income persons have an inappropriate source of care as do insured low income persons.

RELATIVE CONTRIBUTIONS OF INCOME, INSURANCE AND SOURCE OF CARE TO EXPLAINED VARIANCE IN HEALTH SERVICES UTILIZATION

The relative effect of income, insurance, and appropriateness of source of medical care on use of health services are investigated in the following hypotheses:

- Income explains more variation in the utilization of health services than insurance coverage or appropriateness of source of medical care do; and

- Income, insurance coverage, and appropriateness of source of medical care explain the most variation in dental services utilization, less for physician services utilization and the least for hospital services utilization.

Income, then, explains more variation in the use of health services than do insurance or source of care because of its primary causal/temporal position within the subset of policy variables. This assumption has implications for policymaking; policy interventions at earlier points in the causal process should have more encompassing effects, both direct and indirect, on patterns of utilization than intervention later in the process. This early intervention should produce more targeted results on services use. ${ }^{3}$

Dental, physician, and hospital services vary in terms of the control over use afforded consumers relative to providers. The household retains most control over the use of dental services, less for physician services, and least for hospital services (see Figure 5). Conversely, the provider controls most decisions over use of hospital services, less for physician services, and least for dental services. 
The continuum of consumer-provider control over services use depends on several factors, among which are the immediacy and seriousness of health need and areas of decisionmaking traditionally assigned to either the consumer or provider in the American health care system. An examination of the above hypotheses begins by the development of a correlation matrix. zero-order correlations of dependent, policy, and control variables are examined for high correlations (.6 and above) to determine whether any control variables overlap enough to drop those less theoretically useful and whether any dependent variables should be collapsed into a common measure. As can be seen by Table VII, none of the dependent measures of health services hold more than 28 of their variance in common, indicating that, even for submeasures of the same health service, different factors may account for patterns of utilization. As a result of their dissimilarities, the dependent variables are examined separately.

Income, insurance, and source of care have very low intercorrelations; the highest is .18 for income and insurance, with approximately 38 variance commonality. Although these correlations are higher than for the dependent variables, none warrants the development of a common measure, especially in light of their varying implications for policymaking.

Household characteristics have generally low inter-correlations, ranging from .00 to .61 . Age is moderately related to household size $(-.52)$ and to number of health conditions $(.61)$. Years in the community is related to years in the dwelling unit, as expected (.54). Submeasures of each category of household characteristics (structure, health need, residential mobility, and health behaviors) differently 
TABLE VII

ZERO-ORDER CORRELATIONS

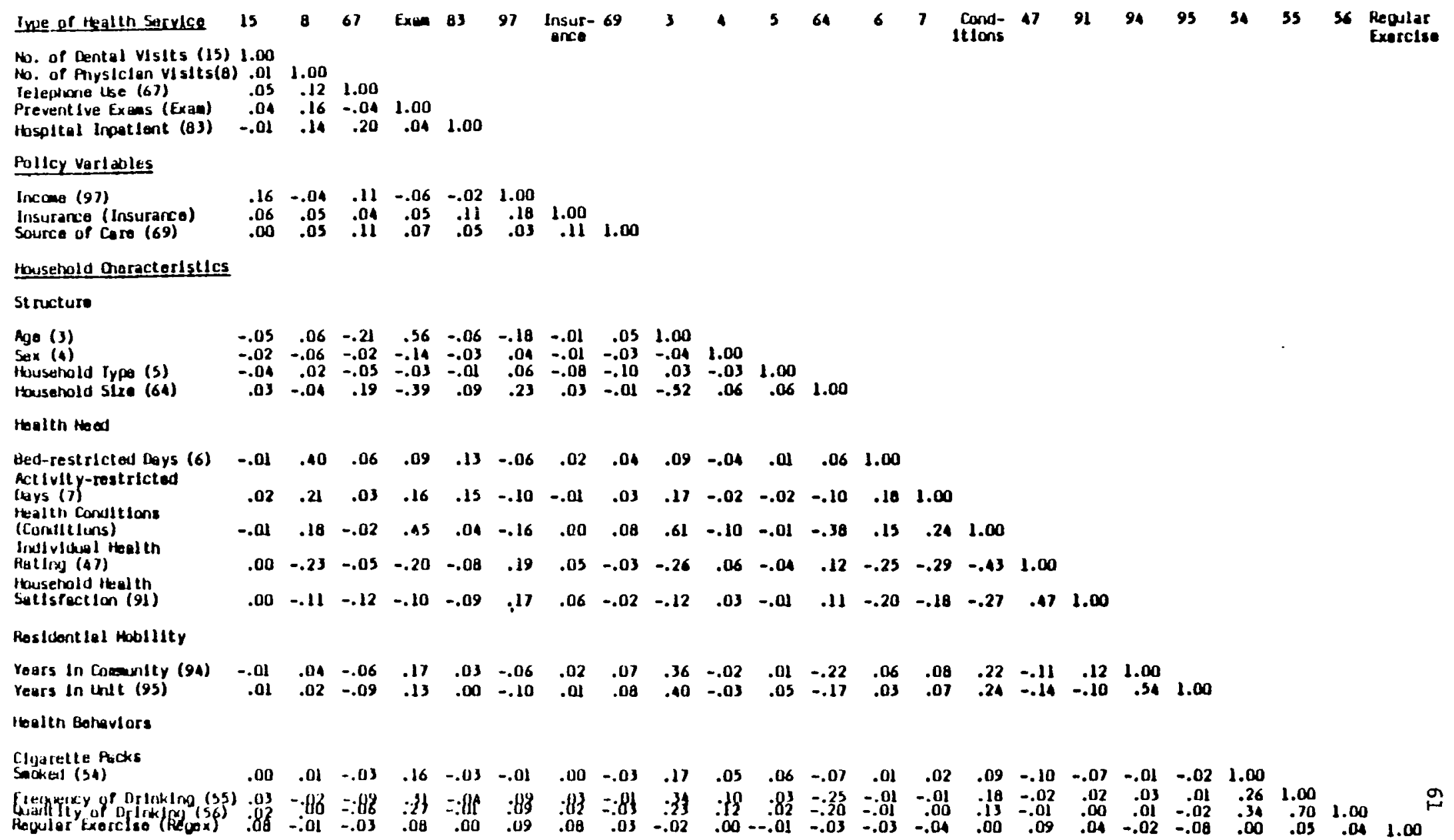


predict the utilization measures. Therefore, none are dropped. Instead, the relationship of health services, policy variables, and household characteristics are individually examined in a set of regression equations.

Series of blocks of variables are entered separately for each health service in the order of their theoretical importance. The policy variables are entered first to discern their contributions (both separately and collectively) to explained variance for each health service measure. Then, in line with the behavioral model, the household structure variables of age, sex, household type, and household size are entered as a group in the second step.

Health need variables, found to be the largest predictors in the literature on health services utilization, are entered as a group in the third step. These include the number of bed-restricted days due to illness, number of activity-restricted days due to illness, number of ill-health conditions, individual health ratings, and degree of satisfaction with household health on the part of the respondent. Residential mobility variables, number of years in the community, and number of years in the unit are entered in the fourth step. Finally, health behaviors which might conceivably affect use of health services are entered. Resulting regression coefficients (standardized Betas) and cumulative coefficients of determination $\left(R^{2}\right)$ for each measure examined are shown in rable VIII.

As anticipated, the policy variables do not have large Betas, nor do they explain a large proportion of variation in each dependent measure compared with the household characteristics. Yet they remain significant even after household and individual characteristics known 
TABLE VIII

REGRESSION BETAS AND CUMULATIVE $\mathrm{R}^{2}$

Independent Variables

Health Services Measures

\begin{tabular}{|c|c|c|c|c|}
\hline Dental & & Physician & & Hospital \\
\hline $\begin{array}{c}\text { \# of } \\
\text { visits }\end{array}$ & $\begin{array}{c}\# \text { of } \\
\text { Visits }\end{array}$ & Phone Use & Exam & In-Patient \\
\hline
\end{tabular}

I. Policy Variables

$\begin{array}{lr}.15 & -.05 \\ .03 & .05 \\ .03 & .05\end{array}$

Medical Insurance

Source of care

.03

.05
.05
.05
.01

.10
.10
.02

$-.08$

.06

.06

$-.05$

.12

.04

.02

II. Control Variables

Household structure

\begin{tabular}{|c|c|c|c|c|c|}
\hline Age & -.03 & .05 & -.15 & .50 & * \\
\hline Sex & -.03 & -.06 & -.03 & -.11 & -.03 \\
\hline Type & -.04 & * & -.04 & -.04 & * \\
\hline Step 2: Cumul R Squared & .03 & .01 & .10 & $\begin{array}{r}. .14 \\
.35\end{array}$ & $\begin{array}{l}.09 \\
.03\end{array}$ \\
\hline \multicolumn{6}{|l|}{ Health Need } \\
\hline Bed-Restricted Days & * & .35 & .03 & $\star$ & .09 \\
\hline Activity-Restricted Days & * & .12 & .03 & .04 & .13 \\
\hline Health Conditions & * & .12 & .12 & .13 & .07 \\
\hline Individual Health Rating & * & -.10 & $\star$ & -.03 & $\star$ \\
\hline Household Health Rating & $\star$ & .05 & -.13 & * & -.05 \\
\hline Step 3: Cumul R Squared & .03 & .21 & .11 & .37 & .07 \\
\hline \multicolumn{6}{|l|}{ Residential Mobility } \\
\hline Yrs in Community & $\star$ & * & $\star$ & * & .05 \\
\hline Yrs in Dwelling Unit & .05 & $\star$ & .03 & -.10 & * \\
\hline Step 4: Cumul $R$ Squared & .03 & .21 & .11 & .38 & .07 \\
\hline
\end{tabular}

Health Behaviors

* Packs Cigarettes Smoked Frequency of Drinking

\# Drinks at one Time

Regular Exercise

Step 5: Cumul R squared

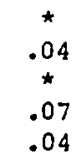

$\begin{array}{lc}\star & \star \\ \star & \star \\ \star & \star \\ .21 & -.04 \\ & .11\end{array}$

.03
.07
.09
.07
.40

$\star$
$\star$
$\star$
.05
.07

* Not significant at $p \leq .05$. 
to be strongly related to use of health services are entered into the equation. The argument is made that the persistence of these findings constitutes policy-mutable barriers to appropriate and equitable utilization of dental, physician and hospital services.

The various Betas (standardized multiple regression correlation coefficients) and cumulative $\mathrm{R}^{2}$ 's are displayed in Table VIII. Income is a significant predictor of use across all services. Insurance and source of care are also statistically significant across most services.

Dental Services

Income is the largest predictor among the policy variables of dental services use, and indeed, of all independent variables entered into the equation. Its Beta is .15 , compared with .03 for insurance. Source of care is not a significant predictor for dental services because dental and medical services are not generally obtained from the same source in this country, with the exclusion of prepaid health care plans such as Raiser. Altogether, both the policy and household characteristics account for only approximately 48 of the total variance in use of dental services.

\section{Physician Services}

All three policy variables are significant predictors of number of physician visits. Income has a negative relationship to number of visits; i.e., those with low incomes tend to see physicians more often. Insurance coverage and an appropriate source of care are 
positively associated with number of visits to a physician. All three variables have equally large correlation coefficjents. Household characteristics emerge, as expected, as strong predictors for the number of physician visits. This finding is especially true for the variable of number of bed-restricted days. Total $\mathrm{R}^{2}$ increases to twenty-one percent of the explained variation in number of physician visits. The policy variables contribute a small but significant part of the total explained variance.

\section{Hospital Services}

Income has a weak negative relationship to use of hospital services (Beta $=-.05)$. Insurance is the most powerful policy predictor, with a Beta of .12. An appropriate source of care is also positively related to hospital services use, though of less importance than insurance $($ Beta $=.04)$.

\section{PATTERNS OF HEALTH SERVICES USE}

The hypothesized barriers of low income, lack of insurance, and an inappropriate source of care are predicted to depress use of health services in the following ways:

- Members of lower income households use fewer health services than do members of higher income households;

- Members of uninsured households use fewer health services than members of households in which at least one person is insured; and

- Members of households without an appropriate source of usual medical care use fewer health services than do members of households with an appropriate source of care. 
Use profiles of Health Policy Gap households are drawn by examining mean levels of use of each service (dental, physician and hospital) by each policy variable (income, insurance, and source of care). For example, the profiles show the average number of times each household member has seen the dentist in the past twelve months for households of different incomes (see Figure 14).

Analysis of variance is employed to check for statistically significant relationships ( $p=.05$ or less) of the policy variables to the dependent measures of services use. It is also used to check for interactions among the policy variables. Multiple classification is then applied, both to find mean levels of service use by each policy variable and to sift out the effects of the control variables on the dependent measures from the effects of the policy variables on the dependent meaures. In this manner, successive statistical tiers of control are applied to the initial bivariate relationship of the policy variable and the measure of use.

Each measure of services use is initially contrasted with each policy variable and is then viewed again while controlling for the effects of the other two policy variables. Finally, the relationship is tested holding constant the effects of the other two policy variables as well as the selected household characteristics variables. The latter are chosen on the basis either of having been found to contribute most to the variation in the particular health service measure, or of having been most effective in decreasing the zero-order correlations of the policy variables with the dependent measures (see Tables IX and $\mathrm{X}$ ). 
2.00

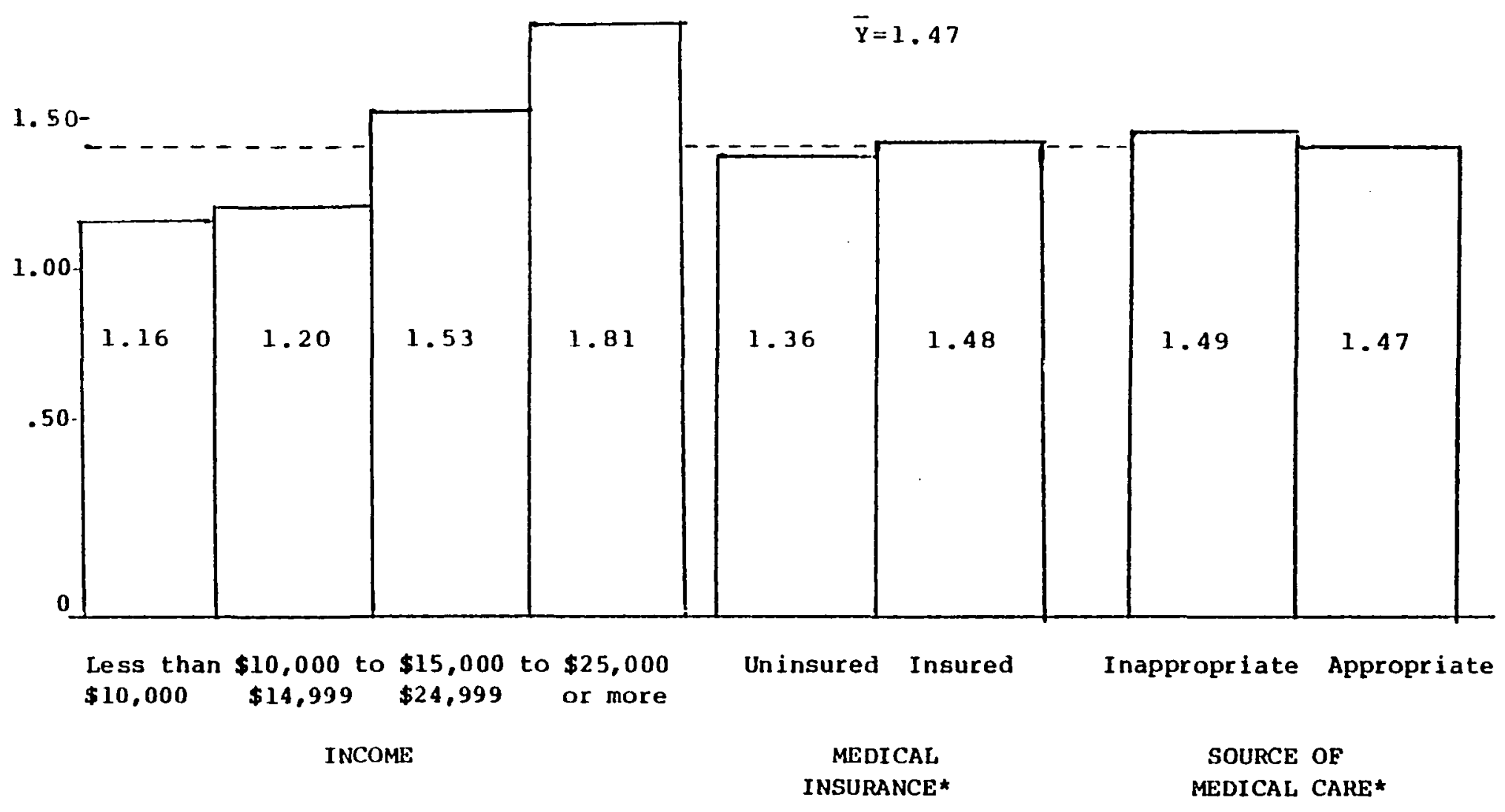

Figure 14. Mean number of times household members saw the dentist in the past year by income, medical insurance coverage, and appropriateness of source of medical care controlling for the other policy variables and household

characteristics (structure, residential mobility and health behaviors)

*Not significant at $\mathrm{p} \neq .05$ 
TABLE IX

PARTIAL COEFFICIENTS: ZERO-ORDER, FIRST-ORDER ANI) SECOND-ORDER

Household Incame Toro- $\frac{\text { Controlling lor }}{\text { order Ineurance source of care poth }}$
Madical Insurence

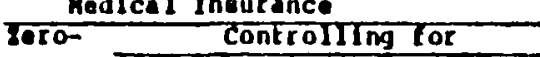

Source of medlcal care

zoro- Controlling for

\section{Dental services}

Mo, of Dontel

vialta

$.15 \quad .15$

.15

.15

order Income bource of cere Both

order Incone Inourance eath

phyelcten services

\section{Mo. of phyolclan}

visited

relephone Use for

Prevent lve exare

$-.05$

$-.04$

$-.05$

$.05 \quad .06$

.05

\section{Hogpltel gervices}

Hospital Inpat lent -.03

$-.05$

$-.01$

$-.06$

$.11 \quad .12$

.11

.12

$.04 \quad .04$

.03

.03 


\section{TABLE $X$}

PARTIAL COEFFICIENTS: ZLRO-ORDFR AND CONTROLLING FOR HOUSEIOLD STRUCTURE, HEALTI NEED, RESIDENTIAL MOBILITY AND HEALTH BEHAVIORS

\begin{tabular}{|c|c|c|c|c|c|c|c|c|c|c|c|c|c|c|c|}
\hline \multirow[t]{2}{*}{$\begin{array}{l}\text { Moalin sorvicas } \\
\text { Meceure }\end{array}$} & \multirow[b]{2}{*}{$\begin{array}{l}\text { Sorro- } \\
\text { ordes }\end{array}$} & \multicolumn{3}{|c|}{$\begin{array}{l}\text { Wounchold Incoes } \\
\text { coptrolltay fos }\end{array}$} & \multirow[b]{2}{*}{ Moelti } & \multirow{2}{*}{$\begin{array}{l}\text { seco- } \\
\text { ordor }\end{array}$} & \multicolumn{3}{|c|}{$\begin{array}{l}\text { Modical Innurance } \\
\text { controlitim gor }\end{array}$} & \multicolumn{6}{|c|}{$\begin{array}{l}\text { Bource of Medical care } \\
\text { Controlling bor } \\
\end{array}$} \\
\hline & & $\begin{array}{l}\text { Touter } \\
\text { bold } \\
\text { otsuctuse }\end{array}$ & $\log$ & mobldity & & & $\begin{array}{l}\text { Mouso- } \\
\text { nold } \\
\text { neructure }\end{array}$ & $\begin{array}{l}- \text { Monteb } \\
\text { moed }\end{array}$ & $\begin{array}{l}\text { Rootdont Iat } \\
\text { moblluty }\end{array}$ & $\begin{array}{l}\text { Toeitit } \\
\text { metaviors }\end{array}$ & $\begin{array}{l}\text { soro- } \\
\text { order }\end{array}$ & $\begin{array}{l}\text { Tound } \\
\text { bold } \\
\text { etruetuce }\end{array}$ & $\log _{\log 2 \pi}$ & $\begin{array}{l}\text { Dofldontlal } \\
\text { mobllity }\end{array}$ & 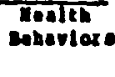 \\
\hline \multicolumn{16}{|l|}{ Dentel } \\
\hline $\begin{array}{l}\text { Mo. of pontel } \\
\text { vialte (1s) }\end{array}$ & .15 & .15 & .16 & .15 & .15 & .05 & .05 & .06 & .05 & .es & - & - & - & - & $\bullet$ \\
\hline \multicolumn{16}{|l|}{ phyelclen } \\
\hline $\begin{array}{l}\text { Mo. at phyelcien } \\
\text { violte lio }\end{array}$ & -.04 & - & - & -.01 & -.01 & .05 & .05 & .05 & .05 & .03 & .03 & .11 & - & .01 & .03 \\
\hline 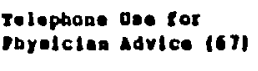 & .12 & .1 & .13 & .11 & .12 & .06 & .64 & .06 & .05 & .06 & .11 & .11 & .12 & .12 & .10 \\
\hline 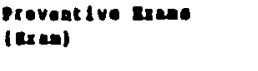 &.- .17 & .00 & .06 & -.06 &.- .11 & .04 & .01 & .06 & .05 & .04 & .06 & .03 & $\bullet$ & .05 & .01 \\
\hline \multicolumn{16}{|l|}{ Dospirel } \\
\hline Ixpet loat (a) & -.03 & -.05 & - & -.03 & -.03 & .11 & .11 & .11 & .12 & .11 & .04 & .04 & .03 & .04 &.$e 4$ \\
\hline
\end{tabular}

-yot algnitlcant at PSOS. 
Across all health services, members of Health Policy Gap households exhibit a distinct profile of use when contrasted with profiles of other households.

\section{Dental Services}

Use of dental services is measured by the number of times household members are said to have seen the dentist during the past twelve months. Household characteristics used as control variables in the analysis include age of household member, household type, residential nobility (number of years in the dwelling unit), and frequency of drinking. As anticipated, the policy variables less directly related to use of dental services, medical insurance, and source of usual medical care, do not significantly differentiate among individuals' levels of service use (see Figure 14).

Those with an inappropriate source of medical care report an average of 1.42 dental visits per year, versus 1.48 dental visits for those with an appropriate source of care. When the relationship is adjusted for the other policy variables of income and insurance, both those with and those without an appropriate source of medical care average of 1.47 dental visits yearly. When both the other policy variables and selected household characteristics are controlled for, those with an inappropriate source of care average only slightly more visits yearly (1.49) than those with an appropriate source of care $(1.47)$.

Uninsured persons report only 1.18 dental visits on the average, compared with 1.51 visits for persons in households with at least one 
household member insured. After adjusting for income and source of care, the uninsured's average number of dental visits rises to 1.31, while the average number of visits of the insured remains approximately the same (1.51). The gap narrows further when household characteristics are held constant. Average number of dental visits for the uninsured increases to 1.36, and insured individuals' dental visits decrease to 1.48. The difference is not statistically significant. Use of dental services by income shows a positive and linear relationship. As income rises, the mean number of dental visits also rises. The average number of dental visits for the low income is 1.10 ; the average is 1.25 for the lower middle income, 1.54 for the upper midale income, and 1.84 for the high income. When source of care and insurance are taken into account, this gap narrows to only 1.12 for the low income, remains at 1.25 for the lower middle income and 1.54 for the upper midale income, and drops only slightly to 1.83 for the high income.

Even after controlling for selected household characteristics, the low income average only 1.16 dental visits versus 1.22 for the lower middle income, 1.53 for the upper middle income, and 1.81 for the high income. Clearly, the low income fall far short of other income classes in their use of dental services. The lower middle income also report fewer than the average of 1.47 dental visits reported for the sample as a whole.

\section{Physician Services}

Use of physician services is explored for three measures. The 
first is the number of visits to a physician in the prior twelve months. Household characteristics used as controls include sex, numbor of bed-restricted days due to ill health, number of activity-restricted days due to ill-health, number of ill-health conditions, and overall rating of each member's health.

The second measure is whether the household is reported as having used the telephone to contact a physician for advice during the past twelve months. Household variables held constant in the analysis include age, household size, number of health conditions, satisfaction with household health, and, a report of regular exercise by at least one household member.

The third measure is whether or not the household member is reported as having had any of five preventive health exams (Pap smear, prostate, blood pressure, blood sugar or breast exam) during the last year. Age, sex, household size, number of ill-health conditions, and quantity of liquor consumption are control variables.

Income, insurance, and source of care all show different patterns of physician services use. Although insurance coverage is not statistically significant for two of the three measures, and source of care for none of the three measures, all policy variables decrease use of physician services.

Income, insurance coverage, and source of care are all significant demarcators of visits to the physician. Persons in the sample visited the physician an average of 3.40 times during the prior year. Adjusted for the effects of other variables, this statistic contrasts sharply with the respective $2.99,2.21$, and 2.89 mean visits to the physician 
by the low income, the uninsured, and those without an appropriate source of care.

The low income at first appear to use more physician services on the average than any other income group. They report a mean of 3.76 physician visits compared with 3.74 for the lower midale income, 3.41 for the upper middle income, and 2.84 for the high income as shown in Figure 15.

The low income use even more physician visits when source of care and insurance coverage are held constant. Mean use climbs to 3.97 visits per year, while that of the lower midale income stays relatively the same, visits by the upper midale income drop to 3.36, and visits by the high income decrease to 2.76 .

Initially, it appears that the low income overutilize services. But when household structure and health need are considered, the average number of physician visits by the low income drops precipitously below that of other income groups. They then average only 2.99 visits, compared with 3.36 for the lower middle income, 3.69 for the upper midale income, and 3.24 for the high income. Controlling for household characteristics reverses the initial pattern of overutilization by the low income to one of underutilization relative to other income groups.

When physician visits are analyzed in terms of insurance coverage, the gap widens. The uninsured, even after adjusting for other variables, still visit the physician only 2.21 times per year versus the insured's reported 3.52 visits. Lack of insurance constitutes a greater obstacle to use of physician visits than do either source of care or income. 


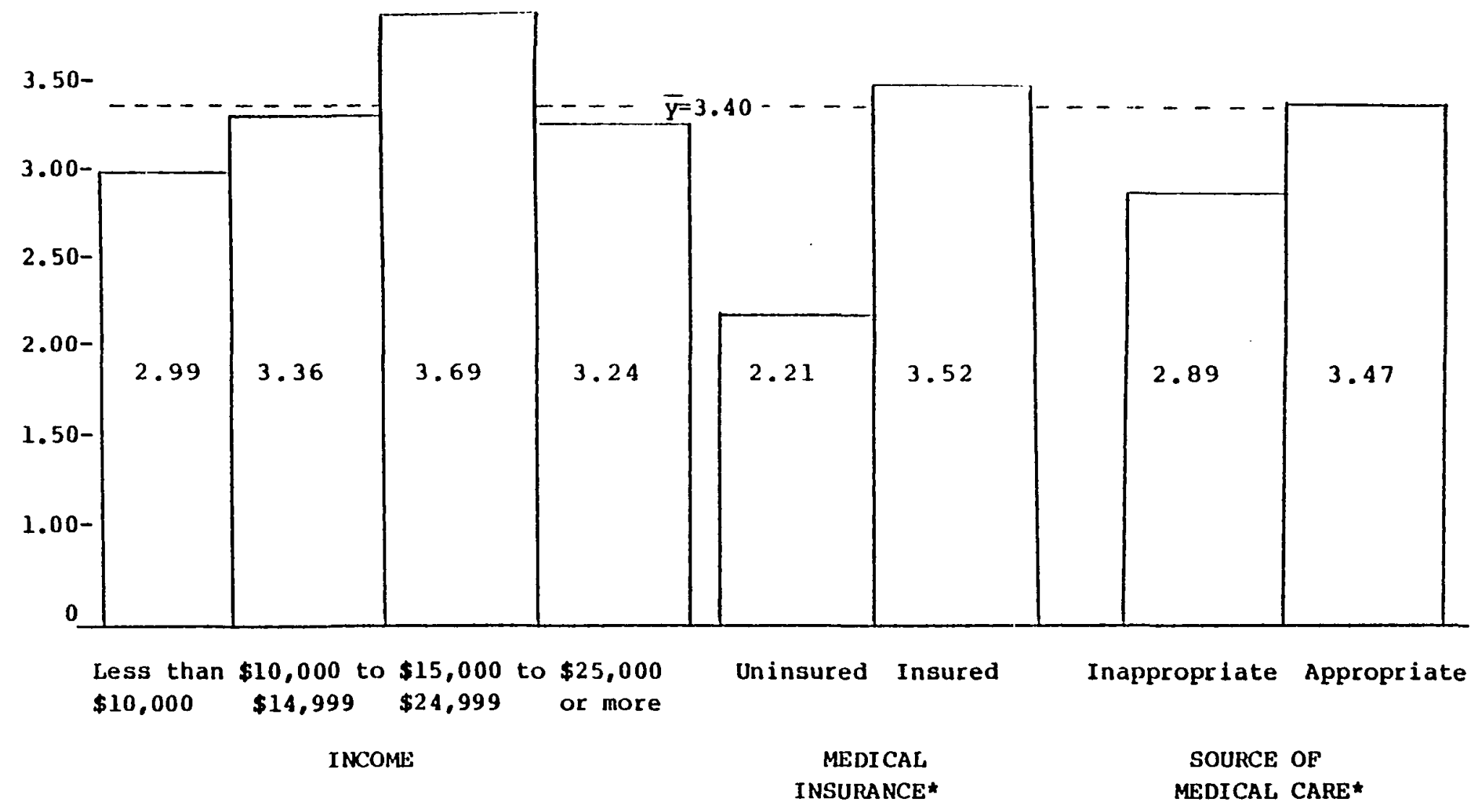

Figure 15. Mean number of times household members saw a physician during the past year by income, medical insurance coverage, and appropriateness of source of medical care controlling for the other policy variables and household characteristics (structure and health need).

*Not significant at $p \leq .05$ 
Source of care shows a pattern in which each successive level of control applied to the bivariate relationship of the policy variable and measure of use decreases, but does not erase, a significant gap among levels of use. Those without an appropriate source of care then average 2.89 physician visits, as opposed to 3.47 visits for those with an appropriate source of care.

Household use of the telephone for physician's advice is the second measure of physician services. Income and insurance coverage (but not source of care) are statistically significant predictors of this measure of use. Thirty-eight percent of all persons reside in households which have contacted the physician by telephone in the past year. After holding other factors constant, this figure may be compared with the 338 and 348 of low income and lower middle income persons, respectively, who have contacted a physician by telephone. of the uninsured, 348 report household use of the telephone for physician advice compared with 388 of insured persons (controlling for policy and household characteristics). This figure decreases to 248 for persons without an appropriate source of care, as opposed to 408 for persons who report an appropriate source of care (see Figure 16). The relationship remains stable even after increasing levels of statistical controls are applied.

The last measure of physician services is whether an individual has had one of five preventive exams (Pap smear, prostate, blood pressure, blood sugar, or breast exam). All three policy variables are important in predicting reported exams. Applying successive levels of control to the relationship of the policy variable and use 
$1.00-$

$.90-$

$.80-$

$.70-$

$.60-$

$.50-\quad \bar{y}=.38$

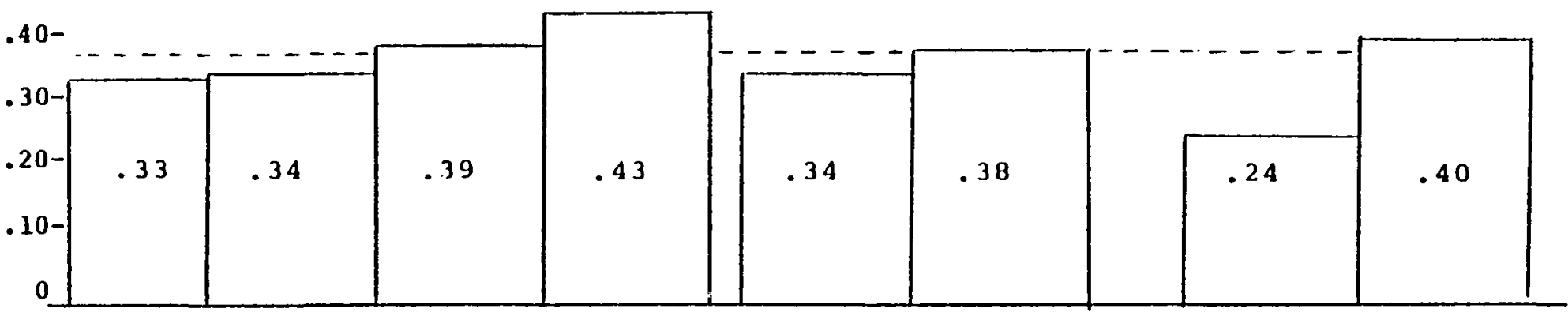

Less than $\$ 10,000$ to $\$ 15,000$ to $\$ 25,000$

Uninsured Insured

Inappropriate Appropriate

$\$ 10,000 \quad \$ 14,999 \$ 24,999$ or more

INCOME

MEDICAL

INSURANCE*

SOURCE OF

MEDICAL CARE*

Figure 16. Mean use of the telephone by the household by income, medical insurance, and source of medical care controlling for the other policy variables and household characteristics (structure, health need and health behavior $\mathbf{s}$ ).

*Not significant at $\mathrm{P} \leqslant .05$ 
of exams measure categorically results in a reduction, but not elimination, of differences among groups.

A pattern similar to that of income and physician visits is found for preventive exams. At first glance, the low income have a much higher reported incidence of exams (568) than do other income groups (who range from 458 to 518 ). After holding other policy variables constant, this pattern becomes even more pronounced. 4 Fifty-eight percent of the low income then report having had an exam, while other income group's use remains relatively the same. But when household structure, health need, and health behaviors are entered into the equation, the pattern reverses itself: the low income underutilize exams relative to other income groups. Exam use drops to 448 for the low income, compared with 50-518 for other income groups as shown in Figure 17.

An examination of insurance coverage and use of preventive exams shows that $43 \%$ of the uninsured compared with 508 of the insured have had an exam in the past year.

Levels of exam use by source of care also vary. Forty-six percent of those without an appropriate source of care have had a preventive exam, compared with 498 of those with an appropriate source of care.

Hospital Services. Use of hospital services is measured by whether any household member is reported to have been hospitalized during the past year. Household size, number of bed-restricted days, number of activity-restricted days, number of ill-health conditions, and satisfaction with household are the selected control variables. 
$1.00-$

$.90-$

$.80-$

$.70-$

$\bar{y}=.30$

$.60-$

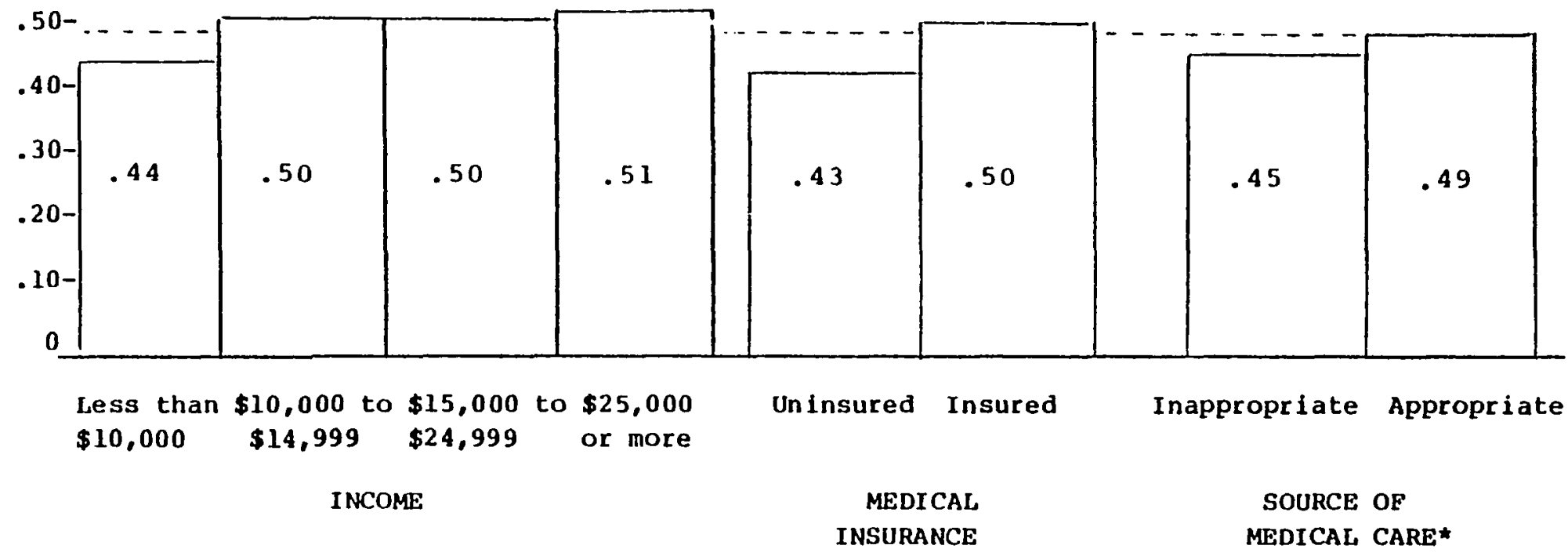

Figure 17. Mean number of preventive exams received by household members in the past year by income, medical insurance coverage, and appropriateness of source of medical care controlling for the other policy variables and household characteristics (structure, health need and health behaviors).**

* Not significant at $p \leqslant .05$

**Significant interactions are found among the policy variables. 
Income, source of care, and insurance are all significant predictors of use. An interesting pattern emerges at this point regarding income. Use of hospital services, unlike use of other health services measures, is described by a nonlinear relationship. That is to say, reported use of hospital services does not proportionately change as income changes. Instead, hospital services use peaks for the lower midale income and is lower for the low income, the upper middle income, and the high income. 5 The low income report a 308 probability of having had a household member hospitalized versus 358 for the lower middle income, 318 for the upper middle income, and 248 for the high income, even after holding all other variables constant, as shown in Figure 18.

In this case, the low income have the same probability of having a household member hospitalized as the general sample, and the high income report a much lower probability than that of the sample as a whole. The latter finding may be attributable to the high income group's ability to maintain ill household members within the household or in alternative care institutions rather than as hospital inpatients. 6

The uninsured demonstrate the lowest probability (158) of having had a household member hospitalized, while the insured report a 328 probability -- almost two times as high. Persons without an appropriate source of care have only a 258 probability of having had a household member hospitalized, versus 318 for those with an appropriate source of care. 


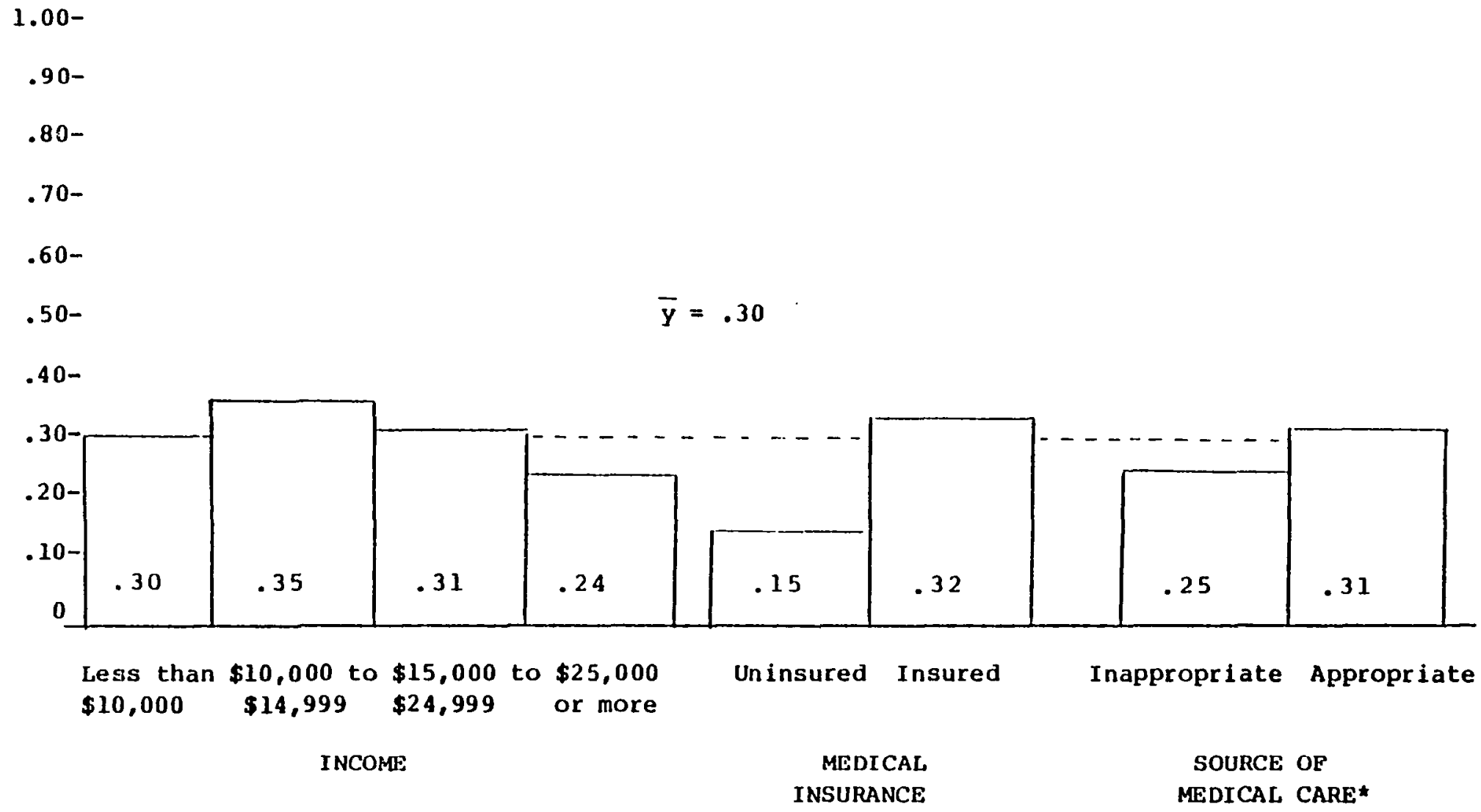

Figure 18. Mean number of household members in the hospital during the past year by income, medical insurance coverage, and appropriateness of source of redical care controlling for the other policy variables and household

characteristics (structure and health need) . $\star \star$

* Not significant at $p \leqslant .05$

**Significant interactions exist beween income and source of care. 
SUMMARY OF FINDINGS

Low income, lack of insurance, and an inappropriate source of care depress health services use. The degree to which they act as barriers varies by the measure of services use examined.

Income is the only policy variable found to significantly vary patterns of dental services use. The low income and the lower middle income visit a dentist, repectively, only 1.10 and 1.22 mean times per year, which is a sharp contrast to the 1.47 times a year reported for the general sample.

Income, insurance coverage, and source of care all affect number of physician visits. The low income see the physician a mean 2.99 times per year, compared with the 3.40 visits for the sample as a whole. The uninsured see the physician an average of 2.21 times a year, while those without an appropriate source of care report a mean 2.89 visits to the physician. Lack of insurance is the highest barrier to use of services, an inappropriate source of care is the second highest barrier, and low income is the third highest barrier. Eousehold use of the telephone for physician advice is related to all three policy variables. Relative barrier effects for use of the telephone are greatest for those in households reporting an inappropriate source of care. They use the telephone approximately half as often as those with an appropriate source of care (24\% versus 408). 
The uninsured and those with lower incomes also use the telephone for physician advice less frequently than does the overall sample. For the sample as a whole, 388 of persons were reported as having contacted a physician by telephone in the past year. Thirty-three percent of the uninsured and approximately the same percentage of the low and lower middle income, by contrast, report their household as having contacted a physician by telephone.

Low income, lack of insurance, and an inappropriate source of care decrease the probability of persons having obtained preventive exams. Almost half $(498)$ of the total sample report having had a preventive exam. Only 448 of the low income, 438 of the uninsured, and 458 of those without an appropriate source of care report preventive exams. The differences are small, but statistically significant.

Although all three variables are significant in predicting differences in use of hospital services, $30 \%$ of the low income report having had a household member hospitalized, which is equal to that of the general sample. Here, it is the high income category which differently utilizes hospital services. Only 248 report having had a household member hospitalized during the past year. This is surmised to reflect the higher income populace's greater ability to maintain supportive environments for household members in nonhospital surroundings.

Nevertheless, the low income exhibit the second lowest use of hospital services, with only 308 reporting having had a household member hospitalized, compared with $35 \%$ of the lower middle income and 318 of the upper middle income. 
Lack of insurance is the greatest barrier to use of hospital services. Only 158 of the uninsured versus 328 of the insured have had a household member hospitalized, even after other factors are controlled for. An inappropriate source of care is the second highest barrier. Only 258 of those without an appropriate source of care have had household members hospitalized during the past year, compared with 318 of those with an appropriate source of care. Low income is the third highest barrier to hospital use among the policy variables.

In conclusion, low income, lack of insurance, and an inappropriate source of care are found to significantly depress use of almost all health service measures examined, although the relative barrier effects differ by type and measure of service examined. Even after controlling for the effects of the other policy variables and selected household characteristics which might explain the relationship of the particular policy variable and measure, these effects persist. Low income, lack of insurance, and an inappropriate source of care clearly function as inequitable barriers to the appropriate utilization of dental, physician, and hospital services by Health Policy Gap households. 
ENDNOTES

$l_{\text {The survey asked whether anyone in the household was presently }}$ covered by a health insurance plan which paid any part of a doctor or hospital bill. Survey Research Center, Data Users' Guide for 1978 Oregon Health Interview Survey, Oregon State University, Corvaliis, Feb. 1979 (p. 10, code book).

$2_{\text {An }}$ age proxy for Medicare coverage is used to adjust the estimate of public insurance coverage. This is necessary because data was not collected in the survey for this category of insurance. The estimate is based on the almost universal availability of Medicare for persons sixty-five years old or older.

3Witness policymakers' reasoning regarding income versus inkind transfers of food, housing, and medical care.

4Income and insurance coverage, as well as income and source of care, are found to have significant interactions (sums of squares are 1.8 and 3.3 respectively, compared with 88.9 total explained sums of squares). Although statistically significant, these interactions are not large enough to change the clear relationship of income, insurance and source of care on use of the telephone for physician advice.

${ }^{5}$ Small interactions of insurance with source of care and for income with insurance with source of care are found for use of preventive exams (sums of squares are 0.6 and 2.0 respectively, compared with a total explained sums of squares of 296.7). Given the small ratio of interaction to total explained sums of squares, interaction effects are relatively unimportant.

${ }^{6}$ Interaction of income and source of care is significant for hospital services. The interaction sums of squares is 9.9 , almost one-fifth of the total explained sums of squares (52.3). Possible confusion of the findings is thus more serious here than for physician services in which the interaction terms amounted to a far smaller proportion of total explained sums of squares. 
CHAPTER IV

ACCESS WIDENING STRATEGIES AND

HEALTH POLICY GAP HOUSEHOLDS

INTRODUCTION

The current system of health care, it is contended, has only survived as Iong as it has because of government intervention, which has moderated the "disastrous effect of free market dynanics." 1 An incremental movement towards increased regulation and planning has attempted to make attainable the opportunity for social justice absent in a health marketplace characterized by free trade and competition. 2 From this perspective, health insurance (especially national health insurance) is a major readjustment to the problems of the free market in operation. ${ }^{3}$ National health insurance has been proposed by almost every administration since that of Franklin D. Roosevelt. In the past ten years, other private or local/state government combinations of access to care strategies have evolved. Alternative delivery systems (ADS) have been proposed in an attempt to address the issues of cost containment, access to care, and freedom of choice. These include health maintenance organizations, preferred provider organizations, independent practioners' associations, primary care networks, and local and state brokerage concepts. 
This chapter will describe the characteristics of each approach and the promises of increased access for households in the Health Policy Gap.

NATIONAL HEALTH INSURANCE (NEI)

The politics of National Health Insurance (NHI) focus on the legitimacy and desirability of governmental intervention into health care. Antagonists in the debate can be categorized as those who wish to shift medical care financing from the private to the public sector because they feel the private financing of medical care has led to intolerable inequities and those who view government financing as synonymous with government control and hence impersonal and inadequate medical care.

Feder and Holahan (1980) assert that these polarized stances on NHI frequently are not objective, reflecting instead,

"ideological predispositions towards private versus public administration, dispersed versus concentrated authority, and incremental versus radical change." 4

Large industrial unions such as the United Automobile Workers, as well as a variety of liberal religious, service, charitable and consumer groups, are advocates of NHI. NHI antagonists range from provider groups including the American Medical Association (AMA) and hospital groups to the conservative Young Americans for Freedom. 5

Aside from basic ideological differences, the major focus of the controversy over NHI has centered on the issue of cost containment. The expansion of private insurance coverage has been accompanied by significant increases in medical care costs, although cost escalation began even before the enactment of Medicare and Medicaid. 
To date, the expansion of health insurance, both private and public, has lowered the out-of-pocket cost to consumers, thereby improving the consumer's ability to pay for noncovered services; it has also facilitated the flow of revenue to providers, especially for fee-for-service providers. ${ }^{6}$ Major changes in the health care system have resulted. 7 More services covered by insurance are consumed, and services have become more complex. These changes, however, are not uniform across all services; rather, they are concentrated on the more costly, insurance-covered ones. Consumption fatterns have thus shifted towards more expensive services. To the extent this occurs, spiraling costs are exacerbated.

Part of these cost increases reflect the rising cost of resources and changes in service quality. Part, however, reflect a monetary transfer to providers above and beyond what might be considered generally acceptable. Price changes by providers account for over $40 \%$ of increases in medical expenditures since 1950. Since the removal of the 1971-74 cost controls, price changes have accounted for 78.38 of the rise in health care expenditures. ${ }^{8}$

NHI opponents argue that expansion of insurance coverage will only exacerbate the recent growth in medical care expenditures. They argue that everyone will be adversely affected by inflated out-ofpocket care costs and that costs will rise exponentially for government. Since third party insurance already pays 948 of hospital care expenses but only 618 of physician services' expenses, most of this expansion would occur in physician services. Some portion of these services, it is argued, will cost more than their derived 
benefits warrant. NHI opponents are also against diverting resources from more productive activities into national health insurance because they believe to do so would hurt the nation's economic health. Finally, they oppose any growth of the federal budget that would be associated with NHI.

\section{Administrative and Fiscal Criteria}

An effective national health insurance program would improve access to care, while restraining total as well as individual medical expenses. $9^{\prime}$ One way in which to gauge the effectiveness of NHI is to look at associated administrative and fiscal factors. National health insurance can be typified by administrative control, definition and scope of benefits, or by fiscal criteria. If the use of financing and benefit provisions are used as base criteria, proposals for health insurance may be separated into three categories:

1. Narrow coverage, minimal federal financial role;

2. Wide coverage, limited federal financial role; and

3. Wide coverage, large federal financial role.10

Cost of an NHI can be analyzed by total cost of the program for individuals, employers, subfederal government units, and the federal government; by costs incurred by all levels of government; or by federal cost alone. Narrow coverage, minimal federal financial role NHI's are characterized by an emphasis on catastrophic medical expense coverage after large deductions and co-payments. 
Since 1974, the Long-Ribicoff-Waggonner bill, covering catastrophic medical costs above a certain level, has been the most widely known. Other examples are the "major risk" proposal of Martin Feldstein and the similar Brock bill. Both of these would pay all medical bills exceeding a certain percent of income, although the latter would administer a tax credit along the same lines. President Carter's National Health Plan also emphasized catastrophic coverage. Catastrophic protection NHI proposals often provide other coverage, typically to specific population segments such as the elderly, the poor, or the very young. 11

Other proposals provide wider benefit and population coverage, but still restrict the financing role of the federal government. Plans may either be voluntary or mandatory for both employers and individuals. Mandatory plans are, in effect, a taxation of the individual in a form that does not appear in the federal budget. 12

The American Medical Association's (AMA) Medicredit proposal is a voluntary plan with extensive benefits for all Americans. This proposal would encourage coverage by the federal government's extension of a tax credit for insurance premiums which would replace the present medical expenses tax deduction to employers and individuals.

The Consumer Choice Health Plan (CCHP), developed by Alain Enthoven, uses a tax credit approach to provide (with private vouchers for the poor) for the purchase of private insurance plans. Credits vary with income and actuarial risk category. Credits would equal 608 of the actuarial cost of a specified basic benefit plan in each 
geographic area. In contrast to the AMA plan, CCEP includes several measures to prevent insurers from competing by denying or limiting coverage to high-risk populations.

CCBP puts a special emphasis on sensitizing individuals to costs as well as benefits in their selection of an insurance plan. Competition is encouraged, not only in claims administration, but also in the delivery of care. Project Health of Multnomah County, Oregon, was based on these principles. Its success as a demonstration project has led to development of a state health proposal to provide universal coverage for all Oregonians.

A mandatory, wide-coverage, limited federal financial role is seen in the Nixon-Ford administrations' Comprehensive Health Insurance Plan (CHIP). CHIP would have required employers with more than a specified number of employees to provide insurance. Premium liability would have been divided between employers and workers. In an aggregation approach, CHIP would have also included other groups of individuals such as the poor and elderly via public plans to effectively constitute a system of universal health insurance.

The Kennedy-Waxman bill is another attempt to cover all groups through aggregation. Relying on mandated private coverage, employers would have been required to offer employees a choice among private insurance plans. Differing from CHIP, individuals not covered through employment would have had access to those same insurance plans.

Wide coverage, large federal financial role NHI proposals include the far-reaching Kennedy-Corman bill which proposes a federal monopoly of the medical insurance business. It seeks to establish a single 
national health insurance program for all Americans with broad benefits and no out-of-pocket costs at time of service use. It envisions the largest federal administrative component of all the plans so far considered. The federal government's involvement would range from payment of claims to allocation of a regional and locally predetermined national health budget.

\section{Administration of a NHI}

National health insurance may be administered at the national or state level, left to the open marketplace, or a combination of these approaches. ${ }^{13}$ The Rennedy-Corman Health Security Plan is the most widely known proposal for a nationally administered plan. The chief advantage of a national approach is that uniform policies would be equally applied to all citizens. Equity would be enhanced by assuring equal treatment of citizens in similar circumstances. This was the argument behind the enactment of a national supplemental security Income (SSI) program replacing state-administered public assistance programs for the elderly and disabled. Under a nationally administered approach, either a centralized or a decentralized policy could emerge. Private administrative agents could be utilized for specific tasks, as is the case with private insurer carriers under Medicare.

Delegation of authority to state or local governments constitutes the second approach. Here, state and local governments could provide a more flexible and tailored approach to their constituencies. CHIP proposed to rely most heavily on state administration. States would 
have had the responsibility to operate insurance plans for the poor, to regulate the insurance market, to license providers, and to set rates of provider payments. Of the three alternatives, the state administration has received the least consideration, chiefly because of general dissatisfaction with early Medicaid programs' widespread variation in benefit levels, eligibility, and provider abuses. State responsibility could range from a continued role for health care for the poor to a financing plan for the general population.

Under the third approach, private insurers would meet consumer choice in a market model. The Consumer Choice Health Plan proposes to rely on this model to provide insurance for almost all the population. The Long-Ribicoff-Waggonner bill would apply this arrangement to all but the poor and elderly.

National administration of NHI does not assure an effective or uniform implementation of programs, as witnessed by the variations in Medicare and Medicaid implementation levels. Lack of uniformity in implementation may result from conflict over goals within as well as between levels of govermment. In national government, these conflicts are exacerbated by the brief tenures of political executives, the lobbying of bureaucrats by members of Congress and special interest groups, and civil service regulations inhibiting effective or innovative administrative performance. ${ }^{14}$ Finally, the very complexity of a national approach causes problems for managerial control. Responsiveness to individual needs often conflicts with equity through uniformity. 
The state administration emphasizes responsiveness to constituent preferences over national uniformity. Because the state government tends to be controlled by certain interest groups, it is often felt that those groups not included in the power structure, e.g., racial minorities and the poor, are harshly dealt with.

The competency of states to administer such programs has also been questioned. The nature of state constitutions and limited terms of office often cause a fragmentation of authority. However, through administrative reform in the late 1960's and early 1970's, forty states have instituted changes in government so as to enhance public accountability, improve administrative capacity, and reduce the control of interest groups.

The wide variation among states in administering the Medicaid program have been also substantially reduced. In 1970 , Medicaid expenditures per enrollee were eight to ten times as large in the most generous state as in the least. ${ }^{15}$ However, six years later, states with the lowest per capita incomes no longer had the lowest levels of Medicaid acute-care expenditures. During this period, the rank order correlation between per capita income and acute care expenditures fell from .48 to .28 .

Theoretically, at least, the competitive market allows simultaneous satisfaction of different preferences, in contrast to the intentional uniformity of a nationally administered system, or the variation of state and local preferences in a state-administered system. In a market model, consumers compare benefits to costs in their choice of a particular product or service. Insurers under this 
model would offer an array of policies reflective of consumer preferences. Proponents believe the result would be a more responsive and flexible system than could be offered by the federal government.

In practice, however, variations in purchasing power, compounded by insurers' incentives to limit financial risk, have resulted in a dual system in which employer-insured consumers enjoy relatively low-cost comprehensive insurance coverage, while the remainder of the population is at a serious disadvantage. Employee groups are generally younger and healthier than other population groups. Because of the competition between providers for employee group insurance, 758 of full-time workers pay less for health coverage than do those unable to obtain employee coverage.

NHI approaches illustrate the complexity and difficulty of designing a system of health insurance to meet the criteria of uniformity, equity of treatment, responsiveness to individual and geographical needs, flexibility, and public accountability. In contrast to these massive NHI designs are numerous alternative delivery systems, some of which combine source of care strategies with insurance strategies, or governmental involvement in a competitive market model.

TYPES OF ALTERNATIVE DELIVERY SYSTEM OPTIONS

Income, insurance, and source of care have been discussed as isolated strategies to bring the low income population's use of health services up to mainstream levels. As with Medicare and Medicaid, each could have massive and unforseeable effects on the health care 
system. This section will discuss innovative methods of health care delivery that minimize costs while providing models of access designed to include those in the Health Policy Gap.

Such alternative delivery systems (known as ADS), range from health maintenance organizations (HMO's), Prepaid Group Practices (PGP's), Independent Practioners' Associations (IPA's), Preferred Provider Organizations (PPO's), and Primary Care Networks (PCN's), to more universal integration of health delivery systems through Project Health's seminal brokerage concept and its extension to the proposed State Health Plan (SHP) of Oregon.

Recent ADS seem to originate with groups of providers, consumers, and government at the grassroots level. This is a sharp contrast to the Medicaid and Medicare programs which were designed and administered primarily at the federal level as an overlay on state and local provider and consumer organizations and practices. ADS arise in response to delivery system inadequacies in dealing with cost containment, access, and efficiency. If organized by providers, they often seek an improved competitive position relative to other forms of alternative delivery systems within their marketing area.

Historically, health care cost containment measures have been one of two types: those which modify existing fee-for-service systems and those which attempt to construct an alternative to those systems. of the latter, most approaches appear to be variants of the generic health maintenance organization (HMO) exemplified by Raiser's beginnings in the 1940's. 
However, during the same period, a number of hybrid solutions to rising medical care costs appeared which do not fall neatly into either fee-for-service or traditional prepaid practice categories, but which promise to restructure the delivery of care. Many of these were made possible by the passage of the Omnibus Reconciliation Act of 1981, which gave states far greater authority to pursue nontraditional alternatives to health care delivery. 16

These varying models of health care delivery systems differ in several key respects, including enrollment options, the way in which professional participation is channelled, whether or not enrollee self-referral is allowed, the form of physician reimbursement, and responsibility for cost containment (see Table XI).

\section{Health Maintenance Organizations (HMO's)}

HMO's, initially developed as a means of providing medical care to workers and their families, have grown continually through the enrollment of employee groups. They have a record of delivering quality care at a reasonable cost to large populations and of offering a complete ambulatory care that minimizes problems of socioorganizational access.

Organizational aspects of HMO's include a set of basic and supplemental health maintenance and treatment services, voluntary enrollment by groups of persons, and a capitation system in which the HMO is reimbursed by predetermined, fixed, and periodic payment. 17 Both prepaid group practices (PGP's) and independent practioner's associations (IPA's) are considered health maintenance organizations 


$$
\text { TABLE XI } 18
$$

COMPARISON OF ORGANIZATIONAL CHARACTERISTICS

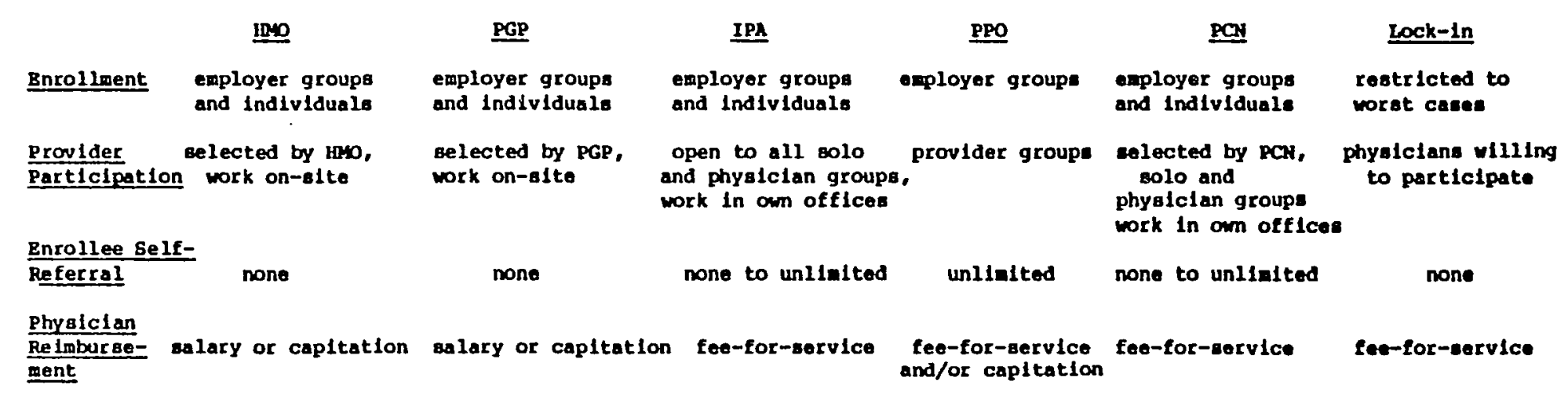


and are financed through capitation fees. The former is composed of three or more physicians providing a defined set of services over time for a fixed periodic prepayment. A PGP differs from an IPA in that physician participation in the former case is restricted through the selection of a closed panel of physicians who are reimbursed on a capitation or salary basis and who are held responsible for providing medical care to enrollees. Services are provided by physicians working on-site. No enrollee self-referral to other physicians is allowed.

Raiser is the most widely known of the PGP's. Originating in California in the 1940's, Raiser has since spread through the Western United States.

The advantages and disadvantages of a PGP such as Raiser are related to its organizational aspects and their effects on the consumer's access to and utilization of health care. Access to care is both inexpensive and covers a continuum of services from preventive care to hospitalization. Its disadvantage is that consumers are locked into the Raiser system, which constrains their choice of providers. For the poor, this may mean they must travel long distances to Raiser locations. Because chronic illness and low income are linked, many of the poor may value highly having a strong relationship with one physician rather than a relatively impersonal relationship of a panel of doctors available in a closed panel HMO. Evidence indicates that enrolling Medicaid eligibles into HMO's is difficult. Potential enrollees seem to perceive the HMO option as substantially reducing choice while appearing to be no better than other available options. However, when few other medical care 
alternatives are geographically available or access is limited by provider preferences, the poor are willing to join kMO's regardless of their quality.

New federal regulations limiting Medicare and Medicaid enrollments in HMO's to a maximum of 508 may render it impossible for PGP's to locate themselves so as both to serve the poor and nonpoor, as the former often tend to be geographically isolated in economic ghettos.

In contrast, independent practice associations were developed between the 1940s-1960s and were sponsored by county medical societies to block the entrance of closed panel health maintenance organizations into the area. ${ }^{19}$ They frequently kept fee-for-service reimbursement, invited all county physicians to take part, and acted to preserve a fee-for-service style of medical practice.

In contrast to the prepaid group practice, the traditional IPA model stays within the fee-for-service system. Physicians are reimbursed on a fee-for-service basis. Membership is often open to all doctors within the community, and services are provided by physicians in their offices. The IPA is, in practice, more variable than the PGP model in that self-referral is unlimited.

\section{Primary Provider Organizations}

Primary provider organizations are a response of traditional health providers to increasing competition from HMO's and to physician surpluses. 20 They follow a pattern of scattered provider groups adapting to changes in their own regional health care delivery 
systems. Although hospitals generally start PPO's to assure higher occupancy rates of their facilities, physicians in at least one area have organized a PPO with an emphasis on outpatient care in response to employer interest in controlling outpatient use. ${ }^{21}$ The only agreement binding participating providers and consumers is that each time a designated service is provided, it is provided at an agreed upon fee.

Since this approach is a variant of traditional fee-for-service delivery systems, it shares certain common characteristics including provider panels, negotiated fee schedules (often with discounted reimbursements to participating physicians and hospitals), use or claims review, some form of control mechanism, a practice of no "lock-in" of consumers (i.e., consumers are not constrained in their choice of provider), and administrative and marketing arms. ${ }^{22}$ Administrative and costs advantages include the features of limited risk for providers and discounts of usually 5-208, consumer choice, quick and cost-efficient claims processing, an emphasis on efficient practices (such as utilization control reviews), flexible benefit packages (i.e. consumer copayments/ coinsurance/ waived deducribles for use of preferred providers), and low administrative costs. Primary provider organizations offer several advantages. Because they are an extension of the fee-for-service system, they are often more readily acceptable as a way of organizing service delivery to achieve cost containment. Satisfaction may also be higher because consumers have the option of choosing a provider rather than of being restricted, as is the case with closed panel M.D.'s. 
Incentives are used to shape consumer behavior. Some of these include the waiving of deductibles/copayments or co-insurance and the increasing of benefits if consumers choose to receive care from a preferred provider. By discounting fees and monitoring use, providers can increase their institutional occupancy rate in areas where there is an oversupply of physicians or hospital beds, i.e., by making their system of health services delivery more competitive.

Because most PPO's feature rapid turnaround on claims, provider satisfaction is higher than in most other systems. Providers are also protected by the minimal financial risk built into the system for providers who agree to the negotiated fee schedules. Administration of typical ppo claims is relatively routine, so the cost of claims processing adds little overhead.

Payers (primarily employers or unions with Taft-Fartley Funds) are initially attracted to PPO's by the expected cost savings from discounted fees and the anticipated long range savings from cost-efficient practices (such as utilization reviews). The PPO design also offers employers the advantage of maximizing their influence over a group of providers through input into the allocation of resources spent on providing health care services to employees or union members.

The main disadvantage is that PPO's are only cost effective if a ccmpetitive market exists and if employers and funds can effectively monitor health care. Wherever the consumer has access to traditional fee-for-service medicine and PPO's with no HMO (or prepaid) option, the consumer's leverage regarding the price of services is limited. 
The consumer is dependent on the PPO to practice cost efficiency in a fee-for-service system. In this system, costs passed on to the consumer have historically risen faster than the total annual change in the Consumer Price Index.

\section{Primary Care Networks}

In contrast to PGP's, IPA's and PPO's, primary care networks (PCN's), which were organized mostly within the past decade, have three principal characteristics:

1) primary care physicians are disbursed throughout the community in solo or group practices,

2) patients are enrolled in the $\mathrm{PCN}$ and assigned to a single primary care physician, and

3) the network increases the primary care physician's control over the total medical care received by the patient. 23

States are provided the flexibility to request waivers for the establishment of PCN's through the Omnibus Reconciliation Act of 1981 (P.I. 97-35), which recognizes the growing acceptance for case management of long term and acute care.

In practice, PCN's can be very similar to HMO's in that the primary care physician in both cases may be responsible for medical and financial patient management; they differ in that PCN's do restrict physician participation. IPA's are at the other end of the continuum with participation open to all local physicians.

The evolution and growing popularity of PCN's is the result of three converging trends: Blue Cross/Blue Shield's selective response to HMO's in the 1970's, the growth and acceptance of family practice 
as a specialty, and a number of developments within Medicaid.

Pertinent Medicaid developments include recurring fiscal problems, difficulties in defining mainstream medicine, questionable application of the freedom of choice provision, a bias towards institutional care, excessive outpatient use of emergency rooms and outpatient departments, growth of lock-in programs, and the relative success of government funded neighborhood health clinics. Another factor has been the ability of California to replace its scandal-ridden Medicaid system with a tightly controlled and sophisticated HMO system.

Unlike PGP's, PCN's employ both solo physicians and physician groups and may also reimburse them on a fee-for-service as well as a capitation basis. PCN's, however, can be much more demanding than IPA's in terms of prospective physicians seeking entry into the network. In contrast to lock-in programs, PCN's do not isolate clients who have inappropriate behavior. Instead, all consumers select their own physician who manages their medical care. The central role of the primary care physician is the key distinguishing characteristic of PCN's (see Table XI).

The advantages of PCN's, especially for low income populations, are several. First, by making the primary care physician responsible for medical and financial management of the patient, they greatly reduce costs because although physicians' direct revenues account for less than 198 of total expenditures, they control about $75 \%$ of total health care costs. ${ }^{24}$ An example of an instance in which expenses have been cut in this manner is the Health Maintenance Program of the Wisconsin Physician's Service. Evidence indicates that benefits 
offered by this PCN are more generous than Blue Shield's fee-for-service package. This is because processing low cost claims under the latter amounts to at least half of the total cost of the benefit. Under capitation, these processing costs are eliminated. The PCN approach may then offer states the means for substantially increasing their low Medicaid fees to office-based physicians without increasing their net costs for processing and reimbursing physician services. 25 other advantages are that they constrain patient misuse of the system by locking all patients into a primary care physician, guarantee clients an entry point into the system as long as the client accepts the conditions of membership, and are more flexible and more easily established than traditional HMO's because they do not require new institutions or large alterations in the existing relationship between physicians and hospitals. 26

One possible disadvantage of PCN's is that they may encourage a reduction in the quality of care provided because physicians obtain a greater fiscal return for greater volume of patient load than they enjoy for providing ongoing comprehensive care for an individual client. Another potential problem is that primary care physicians may be either unable or unwilling to supervise specialists. Evidence from the now defunct United Health Care of Safeco (UHC) indicates that one of the prime reasons for its demise was that primary care physicians often paid after the fact for specialist services not approved in advance and seemed hesitant to question self-referrals by patients to specialists. 27 Unless the primary physician is held responsible fer all care--not just primary care--the PCN has a strong incentive to be 
less efficient and more costly than fee-for-service. PCN's may also foster adverse selection in either of two ways: by selecting potential enrollees from the healthiest of fee-for-service clients, or by a systematic selection of a particular provider within the PCN by clients who tend to be sicker than the main pool of potential clients. The latter occurs when clients who tend to use more services or more costly services choose a specific provider more over other providers on the basis of long-term patient-provider relationships, geographic location, etc. Finally, the administrative and informational systems a state employs may not be appropriate or adequate for PCN's because they often are designed for a traditional fee-for-service system. 28

PCN delivery systems have included innovative approaches designed to serve the indigent, sometimes attempting to integrate them into mainstream health care. Group Health Plan (GHP) of Northeast Ohio, for example, has been termed a "bridge between the private and public sectors. ${ }^{29}$ Begun in 1971 as one of eleven networks designed to provide care to the poor, GHP has successfully integrated both indigent and nonindigent populations into a system serving approximately 24,000 members. Approximately 9,000 are Medicaid recipients. The remaining 15,000 are covered under private group or government agency contracts. A client may move from Medicaid to employer-covered status within the program, preserving his or her insurance carrier and selected physician.

Because of its origins, GHP does not have to answer to county medical associations and can focus on building a plan acceptable to 
its mernber physicians and subscribers. This increased freedom and a heavy emphasis on computerized monitoring of relevant data are key components of GHP.

Physician incentives and constraints aid in controlling physician and system risk while assuring quality care for clients. Three mechanisms limit physician risks. ${ }^{30}$ These include an approach to catastrophic losses wherein medical practice groups are insured against lost costs above a certain level incurred by any individual GRP member, insuring that the physician will not drop a patient once he or she becomes expensive to serve. Medical groups are also rewarded by half the difference if actual per member month hospital expenditures are less than projected per member month projected hospital expenditures. Furthermore, if during a 12 month period, the cost of services exceeds more than 150 percent of a medical group's capitation fee, GHP will extend a short-term interest free loan, acting to reduce risks by allowing the group to carry forward their losses and offset them against future profits.

A special emphasis on reducing health costs without reducing quality of care for the indigent is the hallmark of the Massachusetts Case Management (MCM) demonstration project. Ten thousand AFDC recipients are enrolled in the plan. In this project, case management providers coordinate enrollees' total care. 31

To date, the success of the project has been hindered by three factors: 1) at some sites patients can receive unapproved care elsewhere and they have done so; 2) risk to providers either does not exist or is so limited that it has had no effect on incentives for 
efficient practice; and 3) neither the state nor certain sites have data systems capable of implementing and monitoring a case management project. Administrators conclude that the program would be more effective if the following were to occur:

- case management is operated out of free-standing clinics and offices, because use of outpatient clinics in tertiary care hospitals creates conflicting goals;

- data systems are developed prior to the project's beginning;

- patient education necessary for both marketing and appropriate system use is encouraged;

- patients are locked into one primary care physician who bears financial and medical responsibility for managing all the patient's health needs;

- quality of care is reviewed and monitored (with state access to records);

- sites are accessible to client on 24-hour basis, with time allotted for walkins; transportation is provided if necessary. 32

\section{Project Health's Brokerage Concept and Multicare}

Multicare, a public PCN in in Multnomah County, Oregon, has grown out of the experience of project Health. The latter is a demonstration project pooling public funds and brokering private providers' health plans to provide health insurance to a medically indigent population. The two major concepts behind project Health are important in understanding Multicare's functioning: 1) Multnomah County pools all available health resources (including county funds, Public Health Service 330 grants, client payments and provider refunds); 2) the county, acting as a broker, negotiates prepayment 
contracts with prepaid health plans and, until recently, had an episodic payment plan for office visits to physicians and for offering limited hospitalization coverage.

Project Bealth claims that it allows the consumer freedom to choose among participating providers, involves and sensitizes consumers to cost by requiring copayments and premiums, and stimulates competition among health providers. It integrates fragmented public programs by pooling resources, encourages cost containment through prepayment, and approximates a voucher method of providing health care coverage by offering enrollment in competing health plans to eligible individuals and assisting them in making choices.

Project Health pays a portion of the premium, (similar to an employer) based on the client's income, family size and selected plan. ${ }^{33}$ Both HMO and IPA providers are involved. However, in one instance because of adverse selection by high need clients of the health plan with a flexible IPA arrangement, capitation rates have been found to be insufficient to cover costs. Another health plan found it necessary to substantially increase its premium and close enrollment to Project Health enrollees for an extended period of time. Adverse selection has occurred in Project Health, because the sickest from that population have preferred health plans with an open physician panel. Also, because the poor have been responsible for a portion of program costs, those without immediate need have tended to drop out while the chronically ill have stayed, causing average per person costs to rise dramatically. 34 
Project Bealth has responded to these problems by screening for health status and placing high risk clients into the county's case management system called Multicare. Multicare is a joint venture between county operated clinics and private providers with a broad range of services but with all preventive and primary care occurring in the county clinics.

Health care plans are developed for each patient by a case manager, who authorizes and approves all care. Referrals are limited to specialists not available at the clinics who are carefully screened for high levels of cooperation, high-quality service, and cost-sensitivity. Providers are selected based on Project Health experience, establishment of referral provider panels, and ability to work with community providers.

The major difference between Multicare and most PCN's is that once a high risk client's needs are met, that client is allowed to choose whether to remain in Multicare or to enroll in one of the other HMO's in Project Health. Evidence shows that a very small proportion of the Medicaid eligible population uses a disproportionate amount of funds. Screening out this population and handing their health care in a more efficient system has important possibilities for cutting costs for states' Medicaid programs. 35

\section{Proposed State Health Plan (SHP) for Oregon}

The proposed state Health Plan (SHP) of Oregon extends the seminal brokerage concept exemplified by Project Health to cover all Oregonians. Its goals are to contain health care costs without 
increasing current levels of expenditures by altering consumers', providers' and employers' economic incentives. The plan would employ health insurance pooling to guarantee a minimum level of comprehensive coverage at reasonable cost. ${ }^{36}$ Consumer choice, prepayment for guaranteed comprehensive benefits, and coverage for all Oregonians are the key components of the plan. Estinates indicate that SHP could provide a comprehensive level of benefits to all Oregonians for approximately $\$ 1.53$ billion dollars. ${ }^{37}$ This figure compares favorably to Oregonians' 1980 expenditures of $\$ 2.6$ billion for health care. The latter figure includes only partial health care costs provided under the existing system. (Only 598 of Oregonians are now estimated to have comprehensive health coverage. At least 128 are estimated to have no health coverage whatsoever.)

The importance of universal coverage for all Oregonians is discussed by an SHP staff member in a memo to Don Clark, Multnomah County Commissioner:

Equal access to health services for all oregonians can only be achieved if all residents of the State are eligible to be enrolled in a plan which provides an established minimum level of benefits. The ability to enroll residents in a plan with comprehensive benefits at a reasonable cost can only occur if everyone is enrolled and the risks associated with treating illness and maintaining health are shared across the entire population. Further, if access to benefit coverage is to be continuous, eligibility and enrollment must be separate from financing of the system. 38

Under this plan, all Oregon residents would be eligible for comprehensive health care benefits, including physician, hospital, ancillary services, and limited dental and alternative care services. Medicaid and Medicare benefits would be provided for, but administered 
separately. All Oregonians would be obliged to choose a health plan from offered options.

The SHP program would be financed through federal and state revenues, an employer payroll tax, and limited consumer contributions. These monies would be funneled into a State Health Financing Fund, which would be administered by a fiscal intermediary. Development of organized health plans would be encouraged by state revenue bonding and protection against unreasonable financial risk through reinsurance. In areas where privately sponsored plans are not spontaneously generated, or in the event existing plans are inadequate to serve low income populations, SHP might be expected to sariction a publicly-provided health plan. 39

NHI, ADS and Health Policy Gap Households

National health insurance and alternative service delivery models offer much food for thought relative to access, cost containment and preservation of freedom of choice for providers and consumers. These proposals have varying potential for the access of Health Policy Gap households to health care.

Many ADS models and NHI proposals do not directly address existing gaps in health coverage. Instead, various models either incrementally add groups of covered persons with different characteristics, or simply choose to ignore existing gaps and focus on more efficient service delivery to those already in the health care system. For example, castrophic NHI proposals basically cover only those households in desperate financial straits from illness expenditures above a certain level. Other needy groups may be added 
on in an aggregative approach in various plans. Primary provider organizations are more aware of the need for more efficient delivery of the existing fee-for-service system to those already eligible for coverage within that system.

Prepaid group practices and independent practice associations, although within the capitation model, tend also to focus on the status quo system of health services delivery. They negotiate to deliver a certain set of services to a prespecified group of people for a fixed prepayment, but do not specifically deal with the provision of health services to those not already served by the system. Those who are presently not served or who are underserved by the system are invisible clients. They are hidden behind the barriers of low income, lack of insurance, and an inappropriate system access point of entry. Health maintenance organizations have the capacity, as do many of the other organizations discussed, to pull into the BMO a certain proportion of the underserved "high risk" population. As demonstrated by the HMO projects, the poor, as well as the employer-insured, may be served within a capitation system.

However, HMO performance in the area of enroliment of the poor has had different long-term results than the demonstration project indicated. This may be largely due to differences in incentives for participation. ${ }^{40}$ Because many of those enrolled in Medicaid move in and out of eligibility for assistance, tracking problems are immense. The problem of determining eligibility and use patterns by the poor is not, however, limited to organizational aspects of the HMO system in which the poor are served; rather it is the result of nonflexible 
eligibility requirements of the Medicaid program and lack of an integrated health care system.

Primary care networks form a model that has been used with relative success for publicly-insured populations. The degree of success has depended on the primary care physician's fiscal and managerial skills. Multicare of Multnomah County, Oregon, is an example of a highly successful primary care network.

What the majority of these approaches lack is a vehicle le.g., insurance coverage) to enable the low income access to these health services delivery systems. Accessibility for these people is not an impossible feat. Project Health of Multnomah County, Oregon, for example, translated a model of marketplace consumer choice into a highly acclaimed mainstreaming project for the majority of medically indigent. This project contained a special proviso program, Multicare, for high risk individuals who would have otherwise put too heavy a burden on providers. The extremely successful outgrowth of Project Health has been a State Health Proposal for Oregon.

This proposal brings the seminal concept of consumer choice in a brokered model of pooled resources and providers to full bloom. A universal and mandated system of access and health insurance coverage is envisioned for all Oregonians within a state-administered and monitored system of private providers. Estimated to be less expensive than the current fragmented system, it also would provide a fuller range of preventive, medical, and supplementary health services (including dental care). 
CONCLUSION

Problems exist in making the health care system more responsive to the needs of disadvantaged populations. First, the existing system does not respond to any demand that is not stated in dollar terms. Second, the high risk factor and higher administrative costs associated with disadvantaged populations make them unattractive to private providers seeking to establish a better competitive position in the marketplace. Third, the quality and volume of services utilized by the disadvantaged may not be equivalent to mainstream care enjoyed by the privately insured.

Under the present system, however, certain categories of the poor do gain access to the health marketplace via public insurance or through targeted health delivery systems (such as Maternal and Infant Care projects). Remaining low income groups are put at an even greater disadvantage. The increased demand on the health delivery system, associated spiraling inflation, and increased costs of care associated with insurance expansion create a tripartite health system in which the privately insured are assured of mainstream care, the publicly insured get care, and the uninsured poor are pushed aside. Such is the case when the disadvantaged are essentially left to find their way in the private marketplace as a result of the withdrawal of federal monies and the concurrent inability of state and local government to cover the gaps between health needs and available resources. 
ENDNOTES

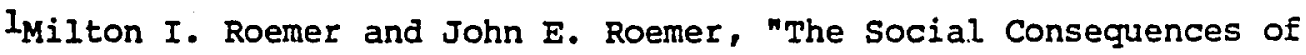
Free Trade in Health Care: A Public Health Response to Orthodox Economics," International Journal of Health Services 12, 1 (1982):112.

2 Ibid.

3rbid., p. 119.

"Judith Feder and John Holahan, "Administrative Choices," in National Health Insurance: Conflicting Goals and Policy Choices, Judith Feder, John Holahan, and Theodore Marmor, eds. (Washington, D.C.: The Orban Institute 1980), p. 21.

5 Theodore Marmor, Judith Feder, and John Holahan, "Introduction," pp. 1-20 in National Health Insurance: Conflicting Goals and Policy Choices, (Washington, D.C.: The Urban Institute 1980), p. 7.

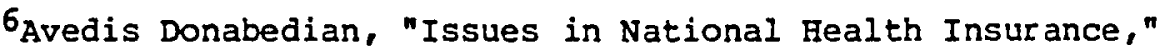
American Journal of Public Health 66, 4 (April 1976):345.

7Ibid., p. 346.

8 Ibia., pp. 9-10.

9'mid., p. 1 .

10 Ibid., p. 4.

Il Ibid., p. 3.

I2Ibid., p. 5 .

13 Feder and Holahan, 1980, pp. 22-23.

14 Ibid. , pp. 34-35.

${ }^{15}$ Ibid., p. 46.

16 Statutory and/or waiver authority for states is provided to implement a primary care case management system restricting beneficiaries to efficient providers or practitioners, sharing with clients the savings of cost effective care through additional services, the entering into of prepaid arrangements with other entities besides federally qualified HMO's and the dropping of providers who generate unnecessary utilization of services from the program. State Medicaid Information Center, Center for Policy Research, National Governors' Association, "Medicaid and Primary Care Networks: A Concept Paper and the Proceedings of the NGA Conference on Medicaid and Primary Care Networks/ Case Management Systems, December 2, 1981," Washington, D.C., March 1982, p. 2. 
17 Multnomah County, Oregon, Project Health Staff, A Glossary of Terminology and Abbreviations for Project Health, Department of Human Services, April 1978, P. 10.

18Derived in part from State Medicaid Information Center, Center for Policy Research, National Governor's Association, "Medicaid and Primary Care Networks," March 1982, Table 1, p. 4.

${ }^{19}$ State Medicaid Information Center, March 1982, p. 4.

20 Linda Rrane Ellwein, and David D. Gregg, "An Introduction to: Preferred Provider Organizations" (Excelsior, Maryland: Interstudy) February 1982, April 1982 Revision), p.I.

$$
\begin{aligned}
& 21 \text { Ibid., p. } 7 . \\
& 22 \text { Ibid., p. } 9 .
\end{aligned}
$$

23 State Medicaid Information Center, March 1982, p. 2.

${ }^{24}$ Ibid., p. 6.

25 Ibid., p.ll.

26 Ibid., pp. 6-7.

27 Ibid., pp. 15-16.

${ }^{28}$ Ibid., pp. 8-9.

29Ibia., p. 17. "Lock-ins" refer to special programs to control abusive utilization behavior by clients, often Medicaid recipients, by restricting the patient to one physician and one pharmacist. A client so "locked-in" cannot receive care aside from those providers who must approve of all services or drugs rendered.

30 Ibia. , p. 19

$31_{\text {Ibid., p. } 26 .}$

32 Ibid., p. 28.

33 Ihid., p. 22.

${ }^{34}$ Ibid., p. 23.

35 Ibid., p. 24.

36 MuItnomah County, Oregon, Department of Human Services, S.H.P. Staff, "Decision Memorandum \#2: Financing Issues Related to Insurance Pooling,", Oct. 2, 1981, p. 1 . 
37Multnomah County, Oregon, Department of Human Services, "Project SHP: Executive Summary of a Proposal of a State Health Plan for Oregon,", April 1, 1982, p. 1).

38Multnomah County, Oregon, Department of Human Services, Project SHP Staff Memorandum to Don Clark, County Executive, "Decision Memo I: Eligibility, Enrollment and Continuity of Coverage," Sept. 15, 1981, p. 1.

${ }^{39}$ Muitnomah County, Oregon, Department of Buman Services, SHP Staff, "Elements of the SHP Rrogram: A Summary of Major Policy Decisions for A State Health Plan for Oregon, April 1, 1982," p. 14.

40 Ibid., p. 324 . 
CHAPTER V

CONCLUSIONS AND IMPLICATIONS FOR POLICY

OREGONIANS IN THE HEALTH POLICY GAP

Income, medical insurance, and source of medical care make real differences in the way Oregonians use health care. The majority of households have "mainstream" access to health care services in this state. But for those ten to trielye percent of state residents who do not have mainstream access to health care, this study finds that low income, lack of insurance or an inappropriate source of care function effectively as barriers to appropriate use of health services. Those affected by these three barriers use fewer health services than do other Oregonians, even given the same level of need. The barriers also contribute to serious inequities in access to health care for Oregonians.

These inequitable effects on the health of disadvantaged Oregon households are, without doubt, intensified by the precipitous rises in unemployment and the closing of industrial and commercial concerns that had employed large numbers of heads of households in this state since the data for this study were collected in 1978. This situation is not unique to oregon. It supports national findings that a large number of of all Americans are without appropriate health care access due to 
barriers anenable to policy intervention by decisionmakers at the federal, state and local level.

often these findings are initially hidden by the effects of varying household characteristics which affect health services use profiles. Household structure (members' ages, sex, and size and type of household), health care needs, mobility, and health behaviors obfuscate or even hide these differences in services use among those of different incomes, those with varying insurance coverage, and those with atypical sources of medical care.

Income and insurance make up the greatest barriers to appropriate use of health services by households in the Health Policy Gap. The third policy variable, source of care, shows small but significant differences in the way in which members of households use different health services.

The effect of source of care on use of medical services seems to be a function of both the prior causal variables of income and insurance as well as a certain unique effect on medical services use that is either very small or is not finely enough measured to produce large "barrier" effects. This may result from the confounding of use patterns by different subgroups, i.e., extremely healthy or higher-income individuals who don't believe in medical care may use less services as do individuals facing income, insurance, or source of care barriers. 
Relative Importance of The Policy Variables

Lack of income creates the largest of the policy barriers to use of dental services by Oregonians. Those in the disadvantaged category saw the dentist approximately once a year compared with the twice a year visits typical of the general populace. A linear relationship exists between dental services use and income class, with both upper middle and high income persons consuming more dental services than do the general population.

Because only a small percentage of insurance covers nonmedical health services (such as dental), the connection between insurance and dental services use is nebulous. Kaiser is one of the few insurers which also provides dental services. Medical insurance and source of medical care are assumed to affect dental services use only if a causal link between general patterns of consumer behavior and all types of health services use is posited. This link would be necessarily based on underlying variables connected to both source of medical care and medical insurance and dental services use. Little or no variation in use of dental services was expected by either medical insurance or by source of medical care.

As expected, all policy variables (income, insurance and source of medical care), were significant predictors of physician visits. Among these, lack of insurance was identified as the greatest barrier to visiting a physician. The uninsured reported fewer visits, while the insured reported more than the average number of visits for the sample as a whole. The uninsured saw a physician at more than one and a half 
times the rate that the uninsured saw the dentist (3.52 versus 2.21

times during the previous twelve months).

An inappropriate source of care was the next largest barrier to visiting the physician. Those with an inappropriate source of medical care (either a public health clinic, a hospital emergency room, or without a regular source of care) reported fewer visits than did those with an established relationship with a practitioner. Those reporting an appropriate source of care tended to see a physician almost three and a half times a year versus less than three times for those without an appropriate source of care.

Income showed a curvilear function for this measure of physician use, with an increase in mean numbers of visits to the physician as income level rose and then a slight drop in visits for the high income.

Mean use of the telephone varied most by source of medical care. Members of households without an appropriate source of care reported only about half as many telephone calls for physician advice as did those in households reporting a physician's office as a regular source of care.

Next in importance for telephone use was income. Only a third (338) of members of low-income households had telephoned a physician for advice during the past year versus forty-three percent of high income households. The relationship between income and use of the telephone was linear and positive.

Only medical insurance coverage was unrelated to telephone use. Having a regular source of care apparently ensures a closer contact and 
monitoring of consumer needs than does the more transitory provider-consumer relationship achieved through the emergency room or public health clinics.

Low income, lack of insurance and an inappropriate source of care slightly depress the probability of having received a preventive exam by members of Oregon households. Members of households with low incomes, those without insurance coverage, and those reporting either an inappropriate source of medical care or no source of medical care all had slight but statistically significant lower mean levels of preventive exams such as Pap smears, breast, prostate, blood pressure and blood sugar. These were below the average level of exams reported for the sample as a whole.

The biggest difference between mean levels of use of hospital services was for those without medical insurance. They averaged only half the probability of insured of having been in the hospital during the prior twelve months, even after controlling for household characteristics such as health care needs.

The next greatest deviation from mean levels of use of hospital services was for members of households without an appropriate source of care. Since the possible effects of varying levels of health need were controlled for in the analysis, source of care was found to have a channeling effect on use of health services beyond that attributable to differing levels of health needs.

Interestingly, the disadvantaged used hospital services at least as frequently as did the upper middle income class. The lower middle income class used hospital services the most, and the high income 
category used them least. The latter finding may be a function of higher income households having more options for extended care needs than use of hospital days (e.g., obtaining other sources of nursing or chronic treatment facilities).

A curvilinear function was found for income, as was the case for physician visits, with the very high income category using slightly less than either the lower middle or upper middle income. However, while for physician visits the low income still used fewer services than did other income groups, this was not the case for hospital services. If hospital services use is ranked by the probability of a household having had a member in the hospital during the past year, the upper income used the fewest hospital services, followed by the low income, the upper middle income and finally the lower middle income who were the highest users of hospital services.

When general patterns were examined across health services measures, income and appropriateness of source of care were found to be significant predictors across all medical measures, including number of physician visits, use of the telephone for physician advice, mean use of preventive exams, and hospital services.

Suprisingly, insurance was a significant predictor for only three out of four medical measures (number of physician visits, preventive exams and hospital services). It seemingly had no effect on use of the telephone for physician advice. At least for dental services use, income alone among the policy variables was significant in predicting use of dental services. 
INITIAI CONSIDERATIONS FOR POLICYMAKERS

What are the implications of a study in which findings energe that indicate various services are differently affected by income, insurance or source of medical care? One significant implication is that the health delivery system needs to be tailored for different services. If one policy objective were to be the increased use of physician services, insurance would be emphasized more than income strategies, based on the findings of this research. Conversely, if the objective were to be the decreased use of hospital services for preventable health needs, policymakers might choose a strategy of investing in preventive exams via insurance, source of care, and and income combinations in lieu of the same resource investments in hospital services. Certainly, specific strategies aimed at increasing use of certain health measures conceivably would be more cost efficient and more beneficial to the consumer than investment in other strategies might be. The first task is to decide whether one type of intervention--income, insurance, or system delivery strategy would best accomplish the objective of increasing utilization rates across the board for persons in the Health Policy Gap.

\section{Single Intervention Strategies}

Income. Income is the first link in the causal chain hypothesized to affect use of health services. As shown, low income depresses all measures examined. Rationally, it is the primary strategy which must be used to raise use of health services by the disadvantaged to mainstream 
levels. Proposals such as the negative income tax (NIT) have been attractive to policymakers because they offer the chance to eliminate the multiplicity of narrow categorical programs that now exist with their confusing array of eligibility requirements, administrative details, and cross-purposes.

A universal income strategy leaving consumption aspects within the household's domain of decisionmaking avoids the pitfalls of paternalism as well as eliminates the major problems involved in devising, implementing and monitoring complex policy combinations.

Income strategies may vary from piecemeal categorical programs such as Aid to Families with Dependent Children (AFDC) to comprehensive income-assurance programs that protect all Americans against potential income level breaks, (whether episodic or chronic). Benefit levels may vary from a minimal survival level to adequate though not luxurious levels with commensurate increases in cost and decreases in political support from taxpayers.

However, one major problem is that there are likely to be substantial differences in the impact of means-tested transfers and taxes on the work effort put forth by different groups. ${ }^{1}$ Although the New Jersey NIT experiment found no evidence of adverse work incentives, Feldstein (1977) attributes the lack of findings to the short term nature of the experiment, to the lack of effects on the supply of part-time jobs because of the small number of participants involved, and to peer group pressures for work effort maintenance that would not exist were the program universal. 
Income intervention strategies such as President Nixon's Family Assistance Plan (FAP) would affect all aspects of consumption of goods and services, including health purchases, by affected households. Effects on houschold behavior vary in direct relation to the specific details of the proposal and the current economic realities in the marketplace. A policy strategy entirely successful in one economic time and place may be a complete catastrophe in another.

The second major problem concerns the effects of a straight cash health insurance transfer on household consumption behaviors. An in-kind program (as opposed to a cash transfer program) may be desirable even if a general negative income tax were enacted. This would result if society placed a higher value on certain health consumption expenditures not valued as highly by the individual household. For example, under a cash transfer program, a household may choose to not invest in preventive health services. Instead it may prefer to invest more of its limited resources in shelter, food, clothing, or even luxuries. This is, in part, an outcome of the unexpected and often involuntary nature of health services consumption. Households are loathe to believe that they may need to save for future potential catastrophic illness, especially for medical services. In-kind programs (e.g., Medicare and Medicaid) tend to direct household behaviors into the desired areas of consumption as valued by society.

Given the unpredictable timing, costs, and unpleasant nature of future illness, it is very unlikely the household will adequately provide for its future health care needs. Indeed, in the short term, it is to the advantage of individuals to not invest in health services, 
particularly preventative health services thereby delaying both health expenditures and potentially frightening or painful treatments as well as anxiety-heightening knowledge of their personal state of health.

Such households will inevitably become a fiscal burden on local, state and/or federal government. Resulting costs are shifted to the public sector, whether by write-offs at local hospitals, downward income shifts which place the household into eligibility categories for public assistance, or, as the household ages, dependency on Medicare.

However, the economic reality is that a minimum income strategy would not enable assisted households to effectively compete in today's health marketplace so long as the present system of health insurance remains unchanged. Households would be unable to effectively function in the health market because increased demand from the publicly insured and inflationary cost increases make a minimum income supplement inadequate. This situation is worsened by the lack of provider motivation to respond to a need that cannot be stated in dollar terms.

Buffering or brokering agents would necessarily have to be placed between assisted households and providers, thereby overlaying an insurance strategy on top of an income strategy. Furthermore, the overwhelming hostility to any such proposal in today's political and economic climate makes consideration of a universal income strategy practically impossible.

Health Insurance. Insurance is the second policy mutable key to enhancing medical services use. Lack of insurance significantly depresses utilization for most health services. If income strategies are politically unfeasible, insurance emerges as a means to overcome the 
barrier effects of inaciequate income as well as existing insurance barriers. Considered as an intervention measure, it of fers the advantage of greater political acceptability than do income interventions, while retaining most of the berefits of choice in the consumer-provider relationship.

Insurance strategies may range from catastrophic iimited coverage with large out-of-pocket sontributions (or deductibles) on the part of the consumer, or to a comprehensive floor under all Americans for preventive, diagnostic, prescriptive, and catastrophic long term coverage of health care costs with minimal out-of-pocket consumer contributions (e.g., the Rennedy-Corman legislation).

Various strategies have been developed, among which are innovative attempts by local and state governments to combine state, local, and federal monies to illustrate brokering approaches. The focus of these efforts is to provide increased access to medical care for indigent populations. One such outstanding effort is Project Health in Multnomah County, Oregon.

Project Health, previously a federal demonstration project, illustrates the strengths of brokering approaches in increasing the access of the disadvantaged to the present health system. This is accomplished by designing new combinations of coverage through a central agent, which more equitabiy pools resources and divides high risk cases across among health care providers.

Findings of Project Health have provided a data base with which to design a state health insurance plan for the state of oregon. This plan would cover all Oregonians under one umbzella brokering plan, providing 
an adequate level of access to health services for all oregonians, minimizing costs to providers as well as consumers, and increasing participation of new health insurers.

Delivery System Strategies. The third type of single policy strategy would be that of changing the source of medical care to increase the access of persons in the Health Policy Gap. An inappropriate source of medical care is a significant barrier, as hypothesized, to utilization of medical services, even after controlling for insurance, income and household characteristics.

Delivery system access mechanisms have been developed most often in response to the health needs of narrow targeted groups of persons, often focussing on a specific health need, such as children's preventive and remedial dental care. These mechanisms vary in scope from local demonstration projects to community-wide, regional, or even state-wide delivery sources that seek to ensure that accessibility is minimally affected by system entry point, distance, transportation, or geographical barriers.

Delivery approaches have had relative success. Community health centers and maternal and infant care programs such as WIC (Women and Infant Care) have provided community outreach to geographically centralized and categorically identifiable target populations. Unfortunately, many of the episodically or chronically low income people who make up a large portion of the Health Policy Gap do not live in centralized areas, nor do they represent an easily identifiable target grouping. 
National health insurance proposals have not been able to overcome the pressures of strong interest groups and conservative ideologies to date, although they continue to be a strong focus of interest to policymakers. Alternative Delivery System models, developed at the grassroots level, show promise for innovative combinations of marketplace competition, consumer choice, and government oversight.

The relative strengths of single source policy interventions--either income, insurance, or source of care--are inadequate to tailor specific service increases or decreases. However, of the three, income strategies have the most potential for efficiently increasing access to health care systems for persons in the Health Policy Gap across all services. Insurance and source of care strategies rank second, due to their limited impacts on medical services use. As this study shows, for specific services, either insurance or source of care strategies better target use than do income approaches alone.

\section{CONCLUSION AND IMPLICATIONS FOR POLICY DIRECTIONS}

In economic periods of radically increased unemployment, a faltering of the national economy, and pervasive anxiety about the future, the public tends to be more cognizant of the insurance aspects of social spending as being potentially necessary to their welfare. It remains to be seen whether or not public opinion has swung towards the reinstatement of social services, although some evidence indicates that particularly for the elderly, Social Security and Medicare are politically well established. 
When national unemployment as well as unemployment in Oregon, peaks at figures higher than have previously occurred since the Depression, anxiety and political pressure for protection from uncontrollable exigencies of the economic climate begin to grow. Again, if this public attitudinal change is not felt by policymakers at all levels of government, it is less likely to be translated into meaningful change. At the state and local government levels in oregon, it is plain that decisionmakers are very aware of the health care needs of state residents, as evidenced by such efforts as Project Health, Multnomah County's Multicare Project, the new State Health Insurance Plan proposal, the Oregon Medical Association's recent plan, and the Blue Ribbon Committee for Health Care for the Medically Indigent.

Combinations of strategies are indicated for increasing use of different health services. Various combinations of income, insurance and source of medical care depend on decisionmakers' underlying values, the relative strength of various lobbying interests, and the current mix of service providers in the marketplace.

Combinations of insurance coverage linked with a regularized entry point into the delivery system could provide the same health services use outcomes as would a far larger increase in nontargeted monies focused on income interventions. An income intervention leaves choice of consumption patterns up to the household. Not every household ranks health care as high on its list of priorities as policymakers might for the overall welfare of society. Some households underutilize health care, while others overutilize it. What must be examinod is the extent 
to which appropriateness of use is linked with any strategy or combinations of strategies.

Any successful policy intervention must include safeguards to protect the access of populations which are not financially profitable to serve. First, governmental subsidization (local, state, federal, or a combination) must be involved in the costs of providing care, and of administrative and monitoring functions. If left to the private sector, providers likely will rationally seek to minimize the problems involved with the higher health need, increased administrative problems, and lesser rates of return associated with disadvantaged populations. They may attempt to select healthier individuals if mandated to serve such a population, or seek to avoid serving them by locating in areas where high risk, poverty populations are not an issue (e.g., the suburbs).

Second, universally mandated coverage of all the population within a particular geographic area seems necessary. It appears to be the only way in which the higher costs associated with low income, less healthy or perceived less desirable populations can be merged in with healthier, lower cost populations served by mainstream health care delivery systems. Third, strong regulatory controls over provider and consumer behaviors are required. This is necessary to ensure adequate control of utilization patterns. Rigorously designed and instituted information monitoring systems are necessary to provide speedy and timely system feedback.

Fourth, a well planned and organized health care system which provides a comprehensive set of health services is crucial to the success 
of any proposal. This system should emphasize preventive rather than remedial services.

In conclusion, a need for a basic structural change in the health care system is clearly indicated. Nowhere is this more graphically illustrated than by the continued barriers to access to health care faced by households in the Health Policy Gap. Although it is widely recognized that national health insurance, income maintenance, and radical restructuring of the health delivery system remain theoretically viable, the practical reality is that given today's economic and political climate, innovative approaches to providing he :th care for the disadvantaged are more likely to arise at the state and local levels. With tilis in mind, the consumer choice model, with a provision for an interim high risk public program to buffer private providers against adverse selection by consumers, offers the widest choice to clients, to private providers, and to government. It provides minimal governmental administration compared with other universal plans and increases competition and provider efficiency in the marketplace. It also offers, through increased monitoring and system feedback, incentives to all involved to control costs and to utilize the system in a rational and appropriate manner. 
ENDNOTES

Martin Feldstein, "Social Insurance," pp. 71-98 in Income Redistribution, ed. by Colin D. Campbell, Washington, D.C.: American Enterprise Institute for Public Policy Research, p. 77. 


\section{A SELECTED BIBLIOGRAPHY}

Aday, Lu Ann, and Andersen, Ronald. Development of Indices of Access to Medical Care. Ann Arbor: Health Administration Press, 1975.

Aday, Lu Ann, and Eichorn, Robert. The Utilization of Health Services: Indices and Correlates. Rockville, Maryland: The National Center for Health Services Research and Development, Department of Health, Education and Welfare, 1972.

Akers, Ronald I. Deviant Behavior: A Social Learning Approach. 2cd ed. Belmont, Calif.: wadsworth Publishing Co., 1974.

Allen, James J., and Hunt, Steven B. In Failing gealth: A Critical Analysis of Fealth Care in the United States. Skokie, Ill.: National Textbook Co., 1977.

Andersen, James G., and Bartkus, Donald E. "Choice of Medical Care: A Behavioral Model of Health and Illness Behavior." Journal of Health and Sociai Behavior 14 (Dec. 1973):348-362.

Andersen, Ronald. A Behavioral Model of Families' Use of Health Services. Chicago: University of Chicago, Center for Health Administration Studies, Graduate School of Business, Research Series 25, 1968.

Andersen, Ronald. "Introduction." In Eguity in Health Services: Empirical Analyses in Social Policy, pp.1-8. Edited by R. Andersen, J. kravits, and 0. Anderson. Cambridge, Mass.: Ballinger Publishing Co., 1975.

Andersen, Ronald, and Aday, Lu Ann. "Access to Medical Care in the U. S.: Realized and Potential." Medical Care 16 (July 1978):533-546.

Andersen, Ronald, and Anderson, Odin w. A Decade of Health Services. Chicago: University of Chicago Press, 1967.

Andersen, Ronald, arid Benham, Lee. "Factors Affecting the Relationship Between Family Income and Medical Care Consumption." In Empirical Studies in Health Economics: Proceedings of the Second Conference on the Economics of Health, FP. 73-95. H. E. RIarman, ed. Baltimore: John Hopkins Press, 1970.

Andersen, Ronald, Kravits, Joanna, and Anderson, Odin $w$. Equity in Fealth Services: Empirical Analyses in Social Policy. Cambridge, Mass.: Ballinger Publishing Co., 1975.

Andersen, Ronald, and Newman, John F. "Societal and Individual Determinants of Medical Care utilization in the United States." Milbank Memozial Fund Quarterly 51 (Winter, 1973):95-124. 
Anderson, Odin $\%$. Health Care: Can There be Equity: The United States, Sweden, and England. New York: John Wiley and Sons, Inc., 1972.

Anderson, Odin. The Uneasy Equibilibrium: Private and Public Financing of Health Services in the United States, 1875-1965. New Haven, Conn.: College and University Press, 1968.

Andreano, Ralph L., and Weisbrod, Burton A. American Health Policy: Perspectives and Choices. Chicago: Rand McNally Publishing Co., 1974 .

Aneshensel, Carol S., Frerichs, Ralph R., Clark, Virginia A., and Yokopenic, Patricia A. "Telephone Versus In-Person Surveys of Community Health Status." American Journal of Public Health 72, 9 (September 1982):1017-1021.

Antonovsky, Aaron. "Social Class, Life Expectancy, and Overall Mortality." Milbank Memorial Fund Quarterly 45 (1967):31-73.

Becker, Marshall H., ed. The Health Belief Model and Personal Health Behaviors: Health Education Monographs 2 (Winter 1974):82-92.

Bice, Thomas W., and White, Rerr L. "Factors Related to the Use of Health Services: An International Comparative Study." Medical Care 7 (March-April 1969): 124-133.

Blue Ribbon Committee Meeting of Aug., 1982, Multnomah County, Oregon.

Boulding, Kenneth E. "The Concept of Need for Health Services." Milbank Memorial Fund Quarterly XIIV, 4, 2 (Oct. 1966):202-220.

Burnham, Vicky, and Freeborn, Donald R. "Oregon Health Survey: Initial Findings for HSA 1." Health Services Research Center, Kaiser Permanente Medical Program, Oregon Region, July 1979.

Cambridge Research Institute. Trends Affecting the U. S. Health Care System. Washington, D.C.: U. S. Government Printing Office, Jan. 1976.

Campbell, Colin D. Income Redistribution. Washington, D.C.: American Enterprise Institute, 1977.

Cater, Douglass. "An Overview." In Politics of Health, pp.1-10. New York: Medcom, Inc., 1972.

Dammann, Peter. "Non Sufficient Funds." Willamette Week 8, 16, Feb. 16-22, 1982, pp. 1,16-22. 
Davis, Karen, and Reynolds, Roger. "The Impact of Medicare and Medicaid on Access to Medical Care." The Role of Health Insurance in the Health Service Sector, pp. 391-417. Edited by R. N. Rosett. New York: National Bureau of Economic Research, 1975.

Davis, Karen, and Schoen, Cathy. Health and the War on Poverty: A Ten Year Appraisal. Washington, D.C.: The Brookings Institution, 1978.

DeSalvo, Joseph. "Housing Subsidies: Do We know what We are Doing?." Policy Analysis 2, 1 (Winter 1976):39-60.

Donabedian, Avedis. Aspects of Medical Care Administration: Specifying Requirements for Health Care. Cambridge, Mass.: A Commonwealth Fund Book, 1973.

- "Effects of Medicare and Medicaid on Assess to and Quality of Health Care." Public Health Reports 91, 4 (July-August 1976) : 322-331.

- Issues in Nationai Fealtin insurance." American Journal of Public Health 66, 4 (April 1976):345-350.

Dutton, Diana B. "Explaining the Low Use of Health Services by the Poor: Costs, Attitudes, or Delivery Systems?" American Sociological Review 43 (June 1978):348-368.

Dworkin, Ronald. Taking Rights Seriously. Cambridge Mass: Howard University Press, 1977.

Dworkin, Ronald, and Magee, Bryan. "Three Concepts of Liberalism." The New Republic, April 14, 1979, pp. 41-49

Eder, Norman R. Project Health: Competition and Consumer Choice for the '80's. Portland, Or.: Multnomah County Press, 1981.

Ellwin, Linda Rrane, and Gregg, David D. "An Introduction to Preferred Provider Organizations." Excelsior, Maryland: InterStudy, April 1982 Revision.

Fabrega, Horacio. "Toward A Model of Illness Behavior." Medical Care 11 (Nov.-Dec., 1973):470-484.

Feder, Judith, and Holahan, John. "Administrative Choices." In National Health Insurance: Conflicting Goals and Policy Choices. Edited by J. Feder, J. Holahan and T. Marmor. Washington, D.C.: The Urban Institute, 1980. 
Feldstein, Martin. "Social Insurance." In Income Redistribution, pp. 71-98. Edited by Colin D. Campbell. Washington, D.C.: American Enterprise Institute for Public Policy Research, 1977.

Feldstein, Paul. Health Care Economics. New York: A Wiley Medical Publication, 1979.

Fink, Raymond. "The Measurement of Medical Care Utilization," Proceedings of a Conference on Conceptual Issues in the Analysis of Medical Utilization Brhavior, pp. 5-32. M. Greenlick, ed. Portland, Or.: DHEW, Public Health Service, Health Services and Mental Bealth Administration, 1969.

Fox, Daniel M. "From Reform to Relativisim: A History of Economists and Health Care." Milbank Memorial Fund Quarterly: Health and Society 57,3 (1979): 297-336.

Freeborn, Donald R., and Greenlick, Merwyn R. "Evaluation of the Performance of Ambulatory Care Systems: Research Requirements and Opportunities." Medical Care 11 (March-April Supplement 1973) : 68-75.

Fuchs, Victor R. Who Shall Live? Health, Economics and Social Choice. New York: Basic Books, Inc., 1974.

Galvin, Michael E., and Fan, Margaret. "The Utilization of Physicians' Services in Los Angeles County, 1973." Journal of Health and Social Behavior 16 (1975):73-94.

Ginzberg, Eli. The Limits of Health Reform: The Search for Realism. New York: Básic Books Inc., Publishers, 1977.

Gove, Philip B., ed. Webster's Third International Dictionary of the English Language, Unabridged. Springfield, Mass.: G. and C. Merriam Co., 1967.

Greenlick, Mervyn R., Lairson, David R., Mullooly, John P., and Bannon, Joan E. O. "Determinants of Utilization of Health Care Systems." Proceedings of an International Conference on Health Technology Systems. M. Collen, ed. San Francisco, Calif., Nov. 14-16, 1973.

Health Services and Mental Health Administration. Health Services Use: National Trends and Variations. Rockville, Maryland: Department of Health, Education and Welfare, 1972.

Herman, Mary $w$. "The Poor: Their Medical Needs and the Health Services Supplied Them." In The Nation's Health: Some Issues. S. Berki and $\mathrm{W}$. Heston, eds. The Annals of the American Academy of Political and Social Science 399 (1972):12-21. 
Byman, Nartin D. "Research Report: Some Links Between Economic Status and Untreated Illness." Social Science and Medicine 4

(1970) : 387-399.

Joint Economic Comnittee, Subcommittee on Fiscal Policy, Congress of the United States. Income Security for Americans: Recommendations of the Public Welfare Study. Washington, D.C.: United States Government Printing Office, Dec. 5, 1974.

Kane, Robert L., Rasteler, Josephine M., and Gray, Robert M. "Poverty, Illness and Medical Utilization: An Overview, pp. 3-24.

"The Health Gap: Medical Services and the Poor. Edited by R. Kane, J. Kasteler and R. Gray. New York: Springer Publishing Co., 1976.

Rasl, Stanislav V., and Cobb, Sidney. "Health Behavior, Illness Behavior and Sick Role Behavior." Archives of Environmental Health 12

(Feb. 1966) : 246-266.

Riker, B. F., ed. Investment in Human Capital. Columbia, South Carolina: University of South Carolina, 1971.

Kirscht, John P. "The Fealth Belief Model and Illness Behavior." The Health Belief Model and Personal Health Behavior. M. Becker, ed. 3 (Winter 1974): 60-81.

Klarman, Herbert E. The Economics of Health. New York: Columbia University Press, 1965.

- "Investment in Health Care," In Investment in Human Capital "pp. 420-432. B. F. Riker, ed. Columbia, South Carolina: University of South Carolina Press, 1971

Kleinman, Joel C., Gold, Marsha, and Makuc, Diane. "Use of Ambulatory Medical Care by the Poor: Another Look at Equity. Medical Care 18, 12 (December 1980):1165-1176.

Koos, Earl L. The Health of Regionville. New York: Hafner Publishing Co., 1954.

Rosa, John, and Robertscn, L. "The Social Aspects of Health and Illness." In Poverty and Health: A Sociological Analysis, pp. 319-342.

J. Kosa et. al. Cambridge, Mass.: Harvard University Press, 1969.

Knupfer, Genevieve. "The Epidemiology of Problem Drinking." American Journal of Public Health 57 (June 1973):973-986.

Knupfer, Genevieve, and Room, Robin. "Age, Sex, and Social Class as Factors in Amount of Drinking in a Metropolitan Community." Social Problems 12 (Fall 1964):224-240. 
Lefcowitz, Myron J. "Poverty and Health: A Re-examination." Inquiry 10 (March, 1973): 3-13.

Lehman, Edward w. Coordinating Health Care: Explorations in Interorganizational Relations. Beverley Hills, Calif.: sage Rublications, 1975.

Lerner, Monroe. "The Level of Physical Health of the Poverty Population: A Conceptual Reappraisal of Structural Factors." Medical Care 6,5 (Sept.-Oct. 1968): 355-367.

Leveson, Irving. "The Economics of Health Services for the Poor." In The Nation's Health: Some Issues. S. Berki and W. Heston, eds. The Annals of the American Academy of Political and Social Sciences 399 (1972):22-29.

Luft, Farold S. Health Maintenance Organizations: Dimensions of Performance. New York: John Wiley, 1981.

Marmor, Theodore, Feder, Judith. and Holahan, John. "Introduction." In National Health Insurance: Conflicting Goals and Policy Choices. Washington, D.C.: The Urban Institute, 1980, pp. 1-20.

Mason, Robert. Director, Survey Research Center, Oregon State University. Telephone Communication. Corvallis, Oregon, Jan. 1979.

Mechanic, David. Medical Sociology. 2cd ed. New York: The Free Press, 1978.

Milner, Murray, Jr. Unequal Care: A Case Study of Interorganizational Relations in Health Care. New York: Columbia University Press, 1980 .

Morris, William, ed., The American Heritage Dictionary of the English Language. Palo Alto, Ca.: American Publishing Co. and Foughton Mifflin Co., 1970.

Multnomah County, Oregon, Department of Human Services, Project Health Staff, "A Glossary of Terminology and Abbreviations for Project Health." April 1978.

Multnomah County, Oregon, Department of Human Services. "Background Paper: BIue Ribbon Committee on Fealth Care Financing for the Medically Indigent." April 28, 1982.

Multnomah County, Oregon, Department of Human Services, SHP Staff. "Elements of the SHP program: A Summary of Major Policy Decisions for A state Health Plan for Oregon." April 1, 1982. 
Multnomah County, Oregon, Department of Human Services. "project SHP: Executive Summary of a Proposal of a state Realth Plan for Oregon." April 1, 1982.

Multnomah County, Oregon, Department of Human Services, Project SHP Staff. "Decision Memo I: Eligibility, Enrollment and Continuity of Coverage." Sept. 15, 1981. (Memorandum)

Multnomah County, Oregon, S.H.P. Staff. "Decision Memorandum $\$ 2$ : Financing Issues Related to Insurance Pooling." Oct. 2, 1981. (Memorandum)

Mushkin, Selma J. "Bealth as an Investment." In Investment in Human Capital, pp. 380-392. B. F. Riker, ed. Columbia, South Carolina, University of South Carolina Press, 1971.

Mushkin, Selma, and Francis d'A Collings. "Economic Costs of Disease and Injury," Investment in Human Capital, pp. 393-419. B. F. Riker, ed. Columbia, South Carolina: University of South Carolina Press, 1971.

Newacheck, Paul W., Butler, Lewis H., Harper, Aileen R., Piontkowski, Dyan L., and Franks, Patricia E. "Income and Illness." Medical Care XVIII, 12 (December 1980):1165-1176.

Newhouse, Joseph P. The Health Insurance Study: A Summary. Santa Monica: Rand Corporation, March 1974.

Newhouse, Joseph P., and Phelps, Charles E. Price and Income Elasticities for Medical Care Services. Santa Monica: Rand Corporation, 1974.

Office of Program Review, Director's Office. "Overview: Block Grant and Welfare Reform Issues in the Omnibus Budget Reconciliation Act of 1981 Establishing FY 1982 Authorization Levels." Department of human Resources, State of Oregon, Sept. 1981.

Oregon Journal. Sept. 3, 1982, p. 1.

Pear, Robert. "U.S. May Change Rules on Free Care." The Sunday Oregonian. August 1, 1982., p. Al2.

Phelps, Charles E. The Demand for Health Insurance: A Theoretical and Empirical Investigation. Santa Monica: Rand Corporation, July 1973.

-Price and Income Elasticities for Medical Care Services. Santa Monica: Rand Corporation, 1974.

Pickett, George E. "The Basics of Health Policy: Rights and Privileges: The 1977 Presidential Address. "American Journal of Public Health 68, 3 (March 1978):236-240. 
Pigou, A. C. Economics in Practice. London: Macmillan and Co., 1935.

Piven, Frances F., and Cloward, Richard A. Regulating the Poor: The Function of Public Welfare. New York: Vintage Books, 1971.

Office of Program Review, Director's Office. "Overview: Block Grant and Welfare Reform Issues in the Omnibus Reconciliation Act of 1981 Establishing FFY 1982 Authorization Levels." Department of Human Resources, state of Oregon, Sept. 1981.

Orr, Larry L., Hollister, R. G., and Lefcowitz, M. J. Income Maintenance: Interdisciplinary Approaches to Research. Chicago: Markham Publishing Co., 1971.

Richardson, William C. "Measuring the Urban Poor's Use of Physicians' Services in Response to IIIness Episodes." Medical Care 8, 2 (March-April 1970) :132-142.

Robert Wood Johnson Foundation. "Special Report, No. 1, 1978." Princeton: Robert Wood Johnson Foundation, 1978.

Roemer, Milton I., and Roemer, John E. "The Social Consequences of Free Trade in Health Care: A Public Health Response to orthodox Economics." International Journal of Health Services 12, 1 (1982) : 111-129.

Roemer, Ruth, Rramer, Charles, and Frink, Jeanne E. Planning Urban Health Services: From Jungle to System. New York: Springer Publishing Co., 1975.

Rosenstock, Irwin M. "The Health Belief Model and Preventive Health Behavior." The Health Belief Model and Personal Health Behavior: Health Education Monographs M. Becker, ed. 2 (Winter 1974):27-59.

Roth, Julius A. "The Treatment of the sick." In Poverty and Health: A Sociological Analysis, pp. 214-243. Edited by A. Antonovsky and I. Zola. Cambridge, Mass.: Harvard University Press, 1969.

Ryan, William. Blaming the Victim. New York: Vintage Books. 1971.

Saward, Ernest $W$. The Regionalization of Personal Health Services. New York: Prodist, 1976.

Schultz, Theodore $w$. Investment in Human Capital: The Role of Education and of Research. New York: The Free Press, 1971.

Shortell, Stephen M., Richardson, William C., LoGerfo, James P., Diehr, Paula, Weaver, Barbara, and Green, Rathy E. "The Relationships Among Dimensions of Fealth Services in Two Provider Systems: A Causal Model Approach." Journal of Health and Social Behavior 18 (June 1977):139-159. 
Sidel, Victor W., and Sidel, Ruth. A Healthy State: An International Perspective on the Crisis in United States Medical Care. New York: Pantheon Books, 1977.

State Medicaid Information Center, Center for Policy Research, National Governors' Association. "Medicaid and Primary Care Networks: A Concept Paper and the Proceedings of the NGA Conference on Medicaid and Primary Care Networks/Case Management Systems Dec. 2, 1981." Washington, D.C., March 1982.

Stoeckle, J., Zola, I., and Davidson. G. "On Going to see the Doctor, The Contribution of the Patient to the Decision to Seek Medical Aid." Journal of Chronic Diseases 16 (Sept. 1963): 975-989.

Suchman, Edward A. "Health Orientation and Medical Care." American Journal of Public Health 56, 1 (Jan. 1966):97-105.

Suchman, Edward A. "Social Patterns of Illness and Medical Care." Journal of Health and Fuman Behavior 6 (1965):2-16.

Sullivan, Ann. "Doctors Offer Care to Poor." Oregonian. July 29, 1982, p. B5.

Survey Research Center. Data Users' Guide for 1978 Oregon Health Interview Survey." Corvallis, Oregon: Oregon State University, 1979.

Syme, Leonard S., and Berkman, Lisa F. "Reviews and Commentary: Social Class, Susceptibility and Sickness." American Journal of Epidemiology (July 1976):101-108.

Tawney, R. E. Equality. New York: Barnes and Noble Inc., Revised, 1952. - Religion and the Rise of Capitalism: A Bistorical study. Gloucester, Mass.: peter Smith, 1962.

United States Congressional Budget office, Congress of the United States. Background Paper No. 17: Poverty Status of Families Under Alternative Definitions of Income. Washington, D. C.: United States Government Printing Office, 1977.

United States Congress, Congressional Budget office. Profile of Health-Care Coverage: The Haves and the Have-Nots. Washington, D.C.: United States Government Printing Office, 1979.

United States Congress, Joint Economic Committee, Subcommittee on Fiscal policy, Income Security for Americans: Recommendations of the Public Welfare Study. Washington D.C.: United States Government Printing Office, 1974 .

United States Department of Health, Education, and Welfare, Public Health Service, Health Resources Administration. Papers on the National Health Guidelines: Conditions for Change in the Health Care System, September 1977. DHEW Publication, 1977. 
Wan, Thomas T. H., and Scott Soifer. "Determinants of Physician Otilization: A Causal Analysis." Journal of Health and Social Behavior 15 (1974):100-108.

Webb, E. J., Campbell, D. T., Schwartz, R. D., and Sechrest, L. Unobtrusive Measures: Nonreactive Research in the Social Sciences. Chicago: Rand McNally, 1966.

Weisbrod, Burton A. Economies of Public Health: Measuring the Economic Impact of Diseases. Philadephia: University of Philadelphia Press, 1961.

Weiss, James E., and Greenlick, Mervyn R. "Determinants of Medical Care Utilization: The Effect of Social Class and Distance on Contacts With the Medical Care System." Medical Care 8, 6 (Nov-Dec. 1970) : 456-462.

Wilensky, Harold L. The Welfare State and Equality: Structural and Ideological Roots of Public Expenditures. Berkeley, Ca.: University of Southern California Press, 1975.

Wirick, Grover C. Jr. "A Multiple Equation Model of Demand for Health Care." Bealth Services Research 1 (Winter 1966).

Wyden, Ron. "Special on Health Issues: Congress of the United States, House of Representatives, Washington, D.C., March 10, 1982. (Newsletter)

Zola, Irving $\mathrm{R}$. "Pathways to the Doctor--From Person to Patient." Social Science and Medicine 7 (Sept. 1973):677-689. 